\title{
A digest of the published work of Michael Rutter 1958-2020
}

\author{
Jim Stevenson \\ Psychology, University of Southampton
}

\section{Author's Note}

This is a digest of all the papers published in peer reviewed journals that Professor Sir Michael Rutter (MR) has authored or co-authored up to 2020. I have also provided a brief commentary on the books he has authored or edited. I have not attempted to do the same for the book chapters that MR has produced. These are difficult to trace with any thoroughness and in many cases contain material that has been published in the papers and books that I have covered.

I hope that I have made an exhaustive search and have included all of the papers published in peer reviewed journals, with the exception of abstracts of papers presented at meetings and book reviews. These papers I have traced by searches in the Web of Science and PubMed databases and by citations in the papers so identified to papers authored by MR. In addition, I checked the papers traced against the list of MR's "Principal scientific publications" 1958-2001 provided in Green \& Yule (2001b). The listing of publications on the following MR webpage on the King's College London website was also consulted:

https://publons.com/researcher/2661418/michael-rutter/publications/.

The books were traced using the British Library catalogue. These searches have produced a total of 540 papers and 52 books published up to the end of 2019.

In producing this digest, I have not attempted to provide anything other than a rudimentary commentary on each. To place the findings in the context of the broader literature is a task beyond anyone other than MR himself! However, I have tried to place individual papers in the context of MR's own research activities and to judge their importance.

I have often taken a direct quote from a paper when producing these digests. The justification for this is that it ensures accuracy and is certain to be more succinct than any paraphrasing I might produce.

In order to simplify the text I have attributed each paper a superscript number in square brackets e.g. ${ }^{[2]}$. When books by MR are referred to these are again in square brackets with the Book number e.g. ${ }^{[B o o k 17]}$. In the text, where I have made reference to publications of which MR is not an author, I have given these in the orthodox manner using round brackets e.g. Tinbergen (1974), and these are presented in a reference list at the end of the text.

The papers have been grouped into the major areas and their sub-divisions to which MR has contributed. The major areas are presented in alphabetical order. Within each sub-division I have reported the papers broadly in the sequence in which they were published.

\section{Observations on Michael Rutter's approach to science}

From his earliest papers MR has referred admiringly to the approach to scientific discovery of Peter Medawar (e.g. Medawar 1967). The following quote makes clear his endorsement of Medawar's way of thinking:

"Of course, it would be quite futile to collect facts without a purpose. As Medawar $(1967,1969)$ has described so well, science consists of both discovery and proof, hypothesis and then careful testing to discriminate between alternative hypotheses". [251] 
A further example of MR endorsement of Medawar's conceptualisation is the following quote from Medawar:

"...The purpose of scientific inquiry is not to compile an inventory of factual information, nor to build up a totalitarian picture of natural laws... We should think of it rather as a logically articulated structure of justifiable beliefs about nature. It begins with a story about a Possible World - a story which we invent and criticise and modify as we go along, so that it ends by being, as nearly as we can make it, a story about real life." [Book18]

In an interview about his own career he states "My research is and should be hypothesis driven" [457] citing Medawar as providing the model for theory formation and testing he has followed.

In most research fields that he has contributed to, MR provides a review of a topic with subsequent updates at about 5 to 10-year intervals. His studies on autism represent a good example of this. An extensive review of the field identified a number of strands of research that needed to be taken further. ${ }^{[244]}$ Subsequently MR conducted studies on a number of these strands such as the cognitive and language deficits at the core of autism (e.g. ${ }^{[7]}$ ) and the contribution of genetic factors to autism (e.g. ${ }^{[92]}\left[{ }^{[93]}[9]\right.$ ). He returned to update the review of the literature on autism. ${ }^{[32]}[338][386]$

It is striking that MR has been able to undertake long term follow-ups with repeated measurements on the same sample. This has been exceptionally productive, for example in studies of developmental language disorders - a sample studied initially in $19755^{[17]}$ and finally in 2005. ${ }^{[64]}$ The Isle of Wight study is another example. The participants were first assessed in early adolescence in 1968-1969 ${ }^{[B o o k 4]}$ and again when aged 44-45 years in 1999. ${ }^{[214]}$

There has been strong continuity of themes in MR's research from the earliest publications. For example, a number of themes emerged from his first research monograph on the psychological well-being of children of sick parents. [Book 1] It considered the question of whether the adverse effects shown on the children of such parents was due to their experience of parental illness or arose from genetic factors. MR has repeatedly addressed such questions of genetic and environment joint action on childhood disorders. In this monograph he considered the role of temperamental factors as influencing the reaction of the child to the experience of parental illness. The impact of the experience of separation from the parent and of a "broken home" on the child is addressed. These questions of gene-environment interaction, temperamental susceptibility to adverse experiences and deprivation of parental care are all major themes that have pre-occupied MR throughout his research studies from this earliest study onwards.

In the empirical research papers there is almost invariably a careful consideration of potential limitations on the findings. In particular by looking for alternative explanations and an emphasis on possible distortions or errors in conclusions. This concern often reflects in particular the subtlety and complexity of the biases that might arise from sampling (especially in case-control studies) that has been documented by Sackett (1979).

In these empirical papers there is a consistent willingness to recognise that a conclusion would be premature, and that an issue requires further study. The importance of such a caution is made in the following:

"... the data do not tell you truth all by themselves. They may be misleading for a while in the early stage, or in a frontier field. The complementary role of scepticisms is, of course, essential and in the end, rigorous proof must be provided. But early on, one has to have some self-confidence and some talent to smell out where it will lead, before it becomes simple to show it." Holton (1997).

MR has this ability to "smell out" the route through to fruitful outcomes.

At times MR has reflected on the research process and his own experience of being guided in the development of his ideas and approach. He gave a very personal account ${ }^{[344]}$ the latter part of which concentrates on autism research. The first section gives a broader biographical sketch of the ways MR's ideas have developed and the role of mentors throughout his work as a scientist. 


\section{A digest of the published work of Michel Rutter 1958-2019}

\section{ADOLESCENCE}

The Isle of Wight (loW) study was a pioneering large-scale epidemiological study of the physical and psychological well-being and educational attainment of the 9-11 year old children living on the Isle of Wight in 1964. ${ }^{\left[{ }^{[B o k 33]}[B o o k 4]\right.}$ When the children were 14-15 a follow-up study provided an opportunity to obtain epidemiological data (prevalence and associated environmental factors) on psychiatric disorders in young adolescent children. ${ }^{[107]}[45]$ The loW findings showed that for the majority of children adolescence was not characterised by turmoil and upheaval. Some teenagers may become seriously disturbed, but the majority negotiate this period of change with only relatively minor emotional and behavioural disturbances. ${ }^{[45]}\left[{ }^{363]}\right.$ MR considered adolescence to be a period of both stability and change in psychological development. ${ }^{[33]} A$ series of papers on adolescence for the general reader were published in the magazine New Society. [269] [270] [271] [272]

\section{ADHD/HYPERACTIVITY/ HYPERKINESIS}

The loW study found prevalence of one in a thousand for the hyperkinetic syndrome. ${ }^{[B o o k 4]}$ This is a value much lower than those that were then being reported in studies from the USA. Subsequent papers in this topic initially centred on the diagnostic validity of the hyperkinetic syndrome as characterised by

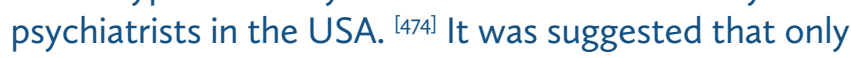
pervasive hyperactivity constitutes a clinically distinct phenomenon. ${ }^{[476]} A$ number of papers identified problems in the rating of hyperactivity. These include distinguishing it from wider disorders of conduct [477] and biases in parental ratings. ${ }^{[477][476]}\left[{ }^{[198]}[\right.$ [496] [497]

The close association between hyperactivity and disorders of conduct is a recurring theme in both clinical [474] [509] and genetically informative studies. [196] [197] [380] [491] The latter suggest that additive genetic factors influence both hyperactivity and conduct problems and that such genetic influences strongly influence the association between these conditions. Caspi et al. conducted a molecular genetic study that demonstrated the role of variations in the catechol O-methyltransferase gene (COMT Val158Met) in the association of antisocial behaviour and ADHD. ${ }^{[5]}$

In three separate studies no evidence was found that maternal smoking during pregnancy is a causal factor for ADHD. [514] [206] [112]

Taylor et al. reported a randomised controlled trial that showed for children with hyperactivity that there was a potential benefit of methylphenidate not just to modify behaviour ${ }^{[512]}$ but also to make families more amenable to other treatments. ${ }^{[478]}$

\section{ANTISOCIAL BEHAVIOUR/CONDUCT DISORDER/ CRIMINALITY}

MR presented a review of research on the relation between family discord and conduct disorder. ${ }^{[319]}$ He strongly emphasised the need for caution in extrapolation from association to cause and reached the following conclusion:
"There is now abundant evidence that serious family discord provides a good risk indicator for conduct disorder in children. For the most part, the associations found in the literature are of only moderate strength... but the weakness of effect is quite likely to reflect a reliance on single questionnaire measures of family functioning and single questionnaire measures of child psychopathology, so that the error variance in the studies will have been very large. On the other hand, it is equally possible that the weak associations mean that, although family discord is indeed a risk indicator, it does not represent a risk mechanism. Rather, it could be that the risk processes involve features that are associated with discord, instead of the discord itself." [319]

Silberg et al. studied the co-occurrence of conduct disorder (CD), depression and substance use and concluded:
"The comorbidity between substance use and depression, and between substance use and conduct disturbance in childhood/adolescence, probably reflects rather different mediating mechanisms - as well as a different time frame, with conduct disturbance preceding substance use but depression following it". [486]

The comorbidity between depression and CD and depression and substance use was more strongly influenced by genetic factors in girls. ${ }^{[486]} \mathrm{A}$ further difference between the sexes was found in relation to the mediation of risks in children from stepfamilies:
"Children living in stepfather families are exposed to more parental psychiatric risk factors than children from intact families. The increased risk for CD symptoms in girls (but not boys) from stepfather families is partly mediated by 
or associated with the stepfather's history of alcoholism". [89]

MR appraised the role of physical aggression and language development as risk factors for antisocial behaviour. The evidence for possible environmental influences on underlying processes resulting in antisocial behaviour and its continuity were also described. [347] [430]

Quinton et al. examined the role of assortative pairing in both an ex-care sample and general population samples (Inner London (IL) and the loW). ${ }^{[224]}$ The pathways whereby conduct disordered individuals did not benefit from the protective influences of stable family relationships and non-deviant peer groups were examined:

"the continuity between CD and adult social functioning is carried by a series of indirect links in which assortative pairing with deviant individuals is a central element." [224]

A study of genetically identical (monozygotic, MZ) twins by Caspi et al. was used to examine the relationship between parental expressed emotion and antisocial behaviour in children. ${ }^{\left[{ }^{22}\right]}$ Using the genetic control this design provided, within MZ pairs the twin with more maternal negativity and less warmth had more antisocial behaviour problems. This suggests that maternal emotional attitudes toward children may play a causal role in the development of antisocial behaviour.

Moffit (1993) developed a taxonomy of antisocial behaviour which differentiated adolescence limited and life-course-persistent forms. Using data from the Virginia Twin Study of Adolescent Behavioural Development (VTSABD) this distinction was tested. The taxonomy was supported by the finding of a genetic factor that influenced antisocial behaviour from age 10 through to adult and a shared environment influence beginning in adolescence. ${ }^{[493]}$ This question was further explored in a subsequent analysis of data from the VTSABD. ${ }^{\left[{ }^{485]}\right.}$ Another aspect of age of onset heterogeneity in criminality is the supposed late onset form i.e. onset after adolescence. In a study of the development of 13 individuals it was found that juvenile antisocial behaviour and/or major mental illness were risk factors that "almost completely" accounted for late onset criminality. ${ }^{[87]}$ In this high-risk sample there were no late onset cases that were not predicted by prior risk factors.

Elander et al. conducted a follow-up study of 148 individuals who were seen as child psychiatric patients between 1948 and 1982. ${ }^{[88]}$ The criminal records of these participants were obtained in late adolescence and in early adulthood. The paper concluded that "the analyses identify hyperactive symptoms as a significant risk factor for future antisocial behaviour among boys with childhood behavioural or emotional disturbances." However more work is needed, and this should aim to "identify the behaviours and processes that mediate associations between hyperactive symptoms and criminal convictions later in life."

MR provided an introduction to a meeting on the neurobiology of violence in which he emphasised the need for a two-way interchange between basic neuroscience and clinical science. ${ }^{[366]}$

\section{ASSESSMENT}

MR has made a major contribution to the development of methods of assessment in child psychiatry clinical practice and research.

\section{Cognition and language}

Parent reports are widely used to assess socioemotional aspects of child development but less commonly to assess cognitive abilities. Saudino et al. demonstrated the feasibility of developing a reliable and valid parent-based report of non-verbal cognitive ability. ${ }^{[475]}$

Cantwell et al. ${ }^{\left[{ }^{[6]}\right]}$ developed a technique to appraise functional abnormalities in language usage which could complement assessments of the level of language development. Howlin et al. provided an account of a method of analysing mother speech to young children with autism. ${ }^{[229]}$ The method provides measures of the mother's language that were related to individual differences in the child's language. Moreover, these measures were shown to have good inter-observer reliability.

\section{Expressed emotion}

George Brown and MR initiated a strand of methodological development that led to a more systematic appraisal of family relationships and included the measurement of expressed emotion. ${ }^{[40]}$ [401] A refinement incorporated in their approach was the recording of observations about the interviewee's behaviour (e.g. tone of voice) during the interview. The assessment of the marital relationship that was included in this study was developed further. ${ }^{[229]}$ The expressed emotion measure was enhanced as part of the Psychosocial Assessment of Childhood Experiences (PACE) ${ }^{[47]}$ and the internal consistency and stability of this expressed emotion measure was established. ${ }^{[472]}$

\section{Parent-child interaction}

Mrazek et al. produced ${ }^{[194]}$ a measure of sequences of parent-child interaction in young children ( 2 to 3 years of age). These were thought likely to be important with respect to influences on children's psychosocial development rather than influences primarily affecting cognitive or linguistic development. It was anticipated 
that such an approach might provide an assessment that would be to be related to psychopathology as well as to normal development.

Dowdney et al. developed a method for observing parent-child interaction in the home. ${ }^{[80]}$ The method focuses on parental responsivity and sensitivity, affect, social communication and social control and used both time-interval and event-sequential sampling of behaviour. It was shown to have good reliability and preliminary evidence of validity was presented.

\section{Personality}

The Adult Personality Functioning Assessment (APFA) is an investigator-based standardised interview to assess patterns of social dysfunction covering six domains of functioning: work; love relationships; friendships; non-intimate social contacts; negotiations; and everyday coping. It was found to have good reliability, ${ }^{[26]}$ inter-rater agreement ${ }^{[24]}$ and to correlate well with other personality measures. ${ }^{[225]}$

\section{Psychiatric interview}

MR initiated a series of studies focussing on the systematic evaluation of child ${ }^{[413]}$ and parent ${ }^{[06]}$ interviews as diagnostic tools.

Subsequently, four contrasting interviewing techniques were subject to a naturalistic study ${ }^{[407]}$ and to an experimental study. ${ }^{[008]}$ The interview styles were labelled "sounding board", "active psychotherapy", "structured" and "systematic exploratory". The study aimed to test the elicitation of factual information [77] [72] and elicitation of feelings. ${ }^{[28]}\left[{ }^{[7]} \mathrm{A}\right.$ further experimental study was conducted on the elicitation of feelings. ${ }^{[73]}$

A similar appraisal was made by Harrington et al. on structured respondent-based and semi-structured investigator-based interviews. This study used a version of the Schedule for Affective Disorders and Schizophrenia-Lifetime designed to assess lifetime psychopathology in adults. ${ }^{[18]}$

The Child and Adolescent Psychiatric Assessment (CAPA) was developed by Adrian Angold and colleagues as:

"an interviewer-based diagnostic interview with versions for use with children and their parents, focused on symptoms occurring during the preceding 3-month period, adapted for assessments in both clinical and epidemiological research". ${ }^{[4]}$

Using the CAPA it was shown that there was considerable uncertainty in attempting to identify the time of onset of symptoms. ${ }^{[3]}$

Shaffer et al. adopted a case history approach to assess the reliability and validity was of a 17-item measure of psychosocial stresses designed to accompany the
International Classification of Diseases Version-9 (ICD9) classification of childhood psychiatric disorders. [482] The reliability was found to be low. A subsequent revision to the assessment of the psychosocial axis

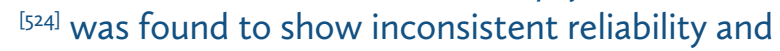
the importance of training in the methodology was demonstrated. ${ }^{[525]}$

A series of papers by Milne et al. examined the utility of alternative methods of measuring and combining reports of the family history of psychiatric disorders. [190] [188] [189] It was concluded that for depression, anxiety disorder, alcohol dependence, and drug dependence family history was useful for determining patients' clinical prognosis and for selecting cases for genetic studies.

\section{Questionnaire based assessment of child psychopathology}

MR developed two rating scales for use in the loW epidemiology study to screen for psychiatric disorders. The Child Scale A [Book 4] for completion by parents and Child Scale $B^{[24]}$ for completion by teachers. The scales were designed to be balanced in assessing neurotic and antisocial symptoms. They have been widely adopted in subsequent studies. ${ }^{[85]\left[{ }^{866]} \text { They }\right.}$ formed the basis of the Strengths and Difficulties Questionnaire (SDQ) (Goodman, 1994, 1997) which has become a measure of behaviour widely used internationally.

\section{AUTISM}

Of the 540 papers in this digest approximately 120 had autism as the central focus. This is an indication of the salience of autism in MR's research and of MR's importance to the field of autisms studies.

\section{Autism - General papers}

The first papers by MR on autism were published in the mid-1960s. ${ }^{[24]}\left[{ }^{[243]}\right.$ The latter is a paper presented at the Royal Institute of Public Health and Hygiene 1967 Conference in Brighton. It addressed the question of what kind of educational help should be provided to the child with autism. MR argued that many children with autism can be educated and he lays out some of the principles on which such schooling should be organised. He ended by identifying the absence of facilities to continue the education of the autistic child into the post-school period.

MR gave an overview of the characteristics of the child with autism and their educational needs. ${ }^{[243]}$ The information provided is based on findings on the "autistic" children who attended the Maudsley Hospital between 1950 and 1958. The paper emphasised the need for experimental approaches to the education of these children that incorporate an evaluation of the impact of alternative forms of provision. MR provided 
a review of the studies then available on autistic children followed into adulthood. ${ }^{[24]]}$ The most striking finding was the better outcome for the autistic child of normal intelligence than for those with mental retardation.

The first major review of autism provided an overview of the early studies on autism and produced some tentative conclusions about the nature and origins of autism which proved very prescient. ${ }^{[24]} \mathrm{He}$ states that autism is "not anything to do with schizophrenia", it is "unlikely that psychogenic or faulty conditioning mechanisms are primary factors in aetiology", "organic brain abnormalities appear to be primary influences in some cases", an approach which "places the primary defect in terms of a language or coding problem appears most promising." In addition, MR concluded that (at that time, 1968) the "importance of genetic factors remains unknown". [244]

MR returned to the issue of the basic cause of autism with particular focus on the cognitive/language deficits. ${ }^{[396]} \mathrm{He}$ gave a more extensive review of research on autism from the 1940 s to 1970 s $^{[258]}$ and provided reviews that considered research in relation to the concept of, diagnosis and definition of autism. [263] [447] [13] The changing understanding of the nature of autism lead, in 1979, MR and his co-editors of the leading specialist journal in the field to change "the scope and title from the Journal of Autism and Childhood Schizophrenia to the Journal of Autism and Developmental Disorders". [479]

MR provided a review of research progress in the study of autism up to the end of the $1980 \mathrm{os} .{ }^{[32]} \mathrm{He}$ argued that progress to date had arisen from an interplay between clinical observation and advances in research techniques. He suggested that future progress will arise from integrating findings from neuropsychology, genetics and studies on brain structure and function.

In 1996 MR gave a wide-ranging review of the future prospect for research in autism. ${ }^{[24]}{ }^{[325]} \mathrm{He}$ says:

"It is evident that the priority is to foster both basic research into the pathophysiology of autism (because that is the way that major advantages in prevention or intervention are likely to be accomplished) and applied research to investigate current modes of intervention in order that we are better able to help the patients that we deal with today." [324]

A review of autism up to the end of the 1990 s concentrated on the interplay between research and clinical practice. ${ }^{[338]}$ This interplay is nicely summarised in this quote:

"Many key advances were prompted by astute clinical observations and some extravagant research claims were given a more balanced perspective through the light of clinical experience." [338]

MR made the case of the importance of linking work on the epidemiology of autism with basic science research. ${ }^{[352]} \mathrm{A}$ narrower time frame for reviews on autism research were presented. ${ }^{[377]}$ [386]

The notion of a spectrum of severity of autistic behaviours and deficits was formulated as autism spectrum disorders (ASD). ${ }^{[35]}$ The issue of whether autism can be considered as on a continuum became crucial in the design of genetic studies. Here studies of the role of genetic factors included milder disorders and a wider range of individual differences. The construct of a broader autistic phenotype (BAP) was tested by Le Couteur et al. in a sample of twins with autism. ${ }^{[59]}$ They concluded that the importance of genetic factors extended beyond the diagnosis of autism per se to include a broader range of communication and social impairments.

MR made a highly critical commentary on 4 papers in the journal Autism on the question of the coherence or fractionation of autism spectrum disorders (ASD). ${ }^{[390]} \mathrm{He}$ asserted that, with the exception of a paper by Brunsdon and Happe, on the case for and against the fractionation of autism in terms of cognition, these papers do not helpfully or appropriately address the question of the heterogeneity of ASD.

Asperger syndrome (AS) was defined as in ICD-10 an autistic disorder in which there are abnormalities in reciprocal social interaction and in patterns of behaviour and interests, without clinically significant delay in spoken or receptive language, or cognitive development. Gilchrist et al. examined the differentiation of AS from high functioning autism (HFA) (i.e. those with autism and an IQ greater 70). ${ }^{[01]}$ They found that the AS and HFA showed very similar behaviour in adolescence despite differences in early speech development.

Bailey et al. argued that there is a need for an integrative framework to understand the relationship between the clinical, genetic, neuropsychological and neurobiological perspectives on autism. ${ }^{[12]}$ Although such an integration is:
"...not yet possible, a partial integration provides a useful strategy for identifying key research questions, the limitations of existing hypotheses, and future research directions that are likely to prove fruitful." [12]

MR addressed the question of changes in the incidence of ASD in a systematic review of studies published up to $2005 .{ }^{[357]} \mathrm{He}$ concluded that the true incidence of ASD in 2005 was of the order of 30 to 60 per 10,000; 
considerably higher than the 4 per 10,000 figure reported in the first survey of the condition (Lotter, 1966). This rise "...is due to the combination of better ascertainment and a broadening of the diagnostic concept, but a true rise over time in the incidence of ASD cannot be entirely ruled out." It may be that this rise is "...due to some environmental risk factor but, if so, it remains quite obscure as to what that factor might be."

$M R$ reiterated his view that a true rise in incidence is uncertain. ${ }^{[368]}$ This paper included a critique of the evidence related to the suggestion of Wakefield et al. (1998) that there was a causal connection between the use of the measles/mumps/rubella (MMR) vaccine and the onset of ASD associated with chronic enterocolitis. MR showed that there is:

"no convincing evidence to support the hypothesis that the measles/mumps/ rubella (MMR) vaccine has contributed to this rise." [357]

These conclusions concerning the lack of an impact of MMR vaccine on ASD were reinforced in study of incidence of ASD in relation to the phasing of a vaccination programme in Japan. ${ }^{[27]}$

A feature of the clinical management of ASD is that overtime it is being diagnosed at an earlier age. In 2006, MR reflected on some of the implications of this for the development of services for ASD. ${ }^{[359]}$

It has been established that autism is associated with obstetric complications. Bolton et al. studied obstetric histories in 78 families with an autistic proband and a comparison group of 27 families with a Down syndrome proband. ${ }^{\left[{ }^{\circ}\right]}$ They concluded that:

"Rather than playing any principal etiological role. The obstetric adversities associated with autism either represent an epiphenomenon of the condition or derive from some shared risk factor(s)." [30]

Bolton et al. tested the possibility that autism shows a birth seasonal effect. ${ }^{[32]}$ There was no consistent evidence of such an effect in two samples, but the paper argues that questions of research design and methods of statistical analysis make season of birth studies problematic to interpret.

In a review of research from the 1960 s onwards, Happé \& Frith (2020) identified seven major features of changes in the conceptualisation of autism:

"(1) from a narrow definition to wide diagnostic criteria; (2) from a rare to a relatively common condition, although probably still under-recognised in women; (3) from something affecting children, to a lifelong condition; (4) from something discreet and distinct, to a dimensional view; (5) from one thing to many 'autisms', and a compound or 'fractionable' condition; (6) from a focus on 'pure' autism, to recognition that complexity and comorbidity is the norm; and finally, (7) from conceptualising autism purely as a 'developmental disorder', to recognising a neurodiversity perspective, operationalised in participatory research models." (Happé \& Frith 2020)

MR has had a major impact on these changes. The following are identified by Happé \& Frith (2020) as areas of relatively neglect in research:

"There is little research on intellectual impairment, evidence-based educational approaches... Language, once such a focus for autism research, is now relatively little studied...".

It is striking that these are just the areas that MR made the focus of his studies on autism in the 1960s and early 1970s (for example, see respectively ${ }^{[18]}\left[{ }^{[136]}{ }^{[16]}\right.$ ).

\section{Autism - Assessment}

MR was involved in the development of a number of methods for the assessment and diagnosis of autism and other pervasive developmental disorders. The Autism Diagnostic Interview (ADI) is an interview conducted with the child's principal caregiver and covers a lifetime assessment of behaviours relevant to the differential diagnosis of pervasive developmental disorders from age 5 years to adulthood. ${ }^{[160]}$ An analysis of videotapes of the ADI conducted with caregivers of 16 autistic and 16 non-autistic mentally handicapped subjects showed good interrater reliability and discriminant validity. ${ }^{[160]}$

Using a revised version of the ADI (ADI-R), Lord et al. found that the discriminant validity between children with autism and non-autistic mentally handicapped children for children with mental ages under 18 months was poor. ${ }^{[169][170]}$ The former paper gives an extensive account of the reorganisation and shortening in the ADI-R. The ADI-R is more appropriate for children with mental ages from about 18-months into adulthood. The psychometric properties are good for pre-school children but needed additional investigation for older children and adults.

The ADI and the ADI-R were applied to a large and heterogeneous sample of autistic $(n=319)$ and other non-autistic mild or moderately mentally handicapped participants ( $n=113){ }^{[166]}$ It was concluded that:

"A single set of criteria, as operationalized by individually structured questions in the ADI/ADI-R, was effective in differentiating autism from mental 
handicap and language impairment in subjects with a range of chronological ages and developmental levels." [166]

The ADI-R is a diagnostic interview with a parent or caregiver. Based on the ADI-R, a 40-item screening questionnaire (Autism Screening Questionnaire - ASQ) was developed by Berument et al. to identify autism. [26] The ASQ could differentiate between those with pervasive developmental disorder (PDD) from those without a PDD diagnosis. However, the differentiation between autism and those with other non-autistic PDD was weaker.

The Autism Diagnostic Observation Schedule (ADOS) was developed to provide a standardised protocol for the observation of social and communicative behaviour associated with autism. ${ }^{[168]}$ This paper provided evidence that ADOS can be used reliably to assess the social and communicative features of autism but not other symptoms such as preoccupations, compulsions, restricted interests or autistic mannerisms. These initial findings were based on children and adolescents with mental ages of 3 years or over.

A version of the ADOS for young pre-linguistic children less than 6 years old (Pre-Linguistic Autism Diagnostic Observation Schedule, PL-ADOS) was produced by Dilavore et al. ${ }^{[79]}$ It was shown to have adequate reliability and clearly discriminated autistic and nonautistic developmentally disabled children. A further refinement of the ADOS was made as the AdaptedPre-Linguistic Autism Diagnostics Observation Schedule (A-PL-ADOS). ${ }^{[27]}$ This assessment is appropriate for older low functioning individuals with little or no language ability. The A-PL-ADOS was used with a sub-sample of the participants with autism $(n=38)$ and a comparison group of participants with Down syndrome $(n=13) .{ }^{[503]}$ These groups had mean non-verbal IQs of 30 and 36. The overall ratings showed good reliability and discriminant diagnostic validity.

Further refinements and extensions of the ADOS were made in the Autism Diagnostic Observation Schedule-Generic (ADOS-G). ${ }^{[167]}$ ADOS-G is a semi-structured, standardized assessment of social interaction, communication, play, and imaginative use of materials for individuals suspected of having autism spectrum disorders. The observational schedule consists of four 30-minute modules, each designed to be administered to individuals according to their level of expressive language. Diagnostic algorithms were developed to use ADOS-G item scores to detect DSM-IV and ICD-10 based diagnoses for autism and broader autistic spectrum/ Pervasive Developmental Disorders Not Otherwise Specified (PDDNOS). The differentiation of autism and PDDNOS from non-spectrum disorders was excellent but with only moderate differentiation of autism from PDDNOS.

The members of the International Molecular Study of Autism Consortium (IMGSAC) developed a Family History Interview (FHI) to measure BAP which is shown by social-communication impairments and rigidity. The measures consisted of a self-report version (FHI-S) and informant report version (FHI-I) and an Impression of Interviewee rating scale (lol) that could be used in combination to derive a dimensional measure of the BAP. The rationale for the lol was that the socio-communicative features of BAP will be elicited when a family member of an autistic individual was being interviewed. A measure of BAP could be obtained from the lol but the retest reliability was only modest. ${ }^{[218]}$ The $\mathrm{FHI}$ is a reliable dimensional measure of BAP with convergent validity across subject and informant forms. ${ }^{[209]}$ The $\mathrm{FHI}$ can differentiate between parents of children with autism and parents of children with Down syndrome. ${ }^{[78]}$ The group differentiation was good especially for fathers.

\section{Autism - Biological processes}

Jacobson et al. undertook a study of the computed tomography (CT) scan of the brains of 9 adult men with autism and 13 healthy male controls. ${ }^{[140]}$ Some differences were observed especially as subcortical rather than cortical abnormalities. The subcortical defects were anatomically selective, affecting third, but not lateral, ventricular size, and caudate, but not thalamic, regions.

Using brain weight as an indicator of brain involvement in autism a proportion of individuals with autism showed heavier than normal brain weights (megalencephaly). ${ }^{[10]}$ This study also reported that most individuals with megalencephaly are not autistic. A further augmented report on this material reported that:

"the findings included increased brain size and developmental abnormalities of the cerebral cortex, brainstem and cerebellum; in some cases, there was also secondary pathology." [11]

Furthermore that:

"we have found no evidence for a highly localized pathology that seems likely to underlie autism."

These findings were consistent with two reports that those with autism ${ }^{[9]}$ and PDD [536] had larger than average head circumferences and have been supported by subsequent longitudinal studies (Donovan \& Basson, 2017). Additional evidence of brain pathology involvement in autism come from a study of the prevalence of epilepsy in individuals with autism. ${ }^{[28]}$ Epilepsy developed in around $20 \%$ of cases and after 
the age of 10 years in the majority of the sample.

This is somewhat later than onset in the non-autistic population.

MR has published on a number of aspects of physiology in autism. A controversy arose as to whether serotonin efflux from platelets related to levels of symptoms in children diagnosed with autism. A reconsideration of the data from the original study concluded that there was no such relationship. ${ }^{[39]}$ A study of glucose hypermetabolism using positron emission tomography (PET) failed to replicate a previous finding of increased metabolic rates of glucose in autism. ${ }^{[22]}$ Another failure replicate concerned the urinary peptide profile patterns previously reported as distinctive in those with autism. ${ }^{[162]}$

\section{Autism - Cognition}

A study by Lawrence Bartak \& MR on the cognitive abilities of children with autism concerned a specific proposal by Betteheim (1967). This was that, from the basis that autism is an emotional disorder of psychogenic origin, in echolalic speech autistic children will not repeat statements containing "I" but will repeat those containing "you". ${ }^{[5]}$ The hypothesis being tested was:

"...that differences in the frequency of spontaneous echoing of personal pronouns by autistic children might be a result of sentence position rather than type of pronoun and in particular to determine whether I would be echoed as often as you, once sentence position was controlled." [15]

The findings of the study were consistent with pronominal reversal in echolalia in some children with autism being related to limitations on language comprehension rather than to disorders of selfconcept. The study did not support the notion that autism has a psychogenic origin.

Autism can occur in children with a wide range of intelligence. MR investigated the question of whether there were differences in the nature of autism in children who showed normal intelligence and those with mental retardation. ${ }^{[6]}$ They found that the primary features of behaviour in autism are present in autistic children with both low and high intelligence. There is however major difference in relation to the incidence of epilepsy. This raised the unresolved question of whether the origins of autism in these two groups may be different.

Bartak et al. undertook a study of boys aged 5 to 10 years with autism and a matched group of boys with "dysphasia". ${ }^{[7]}$ The latter was defined as:

"children without clearly autistic features who were diagnosed as showing uncomplicated developmental language disorder which included an impairment in comprehension as well as in the production of language." [17]

These boys were selected so as not to show demonstrable neurological dysfunction, hearing loss or mental retardation. The boys with autism had more deviant language development included more severe deficits in comprehension and the social usage of language. There were few differences between the groups on non-linguistic abilities. A multivariate discriminant function analysis of these data showed that the autistic and dysphasic groups could be distinguished just as clearly on language and cognitive measures as on social or behavioural measures. ${ }^{[18]}$ It was concluded that a cognitive deficit is an essential component of autism.

The parents of the autistic and dysphasic children showed no differences with respect to parental warmth, emotional demonstrativeness/responsiveness, or sociability. ${ }^{[74]}$ It was concluded that it is unlikely that autism develops as a consequence of such parental personality attributes.

The language used by parents to their children with autism was examined as this was considered by some to play a possible role in the genesis of autism. ${ }^{[42]}$

The participants were a sub-set of 13 of the autistic and 13 of the "dysphasic" children in the Bartak et al. study. ${ }^{\left[{ }^{[7]}\right.}$ No differences were found between the two groups of mothers in level of language usage, pattern of functional interaction, or in overall clarity of communication. These findings do not support the notion that deviant mother-child communication play a causal role in autism. The social context in terms of family life and relationships was compared for children with autism and dysphasia. ${ }^{[44]} \mathrm{Few}$ differences were found and again the results do support the notion of autism arising from abnormal experiences in the family. The language abilities of these two samples were examined and were found to be similar. ${ }^{[43]}$ The groups did not differ on syntactical usage but the autistic children were significantly less likely to make spontaneous remarks and significantly more likely to use delayed echoes, thinking aloud/ action accompaniments and inappropriate echoes of themselves.

A follow-up was made 2 to 3 years later when these children were 6.5 to 11.5 years old. ${ }^{[104][45]]}$ Very few of the boys with autism had good language skills at follow-up in contrast to the dysphasic group where about half the children were now communicating well but more of the dysphasic group were showing behavioural problems. When the participants were in their early 205 they were again assessed on cognitive and language measures. ${ }^{\left[{ }^{[85]}\right.}$ They found that the autism group had 
shown greater improvement in verbal IQ and receptive language scores. The groups showed much more overlap in a discriminant function analysis. In the autism group only early language ability was related to outcome. On behavioural outcomes the autism group continued to show more stereotyped behaviour patterns and difficulties in social relationships; $74 \%$ having severe social difficulties compared to $10 \%$ of the dysphasic group who showed severe social problems. [133]

The cognitive, language and psychosocial outcomes for the dysphasic group (now labelled developmental language disordered (DLD)) were studied one further time when they were in their mid-30s. ${ }^{[64]}$ They were compared to a non-language disordered group of their own siblings, to an age and nonverbal IQ matched group and to a group from the National Child Development Study matched on childhood IQ and social class. The DLD group remained significantly impaired in language functioning and on a range of other cognitive skills.

An experimental study addressed the difficulty of determining whether children with autism have poor performance on cognitive tasks that stems from a real cognitive deficit or is a consequence of motivational factors. ${ }^{[61]}$ This was an attempted replication of an earlier study by Cowan, Hodinott \& Wright (1965). In that previous paper it was concluded that negativism, i.e. "avoidance of a requested response by substituting an alternative", produced the poor performance in a number of children with autism. They were unable to replicate these findings in a sample of 27 nonhospitalised autistic children none of whom showed negativism. ${ }^{[6]]}$ Those studied by Cowan et al. (1965) were living in an institution and it was thought that this experience, rather than autism per se, was responsible for the negativism shown by autistic children in that earlier report.

A subsequent study examined whether task demands had disproportionate impact on the performance of children with autism on cognitive test. ${ }^{[62]}$ They found that:

"for most of the children tested, success or failure on any item was best predicted by the intrinsic difficulty of that item rather than by the child's lack of cooperation. However, it did appear that for some of the lower functioning children, early experience of failure did interfere with subsequent performance." [62]

A further extension of this work on task demands and performance tested a proposal by Tinbergen (1974) that adult initiated approaches to children with autism may be counterproductive. ${ }^{[63]}$ This was an experimental study where situation structure and interpersonal or social demands on the child were varied. It found that contrary to the prediction of Tinbergen (1974) that:

"as social demands were increased, so was the likelihood that the child would make some sort of social response; as the taskrelated features increased, so did the rates of productive behavior." [63]

Lennox et al. tested the notion that parents of children with autism showed thought disorder that may result from elevated levels of anxiety. ${ }^{[163]}$ The study found that:

"(1) there was a lack of agreement between two major tests of thought disorder; (2) parents of autistic children showed closely comparable thought disorder scores to the parents of normals; and (3) there was no consistent association between thought disorder and anxiety." ${ }^{[163]}$

MR provided an overview of the state of knowledge in the early 1980 s concerning the cognitive deficits of children with autism. ${ }^{[285]}$ In this paper he again countered the proposal for Tinbergen and others that in autism there is a primary emotional imbalance involving fear and anxiety to which cognitive deficits are a secondary consequence. Instead he asserted that:
"Although different researchers express their ideas on the nature of autism in rather varied terms, and although they differ in the emphasis placed on particular aspects of cognition, there would be little dispute today on the general notion that autistic children have a basic cognitive deficit." [285]

He concludes that:
"Clearly there are fundamental connections between the abnormalities of cognition, conation and affect found in autism, but we remain ignorant of just what those connections are and, especially, we lack knowledge about the nature of the symptoms of autism that gives the name to the syndrome." [285]

The emergence of studies on theory of mind deficits in children with autism during the 1980 os (e.g. BaronCohen, Leslie \& Frith, 1985) was linked with studies on impairment in the appreciation and expression of emotional cues. HFA adults were found to be limited in the appreciation and production of emotional expressions in both facial and visual modalities. ${ }^{[77]}$ The study left unanswered the question of whether this deficit was based in an impairment of the affective system or whether it was part of a more general cognitive theory of mind deficit. 
Phillips et al. tested another aspect of the basis of theory of mind impairments in children with autism, namely the ability to identify the intention of another person based upon their eye direction. ${ }^{[212]}$ This was an experimental study of normally developing 9-18-month-old babies, a group of 3 to 5 years old children with autism and a group of children with mental handicap. The conclusions from the study were summarised as follows:

"by 9 months of age, normal infants understand that people are goal-directed in their action. So do young children with mental handicap. In contrast, young children with autism appear delayed or impaired in this ability. Because children with autism show severe deficits (later in development) in understanding the mental states of believe, know, and pretend (i.e., they lack many components of the normal theory of mind), it may be that their apparent failure to use eye contact to diagnose a person's goal reflects an abnormality in an important early precursor in the development of a concept of mind". [222]

Children with autism not only failed to understand another's beliefs but also another's desires especially when these are only implicit. ${ }^{[23]} \mathrm{A}$ deficit in the understanding of intentions in children with autism was also found. ${ }^{[211]}$

More sophisticated measures of social understanding in those with autism was needed particularly in studies of adults with HFA and of the broader autism spectrum in genetically informative studies. Heavey et al. developed the Awkward Moments Test to address this need. ${ }^{[22]]}$ This test used film clips that showed a character experiencing a socially awkward or unpleasant moment at some point during the film. The participants were then asked questions on the character's mental state. The study showed that those adults with HFA and AS were most impaired in answering questions requiring mind-reading ability.

A further strand of research on cognition in those with autism was that concerning the cognitive profiles of their relatives. Using standardised tests of IQ, reading and spelling with the parents and siblings of 99 probands with autism and of 36 Down syndrome controls, the unaffected relatives of those with autisms were found to have slightly superior verbal skills. ${ }^{\text {995] }}$ The paper stated that this issue needed further study before firm conclusions can be reached concerning the validity of the enhanced verbal ability in these firstdegree relatives.

There has been a longstanding assertion that savant skills are shown by a number of those with autism. MR addressed the question of the origin of "special talents" in those with autism. ${ }^{[35]} \mathrm{He}$ asserted that the origin of these abilities cannot be attributed to either genetics or experience:
"Skills cannot be divided into those that are and are not innate; cognitive performance ebbs and flows over the course of development (as a result of both genetic and environmental influences); and all skills warrant fostering, regardless of the extent to which they are genetically or environmentally influenced." [335]

There had been few systematic large-scale studies on this issue. Howlin et al. undertook a study to identify the rates and type of savant skills in 137 adults with autism. ${ }^{[33]]}$ It was found that $28 \%$ of these participants met the criteria for showing savant skill and none of these had IQs below 50. These exception abilities on testing were shown most often to be on the block design sub-test.

Early developmental regression (EDR) is the loss of some skills during the preschool period. There have been widely varying reports of the proportion of children with autism that show EDR. In a sample of 458 individuals with ASD, it was found that $24 \%$ of those with ASD showed EDR before the age of 36 months. [210] There was no evidence of family influences on EDR other than as part of autism itself.

\section{Autism - Fragile-X}

The association between the fragile $X$ anomaly and autism was initially recognised in males where about $10 \%$ of boys with autism show the fragile $X$ anomaly (Bregman et al., 1987). It was only subsequently found that females with autism can show fragile X. ${ }^{[66]}{ }^{[36]}$ The difficulties of using cytogenetic methods to identify the presence of fragile $X$ in families of those with ASD was examined. ${ }^{[3]}{ }^{[11]}$ Bailey et al. tested the possibility that fragile $\mathrm{X}$ represent a major contributor to the genetic factors influence autism. ${ }^{[8]}$ Based on data from a number of samples including of twins with autism and clinic attenders with autism, they concluded that:

"The important findings from this study are as follows: firstly, the fragile $X$ anomaly was found in only $1.6 \%$ of the autistic individuals examined from the combined twin and clinic samples (with a total $\mathrm{n}$ of 85 males and 40 females); secondly, the anomaly was at least as common in autistic females as in autistic males; thirdly, the anomaly accounts for only a very small proportion of the genetic influences in autism; and lastly, within families there is phenotypic heterogeneity amongst fragile X positive siblings" 
and

"Our findings indicate that in the vast majority of cases these genetic influences [on autism] are not attributable to the Fragile $\mathrm{X}$ anomaly". ${ }^{8]}$

MR et al. reviewed the evidence that autism was associated with known medical conditions including fragile X. [395] They concluded that the rate of known medical conditions in autism is about $10 \%$ but somewhat higher in those with profound mental retardation and atypical autism.

\section{Autism - Genetics}

A major strand of MR's work on autism has concerned the examination of the genetic basis of the condition. This started with twin studies co-authored with Susan Folstein ${ }^{[2]}\left[{ }^{[93]}\right.$ and with Anthony Bailey and colleagues. [9] This strand of work has continued into the era of molecular genetic studies, initially with linkage studies and later genome wide association studies. At various times MR has reviewed the evidence concerning genetic influences on autism. ${ }^{[94]}$ [342]

The first epidemiological twin study of autism involved 21 pairs of same-sex twins, at least one of which was autistic, identified from multiple sources in Great Britain. ${ }^{[92]}[93]$ Previous twin studies on autism had been unsystematic and there were problems with their interpretation. ${ }^{[33]}$ For autism per se the concordance in identical (MZ) twins was $36 \%$ and for fraternal twins (DZ) was O\%. ${ }^{[92]}{ }^{[93]}$ Using a broader measure of cognitive abnormalities, the respective concordance rates were $82 \%$ and $10 \%$. In addition, in the discordant pairs the twin with autism was much more likely to have experience adverse biological hazards liable to cause brain damage. These findings led to the following conclusions:

"there were important hereditary influences concerning a cognitive deficit which included but was not restricted to autism"

and
"brain injury in the infancy period may lead to autism on its own or in combination with a genetic predisposition." [93]

This study was truly ground-breaking in presenting the first reliable evidence of the role of genetic factors in causing autism.

Both of the conclusions concerning the role of genetic and biological hazards were replicated in a subsequent study by Steffenburg et al. (1989). The original twin sample in ${ }^{\left[{ }^{2}\right]}{ }^{[93]}$ were recontacted and an additional sample of 28 same-sex pairs with an autism proband were recruited, again from multiple sources. ${ }^{[9]}$ This enlarged sample showed 60\% MZ concordance and ०\% DZ concordance for autism. The concordance rates for a broader range of cognitive and social abnormalities was respectively $92 \%$ and $10 \%$. The analysis of obstetric hazards in this sample suggested that these were a consequence not a cause of autism. A meta-analysis of the published twin studies on ASD identified 13 eligible studies. ${ }^{[191]}$ They conclude that:
"(a) ASD is due to strong genetic effects; (b) shared environmental effects become significant as a function of lower prevalence rate; (c) previously reported significant shared environmental influences are likely a statistical artefact of overinclusion of concordant DZ twins." [519]

A further review suggested that genetic factors play a "predominant" role in autism and in a more broadly defined phenotype "characterized by a combination of cognitive and social deficits". ${ }^{35]}$. Further evidence in support of the role of genetic factors in autism was obtained in a study based on family data from 99 autistic and 36 Down syndrome probands. ${ }^{[29]}$ The patterns of family aggregation indicated that:
"...the autism phenotype extends beyond autism as traditionally diagnosed; that aetiology involves several genes; that autism is genetically heterogeneous; and that obstetric abnormalities in autistic subjects may derive from abnormality in the foetus." [29]

Data from these samples were also used in subsequent papers. [33] [195] The former examined whether the liability to autism is associated with the risk for other psychiatric disturbances. The results suggested that obsessive-compulsive disorder (OCD) may be associated with this liability but not affective disorders. The latter investigated the personality profiles of first-degree relatives of the autistic and Down syndrome probands in this sample. They found that traits reflecting 'withdrawn', 'tense' and 'difficult' facets personality were increased in the relatives of the autistic probands.

Starr et al. extended this work on the familial loading for autism to examine whether it was different if autism was accompanied by severe mental retardation.

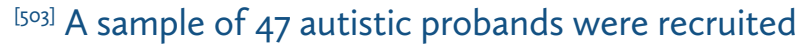
with IQs less than 50. The family history data from this sample was compared with that in Bolton et al. [29] where few of the autistic probands had IQs as low as this. They found that:
"The familial loading for autism and for the broader phenotype was closely comparable to that in the study of higher IQ autism, and different from that for Down syndrome." [29] 
Pickles et al. ${ }^{[220]}$ pooled the samples from the Bolton [29] and Starr ${ }^{[503]}$ studies. Data on family 3095 first- and second-degree relatives and cousins from 149 families with a child with autism and 36 families with a child with Down syndrome were analysed. They concluded that:

"The results provide further evidence of an increased risk among autism relatives for the broadly defined autism phenotype. Of proband characteristics, severity of autism and obstetric optimality were confirmed as being related to familial loading for probands with speech." [220]

The data on the participants the Bailey ${ }^{[9]}$ and Bolton ${ }^{[29]}$ studies were analysed by Pickles et al. ${ }^{[215]}$ to demonstrate the way in which latent class analysis can be used to address some of the methodological difficulties in the analysis of the pattern recurrence risk for complex disorders such as autism. There were 1716 relatives of autistic probands and 769 Down syndrome probands included in the analysis. The paper suggests that latent class analysis can tackle:

\section{"Problems such as uncertain phenotypic definition, unreliable measurement with increased error rates for more distant relatives, and selection due to reduced fertility all complicate the estimation of risk ratios." [215]}

The conclusion from this analysis supported a multiplelocus model of inheritance, with three genetic loci giving the best fit.

The International Molecular Genetic Study of Autism Consortium (IMGSAC) has produced a series of papers starting with a full genome screen on 99 families with affected relative pairs with at least one member with autism. ${ }^{[139]}$ On 83 affected sib pairs with autism significant linkage for autism was found to markers on chromosome 2q, $7 q$ and $16 p$. ${ }^{[208]}$ The linkage to $7 q$ was tested further and the initial findings from the IMGSAC UK sub-sample were replicated in a larger multi-national sample of 170 multiplex families. ${ }^{[207]}$ $\angle A M B 1$ and NRCAM were suggested as the genes on 79 associated with autism. ${ }^{[37]}$

Subsequently the IMGSAC combined with 3 other consortia to publish under the auspices of the Autism Genome Project (AGP). The AGP presented an analysis based on 1,181 families with at least two ASD probands. ${ }^{[07]}$ Linkage was found to loci on 11p12-p13. The linkages suggest that glutamaterelated genes might be promising candidates for genes contributing to autism. The AGP tested for the frequency of rare copy number variants (CNV) on a genome wide basis. ${ }^{[221]} \mathrm{CNV}$ are duplications of parts of the DNA which can vary in number and which may influence gene expression. They found that CNVs were more common in those with ASD. They conclude that:

“...results reveal many new genetic and functional targets in ASD that may lead to final connected pathways." [221]

Genome-wide association (GWAS) methods were used to search amongst 1 million single-nucleotide polymorphisms (SNPs) for those associated with ASD.

[7] Despite some initial indication that a SNP within the MACROD2 gene might be implicated, this association did not stand up to a test of replication. They concluded that the sample of 1558 ASD families studied was too small to be able to detect the significant associations with "CNVs, rare sequence variation and common alleles." Later the sample size was increased by 1303 families but associations for SNPs and for common gene variants remained non-significant. ${ }^{[6]}$ The AGP demonstrated that homozygous haplotype $(\mathrm{HH})$ mapping might be available alternative approach to the analysis of genome-wide association data for ASD. ${ }^{[50]}$

Bolton et al. presented a single case study of the chromosomal abnormalities $(46, \mathrm{X}, \mathrm{t}(\mathrm{X} ; 8)(\mathrm{p} 22.13 ; \mathrm{q} 22.1))$ of a girl with physical disabilities, autism and mental retardation. ${ }^{[34]}$

Starr et al. reported on the rate of ASD in those with Down syndrome. ${ }^{[504]}$ In a small sample of 13 individuals with Down syndrome, 5 "met or almost met" the criteria of autism. The question of whether this is a high rate of "true" autism or whether there is a measurement artefact was considered. The conclusion is reached that:
"there are individuals with Down
syndrome whose behavior probably truly fulfils the lifetime diagnostic criteria for an autism spectrum disorder." [504]

However, they stated that it requires further studies to determine the meaning of this association.

ASD and ADHD show symptom overlap and often children meet the diagnostic for both conditions. Martin et al. investigated the similarity of the factor structure of ASD traits in children diagnosed with ADHD and that found in children with ASD. ${ }^{[75]}$ Previous factor analyses had found two distinct factors for social and restrictive-repetitive behaviours (RRB) in children with ASD and the general population. This factor structure was replicated in a sample of children with ADHD. ${ }^{[75]}$ They highlighted the need to study further the overlap between hyperactive-impulsive symptoms and RRB traits in children with ADHD.

\section{Autism - Infantile psychosis}

The contentious distinction between infantile psychosis, childhood schizophrenia and autism was first addressed by MR in 1965. ${ }^{[239]}$ In that paper he 
reported on a follow-up study of 63 pre-pubescent children who received the unequivocal diagnosis of child psychosis (or one of its synonyms) - these children were first studied by Anthony (1958) and Cameron (1958). MR concluded that child psychosis is not related to schizophrenia and is distinguished by early receptive and expressive speech defects arising for organic brain damage. Psychogenic factors play only a secondary role in its development. The child's emotional relationships are the prime determiner of continuing handicaps. These children were the subject of a number of later reports. ${ }^{[425]}$ [416] [245] [164] [165]

These studies and reviews were summarised ${ }^{[253]}$ and MR concluded that

"'childhood schizophrenia' includes at least three main disorders differing in age of onset: Autism, schizophrenia, and disintegrative psychosis, which constitute disparate conditions requiring separate classification"

and that

"the evidence suggests that autism
develops on the basis of a central
disorder of cognition which involves the
impairment of both the comprehension of
language and defects in the utilization of
language or conceptual skills in thinking."
[253]

\section{Autism - Outcome in adulthood}

Howlin et al. traced 68 individuals now over 21 years old who had been referred in childhood to the Children's Dept at the Maudsley Hospital and who had been diagnosed with autism. ${ }^{[130]}$ The aim of the study was to establish the outcome in adulthood in children with autism and performance IQs of at least 50 in terms of cognitive, linguistic and behavioural functioning and to what extent early cognitive ability was predictive of outcome. The outcome was assessed when the participants were on average 29 years of age. The results indicated that most participants remained very dependent on their families with continuing difficulties in communication and literacy. Only $12 \%$ were rated as having a good outcome with the majority having outcomes rated as poor (46\%) or very poor ( $12 \%$ ). Those with performance IQs above 70 had better outcomes. This same sample formed the core of a group of 135 studied to determine the rate of newonset psychiatric disorders in adulthood on those diagnosed with autism in childhood. ${ }^{[138]}$ They found that $16 \%$ developed a new psychiatric disorder with an addition $6 \%$ have a possible new onset disorder. There was a range of diagnoses identified but no cases of schizophrenia.
Howlin et al. studied a group from the Maudsley Hospital follow-up when they were on average 44 years of age. ${ }^{[135]}$ This group all had nonverbal IQs greater than 70 at age 7 years. They found that:

"social inclusion remains very limited, despite general improvements in autism symptomatology with age." [135]

This same sample were examined for their cognitive and language skills in mid-adulthood ${ }^{[137]}$ and Howlin et al. found that:
"most individuals with an IQ in the average range as children maintain this level of functioning at least until the middle adult years"

and
"that individuals who fail to progress in early language are at significant risk of more severe impairments in adulthood." [137]

In this group of adults where autism measures were taken of self-reported mental health. ${ }^{[193]}$ There were only moderate (but significant) associations between self and other informant reports of mental health. Both self and informant ratings indicated good mental health in $40 \%-45 \%$ of the participants. They found that:

"if problems did occur these were frequently associated with anxiety, depression and OCD." [193]

They comment on the paucity of appropriately validated measures of mental health for adults with autism.

Howlin et al. ${ }^{[134]}$ undertook a separate follow-up of the siblings of autistic probands in family studies at the Maudsley Hospital. [9] [29] [159] [95] In childhood these siblings were classified as either unaffected by autism (UA) or as showing the BAP. The UA siblings were functioning well in adulthood, but the social relationships and employment history of the BAP group was less good. The BAP group showed high scores on measures of autistic traits and had more mental health problems.

\section{Autism - Treatment}

In 1971 MR \& Fraida Sussenwein described the approach to the treatment of autism being developed at the Maudsley Hospital as follows:

"...an approach to the treatment of the young preschool autistic child which emphasizes both the positive development of normal functioning and the elimination of abnormal behavior. Behavioural techniques are utilized in this 
connection with due attention to the normal requirements for development and to the ways in which they are impaired by the cognitive handicaps of the child. Therapy must be planned with an eye for the specific needs of each child, based on a careful diagnostic appraisal and functional analysis of the child's behavior with respect to environmental circumstances." [460]

MR gave details of some of the findings from the work he undertook with Lionel Hersov, Michael Berger, Bill Yule, Pat Howlin and Rosemary Marchant on the behavioural treatment of pre-school children with autism. ${ }^{[257]}$ The summarising conclusion was that:

"services should develop in the context of facilities for children with a wider range of developmental disorders, rather than in clinics specifically for autistic children." [257]

Lawrence Bartak \& MR gave an account of an approach to the measurement of staff-child interaction in three units for children with autism. ${ }^{[14]}$ They found substantial differences between units and between staff in the same unit. The children in these units were followed over a 4-year period. It was concluded that large amounts of specific teaching in well-controlled classroom setting are likely to be optimal for the progress of the children. ${ }^{[397]}$

Howlin et al. developed a home-based approach to the treatment of children with autism. ${ }^{[32]}$ Twelve cases were presented in detail and these suggested that behavioural techniques are effective in the home treatment of autistic children. The specific benefits introducing slight and gradual changes into the autistic child's environment are discussed in the presentation of two case histories. ${ }^{[74]}$ A summary of this homebased treatment for autism concluded that:

"...while there is no evidence that parents of autistic children provide deficient language models for their children, it is apparent that existing language environments can be changed, and that these changes are associated with improvements in children's speech." ${ }^{[136]}$

MR provided an overview of the approach to treatment of the child with autism. ${ }^{[293]}$ He concludes that:

"...the first goal must be to foster normal development; with autistic children this involves a focus on intellectual, language and social development. The further goals include: the reduction of rigidity/ stereotypy; the elimination of non-specific maladaptive behaviours; and alleviation of family distress. Research findings are used to translate these goals into a practical overall therapeutic programme with three main elements: a full diagnostic appraisal, special educational provision and a homebased programme for the family." [293]

MR was one of a number of experts who were signatories to letter to the Editor of the Journal of the American Academy of Child and Adolescent Psychiatry condemning as unethical the approach to therapy called "le packing". ${ }^{[2]}$ This therapy was being applied to children with autism particularly in francophone countries.

\section{CHILDHOOD DISORDERS AND LATER ADULTHOOD DISORDERS}

MR addressed the relationship between childhood disorders and adult outcomes. ${ }^{[249]}$ He made the distinction between disorders that are temporary and those likely to have a persistent effect. He developed a framework that differentiated between disorders arising within the child and those linked to experience and in both cases identified factors that were low and high risk for continuing difficulties. MR went on show how fallacious and simplistic is the notion that adult psychiatric disorders "have their roots" in childhood. ${ }^{[254]}$ He demonstrated that different groups of conditions have contrasting patterns of association between childhood and adulthood. For emotional disorders the associations are weak, schizophrenic psychoses in adulthood are often preceded by nonpsychotic abnormalities of behaviour and there are only infrequent precursors of adult depression in childhood. It is with conduct disorder in childhood and adult personality disorders that the strongest overtime associations are found. ${ }^{[288]}$ [540] [322] [326] The complexity of the interrelations between the factors involved in the link between childhood antisocial behaviour and adulthood was demonstrated in a longitudinal study by Simonoff et al. [495]

MR discussed the complexity of the processes involved in the development of patterns of behaviour in adulthood and childhood experiences. ${ }^{[289]}$ The approach to this issue he developed further in his Tizard Memorial Lecture. ${ }^{[306]}$ In this lecture he attributes Jack Tizard with influencing his views on the links between childhood experiences and later development. He says that:

"His [Jack Tizard's] point was not that continuities did not occur, but rather that simplistic concepts of immutable effects needed to be put aside and replaced by more dynamic notions of the continuing interplay over time between intrinsic and extrinsic influences on individual development." [306] 
This principle was shown in a follow up of children from the IL study. ${ }^{[59]}$ Where it was concluded that:

"...emotional or behavioural disturbance in childhood was associated with a marked increase in the rate of severely negative events and difficulties some two decades later. This increase was only obtained for stressors with severe negative impact of the type shown in previous investigations to be associated with the onset of psychiatric disorder. Additional results demonstrated that this main finding could not be accounted for by stressors that were a result of adult psychiatric disorder, by the respondent's own behaviour, or by continuing association with the family of origin." [59]

There are "turning points" at which discontinuities in the course of psychopathology may occur. ${ }^{[228]} \mathrm{MR}$ concluded that:

"turning point effects represent a heterogeneous range of lasting changes in psychological functioning". [328]

These turning points were experienced by only sub-groups in the population and may involve both biological processes and external experiences. MR et al. gave a more extensive account of the mechanisms underlying both continuities and discontinuities. ${ }^{[47]}$ That review discussed:

"heterotypic continuity and psychopathologic progression, early age at onset and a range of possible mediating mechanisms - including genetic mediation, 'kindling' effects, environmental influences, coping mechanisms and cognitive processing of experiences." [477]

Laurens et al. studied the specific difficulties of identifying individuals in childhood who may later develop schizophrenia but who do not have a family history. ${ }^{[158]}$ They found that in 9 to 12 -year olds $9 \%$ of boys and $4 \%$ of girls displayed a triad of antecedents to schizophrenia i.e. speech and/or motor delays, social, emotional or behavioural problems and psychotic-likeexperiences. So, although it is feasible to screen for antecedents of future schizophrenia, the accuracy of identification needs to be tested in follow-up studies.

\section{CLASSIFICATION CHILD PSYCHIATRIC DISORDERS}

In his earliest publications MR advocated the need for a system for the classification of child psychiatric disorders. He argues that the then available approaches to classification were inadequate; this was written in $1965 .{ }^{[238]} \mathrm{He}$ laid out a set of principles that should hold for such a classification and made a tentative suggestion for a possible framework childhood disorder that included neurotic disorders, antisocial or conduct disorders, a mixed group, developmental disorders, hyperkinetic syndrome, child psychosis, psychosis developing at or after puberty, mental sub-normality, educational retardation as a primary problem, depression and adult-type neurotic illness. This grouping of disorders was subsequently applied in the loW study. ${ }^{\left[{ }^{[B o k k]}\right]}\left[{ }^{[B o k k 4]}\right.$ The term autism is not used in this paper but instead the condition is referred to as "child psychosis".

MR published a paper in French that arose from a seminar held in Paris in 1967 on the theme of the classification of mental disorders. ${ }^{[246]}$ The journal ( $L a$ Psychiatrie de L'Enfant) is described on its own website as "The oldest psychoanalytical journal dedicated to children and adolescents".

A number of reports were published at the end of the 1960 s and early 1970 s that arose from the discussions and studies related to the World Health Organisation (WHO) Seminars on Psychiatric Disorders, Classification and Statistics which were preparatory to a subsequent revision of the ICD-9. ${ }^{[424]}\left[{ }^{[508]}{ }^{[451]}\right.$ The outcome was a proposal to adopt a classification based on a tri-axial framework: First Axis - Clinical psychiatric syndrome, Second Axis - Intellectual level and Third Axis - Associated or aetiological factors. Here "infantile autism" is specifically referred to a category of psychosis.

In 1980 MR \& David Shaffer provided a commentary on DSM-III. ${ }^{[450]}$ The critique was stringent:

"criticisms are made of the structure of the multiaxial system, the decision not to put mental retardation on a separate axis, the principles employed on the psychosocial axes, the proliferation of unvalidated diagnostic categories, and the extension of research diagnostic criteria to categories which lack the empirical findings which might justify them." ${ }^{[450]}$

This notwithstanding it is concluded that DSM-III is a marked improvement over the previous edition of the DSM. An Annotation highlighted the beneficial impact of DSM-III on the later revisions in ICD-10 and described the relations between the development of DSM-III and ICD-10. [304]

After the initial proposal for the third Axis, revision and refinements were suggested. ${ }^{[B o o k 8]}[$ [Bookı] $\ln 1978$ MR provided an overview of the classification of childhood disorders and an appraisal of the validity of diagnostic categories. ${ }^{[264]} \mathrm{He}$ concludes that autism is a well-established diagnosis and that the distinction between emotional disturbance and disorders of 
conduct is well supported. It is suggested that the basis is in place to start to develop a multi-axial framework for the classification of childhood disorders. A further radical revision to this psychosocial axis in the tri-axial classification scheme was presented in 1990. ${ }^{[524]}$

Comorbidity is an aspect of childhood disorders that was not well addressed in either ICD-9 or DSMIII-R. A landmark paper by Chantal Caron \& MR provided a framework for examining comorbidity and the developmental relationships between disorders. [49] The ideas in that paper were developed further and MR emphasised the potential value of studying comorbidity to provide insights into casual processes. [323] [332]

The field trial for autistic disorder in DSM-IV was undertaken. ${ }^{[27]}$ MR \& Eric Schopler considered the specific issues concerning the classification of pervasive developmental disorders. ${ }^{[48]}$ The analysis of this question is made in relation to need for revisions in DSM-IV. This paper provoked a response to which they replied. ${ }^{[49]}$ The question of how childhood disintegrative disorder (CDD) (incorporated in DSM-IV) relates to autism was considered by Volkmar et al. and they concluded that CDD and autism are usefully and meaningfully distinct. ${ }^{[26]}$

The controversy over the status of impairment and whether it should be incorporated in the diagnosis and classification of childhood disorders was examined empirically in an analysis of longitudinal data from the VTSABD. ${ }^{[219]}$ A different result was found for depression, where impairment was not predictive of later diagnosis, and conduct and oppositional defiant disorders where impairment was predictive. Pickles et al. concluded that "Impairment, in addition to symptoms, is important for both nosology and prognosis." [219]

MR reviewed the question of the relative value of categories in childhood disorders and measures based on dimensions. ${ }^{[346]} \mathrm{He}$ concluded that in respect to both the evidence on genetic influences on disorders and the impact of environmental risk factors, that measures of both dimensions and categories are needed to adequately inform research strategies examining questions of causality.

This issue was returned to and MR presented a critique of the ICD-10 and scoped the developments that need to be incorporated into the next revision i.e. ICD-11, and similarly for DSM-IV and DSM-V. ${ }^{[376]}$ The suggestions for ICD-11 were subsequently elaborated in more detail. ${ }^{[464]}$ Some of the proposed changes are radical and are summarised in the following quotation from the earlier paper:

"...some of the main concepts and their implications are reviewed and various changes in diagnosis and classification that seem desirable are put forward as the basis for further discussion. The most important of these are 1) the removal of a separate grouping of disorders with an onset specific to childhood, the various specific disorders being placed in appropriate places in the overall classification structure, and the ways in which manifestations vary with age being specified for all disorders; 2) the addition of a grouping for disorders that are known to occur, but for which further testing is needed to assess their validity; 3) a major reduction in the number of diagnoses, many of which are rarely used and with the major problem for some disorders of ridiculously high levels of cooccurrence; 4) the use of a combination of categorical and dimensional approaches; 5) the exclusion of a criterion of impairment; 6) the separation of research and clinical classifications; and 7) the need to develop a primary care classification for causes of referral to both medical and non-medical primary care." [376]

A number of commentaries on ${ }^{[376]}$ were produced, to which MR responded. ${ }^{[378]}$

The case from scientific research for this radical revision to classification was made by Rudolf Uher \& MR. ${ }^{[522]}$ They concluded that:
"...evidence from multiple lines of research converges to indicate that current classifications contain excessively large numbers of categories of limited validity. Dimensional classification will not solve the problem because the number of dimensions is as uncertain as the number of categories. Psychiatric research should discard the assumption that current classification is valid. Instead of diagnosis- specific investigations, studies of unselected groups assessed with bottom- up approaches are needed to advance psychiatry." [522]

Uher \& MR produced a similar critique of the approach to the classification, but specifically related to eating disorders. ${ }^{[523]}$

MR considered the potential position of psychopathy as a category in the classification of childhood (and adult) disorders. ${ }^{[353]}{ }^{[382]} \mathrm{He}$ notes that it is anomalous that psychopathy is not included in either ICD-10 and DSM-IV. He endorsed psychopathy as a meaningful diagnosis in childhood. ${ }^{[382]}$ Data from the English Romanian Adoption study (see below) was used to determine whether callous-unemotional traits 
(a component of psychopathy) was distinguishable from disruptive behaviour and conduct disorders. [156] In these children experiencing early institutional deprivation those with high callous-unemotional traits did not show conduct disorders suggesting that, although commonly co-occurring, psychopathy should be diagnosed separately from conduct disorder.

In a broad overview of neurodevelopmental disorders such as autism spectrum disorders and attention deficit hyperactivity disorders by Anita Thapar et al., it was maintained that this grouping is helpful, but it is necessary to recognise that there is a high level of heterogeneity and overlap in these disorders. [513]

MR contributed one of a number of commentaries on DSM-5 where he concentrated on its significance for clinicians treating autism. ${ }^{[199]} \mathrm{He}$ is very stringent in his criticisms of the failures in DSM-5 in general in that it did not reduce the number of diagnostic categories and failed to harmonise with ICD-10. In relation to autism his concerns centred on the absence of considerations of the broader phenotype of autism and the potential detrimental effects of the DSM-5 revision on the access to services for those with higher functioning autism.

\section{DEPRESSION}

In conjunction with Dick Harrington, MR conducted a follow-up into adulthood of children and adolescents who showed depression. They found that there was a specific association with affective disturbances ${ }^{[115]}$ and suicidal behaviours ${ }^{[14]}$ in adulthood but no increased risk of non-depressive adult psychiatric disorders. Children with depression and conduct disorder had a different adult outcome to those with depression only. The combined group had a lower risk of depression in adulthood and a higher risk of adult criminality than those with depression alone. ${ }^{[16]}$ An extension to this study assessed family members and found that depression in young people had a number of characteristics similar to that of depression in adults: it tends to run in families and rates of depression are higher in female than male first-degree relatives. ${ }^{[17]}\left[{ }^{120]}\right.$ [230]

A cross-sectional study of psychiatric patients aged 8 to 16 years without a pervasive developmental disorders or schizophrenia examined the effects of age and pubertal status on the sex ratio in depression. ${ }^{[5]}$ The increase in proportion of girls with depression was a reflection of age and not primarily of pubertal status. In a 1996 review of studies on childhood depression Harrington et al. concluded that:

"there are probably several different kinds of depressive syndromes in children.

Some are strongly linked with depressive disorders in adulthood, but others are probably better conceptualized as part of another psychopathological problem altogether." [119]

Fombonne et al. conducted a subsequent long-term follow-up study of children with major depressive disorder who had attended the Maudsley Hospital. [96] [97] This replicated and extended the findings from the earlier study. ${ }^{[115]}$

MR provided a commentary on a paper by Kashani \& Sherman (1988) on the epidemiology of childhood depression, where he suggested that such studies need to take into account both the heterogeneity of depression and its co-occurrence with other psychiatric conditions. ${ }^{[302]}$ Equally attention needs to be paid to age related changes in prevalence especially in relation to increases during the teenage years. MR also urged caution in relation to endorsing the tricyclic drugs as an effective treatment for major depression in children: the evidence for this is limited, contradictory and inconclusive.

Judy Silberg, Lindon Eaves \& MR conducted a genetically informative study on depression using data from the VTSABD. The results of these analyses suggested that depression before and after age 14 years may be aetiologically distinct syndromes [489] [490] and that there is an environmentally mediated effect of life events on depression/anxiety and that these risks are moderated by genetic differences. [492]

Child patients from the Camberwell Psychiatric Register with a combined diagnosis of unipolar depression and personality disorder had more adverse outcomes in adulthood than those with other diagnoses. ${ }^{[223]}$

\section{EPIDEMIOLOGY}

The epidemiological studies on the loW and in IL are the sources of much of the subsequent research by MR.

\section{Epidemiology- loW and IL studies}

The preliminary findings for the loW study were presented. [412] [538] The main findings were subsequently published ${ }^{\left[B_{0} k_{4}\right]\left[B^{[} o_{3}\right]}$ and an appraisal of the significance of these findings was made. ${ }^{[463]}$ [305] There was further follow-up on the loW sample investigating predictors of suicidality. ${ }^{[214]}$

The particular value of the epidemiological study in IL was that it provided a contrasting social context to the loW. The rates of emotional disorders, conduct disorders ${ }^{[409]}$ and specific reading retardation ${ }^{[25]}$ were found to be substantially higher in IL compared to the loW. The possible origins of these difference in prevalence were discussed. [256] [466]

The IL study also provided scope for comparing ethnic difference in the rates of psychiatric and educational 
difficulties specifically in relation to children of West Indian immigrants. ${ }^{\text {[469] [468] [465] }}$

Data from the loW and IL studies was used by Stephen Wolkind and MR to examine the effects of time in care on later psychiatric disorder. ${ }^{[534]}$ Boys (but not girls) who had experienced care were much more likely to show antisocial disorders. This was thought not to be an effect of being in care per se but rather a consequence of being returned to families characterised by parental discord.

\section{Epidemiology - Epidemiological methods}

In 1982 MR published a paper based on material from an earlier book chapter. ${ }^{[284]}$ This provided an introductory guide to the conduct of epidemiology studies in child psychiatry. MR has identified the importance of epidemiological research strategies to answer causal questions in child psychiatry. ${ }^{[445]} \mathrm{He}$ also appraised epidemiological approaches in relation to longitudinal and developmental methods. ${ }^{[273]}\left[{ }^{[301]}\right.$ This issue is taken further in a review paper that considered the various component parts that contribute to age effects. ${ }^{[033]}$ In reviews of the significance of longitudinal studies of psychopathology ${ }^{[315]}\left[{ }^{[36]}\right.$ he emphasised that in addition to investigating within individual change other research strategies need to be employed. These include:

"using longitudinal data to test cause-and-effect relationships, including natural experiments, testing of competing hypotheses on mechanisms, study of reversal effects, multiple replications in different circumstances, use of designs to dissociate possible mechanisms, testing for dose-response relationships, examination of effect-specificity, considering biological plausibility, and assessing the strength of effects." ${ }^{[316]}$

MR discussed a number of statistical methods that can be applied to epidemiological data. ${ }^{[369]}$

\section{GENETICS}

\section{Genetics - General}

MR identified a number of "stereotypes" that he suggested misrepresent the significance of genetic studies for an understanding of the origins of psychopathology. ${ }^{\left[{ }^{11]}\right]} \mathrm{He}$ argues that each of the following beliefs are mistaken:

"that strong effects mean that environmental influences must be unimportant; that genes provide a limit to potential; that genetic strategies are of no value for studying environmental influences; that nature and nurture are separate; that genes for serious diseases are necessarily bad; that diseases have nothing to do with normal variation; that genetic findings will not help identify diseases; that genetic influences diminish with age; that disorders that run in families must be genetic; that disorders that seem not to run in families cannot be genetic; and that single major genes lead only to specific rare diseases that follow a Mendelian pattern." [311]

In a subsequent paper MR reviewed progress in the study of nature and nurture in child development. [344] He emphasised the need for a "bringing together of genetics, environmental studies, and developmental investigations" to adequately inform policy and practice.

A review of the evidence of genetic influences on mild mental retardation (i.e. IQ 50-69) suggested that too few studies had been conducted to draw strong conclusions. [455] Instead the paper laid out a number of research questions and suggested ways they could be addressed. Simonoff et al. reviewed the literature on learning disabilities (mental retardation) with a particular focus on genetic aspects. ${ }^{[494]}$ They emphasised that there is a need for more systematic research into the origins of mental retardation where no pathological cause is known.

\section{Genetics - Gene-Environment Interplay}

MR made a case for studies of "nature-nurture integration" in relation to antisocial behaviour. [331]

The need for such an approach is stated succinctly as follows:
"Nature and nurture do not operate independently of each other, and, to an important degree, genetic effects on behavior come about because they either influence the extent to which the individual is likely to be exposed to individual differences in environmental risk or they affect how susceptible the individual is to environmental adversities." [331]

This paper gives an account of the various quantitative behaviour genetic methods that tested for geneenvironment correlation, interaction and mediation. ${ }^{[187]}\left[{ }^{[14]}\right.$ Robert Plomin \& MR have argued that molecular genetic studies provide the best way to take further the examination of nature-nurture interplay. ${ }^{[222]} \mathrm{MR}$ summarised the main routes by which genes lead to multifactorial psychiatric disorders. ${ }^{[35]}$ The interplay between genes and environment is paramount [434] [361] and this means that studies:

"...must move beyond the search for susceptibility genes 'for' specific mental disorders, must include a study of environmental risk factors, and must involve the study of the 
various forms of gene-environment interplay. Particularly as exemplified by epigenetic environmental effects on gene expression, and by $\mathrm{GxE}$, it is not putting it too strongly to refer to the interplay as often (but certainly not always) involving gene-environment interdependence." [361]

MR discussed the influence of genetic factors on experiences of the environment. ${ }^{[309]}$ Here he argues that genetics should not just be studied in terms of its influence on measures of the environment but rather as influencing the distribution of environments themselves. Further that genetic influences on an aspect of the environment does not mean the effects of that environment cannot be environmentally mediated.

Quantitative genetic analysis distinguishes between gene-environment interactions (GxE) and geneenvironment correlations ( $\mathrm{rGE}$ ) (sub-divided into passive evocative and active correlations). MR et al. reviewed the implications of these processes for developmental psychopathology. ${ }^{[40]}$ The role of rGE acting in relation to antisocial behaviour was tested. [201] This found evidence for evocative rGE but they concluded that this explained only small part of the association between negative parenting and children's externalising behaviour. This approach was extended to examine the role of GxE and rGE in relation to both emotional and behavioural disturbance. [452] [348] MR, with Terrie Moffitt and Avshalom Caspi, made the case for of studying GxE in relation to psychiatric disorder. ${ }^{[191]}{ }^{[192]}$ Seven strategic steps were identified that "may be used to organise further hypothesisdriven studies of GxE." MR argued that there is a need to examine the biological processes whereby GxE emerges. ${ }^{[365]}$ [373] The claim by Risch et al. (2009) that GXE are seen only as an artefact was countered [461] and this argument developed further. ${ }^{[372]}{ }^{[381]}{ }^{[384]} \mathrm{MR}$ concluded that "multiple research strategies have confirmed the GxE finding from the epidemiological studies." A further defence of the importance of GxE is given in response to a critique by Munafo et al. (2014). [389] This debate over the relative value of direct studies of GxE and GWAS was continued in a commentary on a paper by Tabery (2015). ${ }^{[392]}$

\section{Genetics - Genetic Research Methods}

MR published two major review papers in 1990. One gave an overview of research methods in child psychiatry that provided insight into genetic factors. [400] The second paper summarised the empirical findings on genetic influences on child psychiatric disorders. ${ }^{[426]}$ MR provided an updating of these papers some 10 years later. ${ }^{[453]}$ [454] In a review paper he emphasised the need to use a wide range of research design (twin, adoption and family studies) in quantitative genetics; ${ }^{[37]}$ this paper also identified the way molecular genetic studies could be taken forward. Similar reviews were produced subsequently. ${ }^{[330]}$ [438] ${ }^{[440]}{ }^{[345]} \mathrm{A}$ modified version of ${ }^{[438]}$ was reproduced in a French language journal. [439]

The recognition of the importance of non-shared environment in influencing development emerged from quantitative genetic analyses. Carbonneau et al. demonstrated that the differential experiences of two twins assessed directly by asking informants to rate the relative difference in experience between the twins was the most efficient way to measure the non-shared environment. ${ }^{[47]}[48]$

MR et al. examined the ways in which research should be designed to adequately test for the role of the environment in influencing psychological development. [437] In particular they addressed the suggestion from behaviour genetic research that shared environment effects are nugatory and that presumed environment effects are in fact genetically mediated. They argue that:

"the extensive evidence of quite strong associations between adverse environmental experiences and an increased risk of psychopathology provides a prima facie case for environmental mediation of risk, given that genetic factors account for only a part, usually a small part, of the association." [437]

They emphasised five design features crucial to isolate environmental effects: 1 . the selection of samples that pull part variables that ordinarily go together e.g. adoption studies, 2. considering the processes that lead to the non-random risk exposure, 3. the need to test alternative causal mechanisms - not just one in isolation, 4. to fully examine the underlying assumptions of each designs, and 5 . to consider simultaneously effects of individual differences and group differences in rates or levels of psychopathology. ${ }^{[437]}$ In a commentary on a paper by Burt et al. (2011) MR identified the need for caution in interpreting studies seeking to dismiss shared environment effects. ${ }^{[374]}$

Pickles et al. developed an approach to the analysis of survival analysis for genetically informative data. ${ }^{[216]}$ This paper illustrated the application of the method to the impact of puberty on the onset of conduct disorder. The related question of dealing with censored observations i.e. where the only information on individuals is that they have reached a certain age but without onset of a condition having occurred. A method to address this problem was described. ${ }^{[27]}$ 


\section{Genetics - Virginia Twin Study of Adolescent Behavioural Development}

During the 1990 s and 2000 s MR developed a collaboration with the Virginia Twin Study of Adolescent Behavioural Development (VTSABD). The initial papers from this collaboration concerned the methods of applying latent class ${ }^{[83]}$ and structural equation models to the analysis of twin data to identify the role of genetic and environment factors to problem behaviours in adolescents. ${ }^{[483][484]}$ They concluded that:

"additive genetic, shared, and nonshared environmental factors all play a significant role in explaining individual differences in the maternal ratings of externalizing and internalizing behaviors in boys and girls between the ages of 8 and 16." [483]

A more extensive analysis of the results of fitting univariate models to a range of behaviours in adolescence was produced. ${ }^{[84]}[223]$ These findings suggested that small to moderate additive genetic effects and moderate to large effects of the nonshared environment act on a wide range of behaviours. These analyses were extended by applying multivariate genetic models to components of disruptive behaviour. ${ }^{[82]}$ It was concluded that oppositional defiant disorder and conduct disorder:

"should be viewed as probably reflecting varying manifestations of the same genetic liability but that the same may not necessarily apply to ADHD." ${ }^{[82]}$

Multivariate analyses were also used to examine the genetic relationship between symptoms of depression, anxiety and phobias in younger (8-13-year old) and older (14-17-year old) children. [487] [489][490] These analyses showed that depression before and after age 14 may be aetiologically distinct syndromes. Foley et al. made a more detailed examination of the origins of disagreements between child and parent reports of anxiety symptoms in this sample. ${ }^{\left[{ }^{[0]}\left[{ }^{[9]} \mathrm{A} \text { complex set }\right.\right.}$ of factors contributed to these disagreements and it was noted that "contrary to popular wisdom, mothers may be more biased raters than fathers."

Maes et al. tested for assortative mating in two samples of twins. ${ }^{\left[{ }^{[72]}\right]}$ This found only a moderate degree of assortment for psychiatric disorders. They conclude that the bias that might have arisen in twin studies from ignoring this small amount of assortment would be negligible. The prevalence of psychiatric disorders in this sample were similar to those obtained in non-twin epidemiological studies. ${ }^{[498]}$ These results support the generalisability of findings from this twin study to the general population.

Maes et al. estimated the magnitude of genetic and environmental effects on tobacco, alcohol and drug use in the VTSABD. ${ }^{[173]}$ Genetic effects were substantial with shared environment effects also present, especially in marijuana use. These analyses were extended to examine to role of shared genetic and environmental factors on substance use and depression and substance use and conduct disturbance. ${ }^{\left[{ }^{[88]}\right.}$ The patterns were somewhat distinct in that conduct disturbance tends to precede substance use and depression tends to follow it. The mechanisms underlying these associations appear to be different for boys and girls.

Topolski et al. used this twin sample to estimate the effects of genetic and environmental effects on child self-reports of separation anxiety, overanxious disorder and manifest anxiety and how these might change with age and gender. ${ }^{\left[{ }^{220}\right]}$ [52]] They concluded that: "..although the present study provided partial support for the hypothesis that during adolescence selfreported anxiety was more reflective of environmental than genetic influences, the analyses highlight the complexity of the factors involved in assessments of manifest anxiety." [520]

\section{HEAD INJURY/BRAIN DYSFUNCTION}

Using data from the loW study Philip Graham \& MR found a "very high rate of psychiatric disorder (34\%) for children with epilepsy, cerebral palsy, and other pathological disorders of the brain". [105] It was concluded that this association arose from organic brain dysfunction rather than physical handicap and that this association was not limited to any specific type of psychiatric disorder. In this sample, MR et al. found that choreiform movements were not associated with reading disability, psychiatric disorder or neurological abnormalities. ${ }^{[44]}$ Accordingly, the label of choreiform syndrome was deemed to be of limited value. These findings were replicated by in a study of children in London ${ }^{[480]}$ which also found that various forms of family disturbance were related to psychiatric disorders. These studies had recorded the link between brain damage and reading disability. ${ }^{[05]}\left[{ }^{[480]}\right.$ This issue was taken further in a study of school aged children who had sustained a compound depressed fracture of the skull resulting in damage to the underlying cortex. ${ }^{[481]}$ It was found that a third of these children had a reading age at least 2 years below their chronological age.

MR et al. conducted a prospective study of children with severe head injuries (post-traumatic amnesia of 7 days or more), a control group of children without head injury but who had some other injury and a third group of children with mild head injury with post-traumatic amnesia of less than 7 days. ${ }^{[404]}$ The children with severe head injuries showed a marked increase in psychiatric disorders that also showed a' dose-response' relationship with the duration of post 
traumatic amnesia (PTA), the degree of intellectual impairment, and the presence of neurological abnormalities. ${ }^{[4]]}$ The extent of intellectual impairment was related to the duration of PTA with impairment common with a PTA of at least 2 weeks and no cognitive impairment detected when PTA was less than 24 hours. ${ }^{[5]}$ Tests of specific cognitive ability did not identify deficits that were not already shown on the broader IQ measures. ${ }^{[5]}$

In a separate sample of 97 school-age children who had previously sustained a unilateral compound depressed fracture of the skull, involving a tear in the dura and observed damage to the underlying brain, Chadwick et al. found that intellectual impairment was significantly associated with the overall severity of brain trauma, as reflected in the duration of unconsciousness and treatment for cerebral oedema. ${ }^{[57]}$

MR reviewed the literature on the psychological sequalae to brain damage. ${ }^{[274]}$ This was extended in a broader review of developmental neuropsychiatry which emphasised the lack of specificity of the cognitive sequelae of localized brain lesions in childhood and the probable importance of age effects in altering the impact of brain lesions. ${ }^{\left[{ }^{[28]}\right]} \mathrm{He}$ commented on the difficulties of interpreting the results of epidemiolocal studies of whether head injury causes cognitive deficits. ${ }^{[327]}$

MR examined the concept of "minimal brain damage" or the "brain damaged child". [261] [280] He provided both a conceptual analysis of the problems with this formulation and reviewed the evidence from his own and other studies. He concluded that although the stereotypes reflected in these terms are mistaken and misleading, brain damage does indeed make substantial contribution to the origins of child psychiatric disorder. MR addressed the question of whether a condition with a neurological basis (i.e. Rett syndrome) should be classified as a psychiatric disorder; he concluded that it should, even if this is merely an expedient. ${ }^{[318]}$

\section{INSTITUTIONAL CARE}

\section{Institutional care - General}

The question of the impact on the child of care outside the family has been a recurrent topic of MR's research. With David Quinton he undertook a longitudinal follow-up into adulthood (to age 21-27 years) of women originally studied in childhood when they were living in institutions (King, Raynes \& Tizard, 1971). [442] [228] Compared to a control group of women from the general population the institution-reared women showed a markedly increased rate of poor psychosocial function and parenting difficulties. The effect was reduced for those with a non-deviant spouse and/or good living conditions.
David Quinton and MR undertook a study of families with children who had been in-care and a comparison group selected from general practitioner registers serving the same inner London borough. ${ }^{[226]}{ }^{[227]}$ The parents in the multiply-admitted-to-care families had a high frequency of severe family discord and harsh parenting in their own upbringing. Although these parents showed a high degree of problems in parenting, it was thought that this was a reflection of more general problems with inter-personal relations. Dowdney et al. investigated the quality of parenting in these samples in more detail. ${ }^{[8]}$ Using both interview and direct observation measures they found that:
"Differences in parenting styles between the case and comparison groups were on the whole subtle. Ex-care women were relatively less sensitive to their children's cues and, in response to their demands and opposition, exercised control by confrontation rather than by circumvention." [81]

An additional set of children in intuitional care were the subject of a separate study. ${ }^{[233]}$ Compared to a similarly disadvantaged comparison children, who had not experienced such care, a pattern of hyperactivity/ inattention behaviour was found more frequently. Moreover, this pattern was found to frequently co-occur with a lack of selective attachments in the institutional care children. ${ }^{[234]}$ This was not an inevitable result of institutional rearing as it occurred in about one third of the cases. The hyperactivity/ inattention pattern was associated with poor reading performance. ${ }^{[232]}$

MR reviewed the findings of research into substitute care were reviewed and made a case for the need for better quality research on the issue and for a greater focus on the addressing questions related to policy and implications for practice. ${ }^{[34]}$ In a commentary on a Russian study of institutional care MR identified the way a number of the features of quasi-experimental research in this area had been successfully addressed. ${ }^{[367]}$ Along similar lines he endorsed the research design adopted in the Bucharest Early Intervention Study as a rare, if not unique, example of a randomised controlled trial of the effects of foster care to offset the consequences of profound deprivation in Romanian institutions. ${ }^{[391]}$

\section{Institutional care - English Romanian Adoption (ERA) Study}

Starting in the late 1990 MR and a research team started to publish a series of nearly 50 papers arising from a longitudinal study of children adopted into England who had been formerly in institutions in Romania and a comparison group of within-country adopted children. A major feature of the research 
design was variation in the age at which the children entered England. There were 111 Romanian children adopted into England before the age of 2 years, 54 who enter between 24 and 42 months of age and 52 withincountry adoptees: see ${ }^{[41]}$ for details about the sample and the design of the study. The ERA study identified a number of deprivation-specific psychological patterns (DSPs) - quasi-autistic patterns (Q-A), disinhibited attachment (DA), inattention/overactivity $(\mathrm{I} / \mathrm{O})$ and cognitive impairment $(\mathrm{Cl})$. They found dramatic catch-up by 4 years of age in physical growth and cognitive development in those adopted into the UK before 6 months of age. ${ }^{[41]}$ There was relatively little further catch-up after the age of 4 years. ${ }^{[204]}$ By 6 years of age the extent of developmental delay catchup was related to a positive change in the quality of relationships with the child's adoptive parents with the effect being primarily from child to parent. ${ }^{[7]}$ At 11 years of age the marked cognitive deficits in those over 6 months of age on arrival persisted, but in this group $15 \%$ showed some catch-up. ${ }^{[2]}{ }^{[149]}$ Individual differences in outcome were large and not related to the educational background of the adoptive families. These cognitive deficits at age 11 years associated with more than 6 months in intuitional care were paralleled by lower school attainment. ${ }^{[2]}$ These effects of institutional care on scholastic attainment were almost entirely mediated by IQ and by I/O.

At 4 years of age $6 \%$ of the Romanian adoptees showed an autistic-like pattern of behaviour and a further $6 \%$ showed milder, usually isolated, autistic behaviours. [394] None of the within-country adoptees showed these behaviours. At 6 years of age duration of deprivation was associated with the prevalence and persistence of the behaviours related to rocking, self-injury, unusual sensory interests, and eating problems. ${ }^{[19]}$ Although a quarter of the children lost their quasi-autistic pattern of behaviour, this was still found in over $10 \%$ of the Romanian adoptees at 11 years of age. ${ }^{[499]}$

Attachment disorder behaviours were found more commonly in the Romanian children than in the withincountry adoptees, especially in those entering the country after 6 months of age. However, a substantial number of children exposed to even prolonged severe early privation did not exhibit these symptoms. ${ }^{[200]}$ ${ }^{[202]}$ At 6 years of age there was a strong relationship between the severity of the attachment disorder and the duration of deprivation experienced. Attachment disorder was related to attentional and conduct problems and to cognitive ability. There was stability from age 4 and little evidence of mean decrease in disordered attachment behaviours over that time. [205] This stability was maintained to age 11 years and mild disinhibited attachment was found in noninstitutionalised adopted children but was shown to be qualitatively different from that shown by institution reared children. [405] [406] MR draws on findings from the ERA study to consider the inadequacy of models of attachment that conceptualise variation in attachment patterns simply in terms of security/insecurity. ${ }^{[420]}$ Data from the ERA study was used to assess the utility of an extended strange situation procedure to assess attachment quality. ${ }^{[50]}$

The assessments made at 6 years of age showed that the duration of deprivation was related I/O but not to conduct or emotional problems. ${ }^{[48]}$ The effect of duration of deprivation on I/O did not decline with age. It was tentatively suggested that I/O may constitute an institutional deprivation syndrome with a clinical picture somewhat distinct from ADHD arising from other causes. $1 / O$ persisted to age 11 and the rates of $1 / O$ at 11 years were higher in boys than girls. ${ }^{[06]}$ In early adulthood (22 to 25 years of age) the persistent 1/O problems were still present and represented a complex and impairing variant of ADHD. ${ }^{[144]}$

Emotional difficulties were shown at both ages 6 and 11 years in the ERA sample and were related to deprivation-specific problems but these early problems did not explain fully the onset of emotional problems. ${ }^{[6]}$

Duration of poor quality care within the Romanian sample had a significant effect on cognitive functioning at 6 years of age. The lack of individualised care had the biggest effect - more so than malnutrition. ${ }^{[55]}$ The effects of institutional care on cognition were similarly shown in language abilities at 11 years. Among those arriving between 18 and 42 months of age rudimentary language skills were strongly related to better cognitive and language abilities but not to social/emotional/ behavioural outcomes. ${ }^{[76]}$ The institution reared children showed deficits in Theory of Mind tasks and in Executive Functioning. These cognitive deficits may in part account for some aspects of the deprivationspecific difficulties in institution reared Romanian adoptees. ${ }^{[67]}$

In addition to psychosocial deprivation the Romanian adoptees also experienced sub-optimal nutrition. There was a question of the extent to which the deficits on psychological development and the increase in psychopathology found at age 11 years in the Romanian adoptees could be attributed to either sub-nutrition, psychosocial deprivation or to both. ${ }^{[499]}$ The findings showed that psychosocial deprivation had a much greater effect than sub-nutrition. There was a striking finding that deprivation had a negative effect on head circumference (an index of brain growth) even in the absence of sub-nutrition. MR and colleagues returned to the question of the relative contribution of "pure" institutional deprivation and sub-nutrition to the DSPs. They concluded that sub-nutrition had only a small effect on DSPs. ${ }^{[423]}$ 
The response of the parents to the adoption of the Romanian children was very favourable when the children were 4 and 6 years. The same was found at 11 years and where a negative attitude was shown this was related to the later-placed children's higher rates of problem behaviour. ${ }^{54]}$

MR examined, in a number of papers, the possible biological processes in moderating and mediating the effects of institutional deprivation. When the children reached 15 years of age genetic polymorphism in genes implicated in the regulation of dopamine neurotransmission, were examined to establish whether they could account for some of the heterogeneity in children's I/O response to severe deprivation. The polymorphisms in the dopamine D4 receptor gene (DRD4) showed no such effect but variants in the dopamine transporter gene (DAT1) did moderate the impact of deprivation on I/O. ${ }^{[505]}$ The effects of severe early institutional deprivation on emotional problems in adolescence are moderated by ${ }_{5}$ HTT genotype of the serotonin transporter gene and influenced by stressful life events in adolescence. ${ }^{[57]}$ Genetic mechanisms, i.e. epigenetic changes, were also examined as potential mediating factors. ${ }^{[53]}$ This paper concludes that:

"environmental insults of sufficient
biological impact during early
development are associated with long-
lasting epigenetic changes, potentially
reflecting a biological mechanism
linking the effects of early-life adversity
to cognitive and neurobiological
phenotypes." ${ }^{[153]}$

Kumsta et al. examined whether the disruption of hypothalamic-pituitary-adrenal (HPA) axis function, as indicated by reduced morning cortisol, flattened diurnal slope and blunted reactivity, persist even after successful adoption. ${ }^{[155]}$ The results suggested that long-term programming effects on HPA functioning contribute to the mediation of the effects of early institutional deprivation.

Mehta et al. investigated brain mechanisms that might mediate the effect of institutional deprivation on psychological functioning using magnetic resonance imaging (MRI). ${ }^{[186]}$ These first pilot findings suggested that longer periods of deprivation were related to reduced left amygdala volume.

In reviewing the findings from the ERA study on behaviour up to age 6 years MR concluded that $20 \%$ of the children who experienced the longest duration of deprivation showed normal functioning. [421] [422] However, attachment disorder behaviour, inattention/ overactivity and quasi-autistic behaviour constitute institutional privation patterns. It is suggested that the pattern of results seen up to age 6 years indicates some form of early biologically mediated process arising from institutional deprivation may be acting, but the variation in outcome implies that the effects are not inevitable. ${ }^{[435]}$ A similar pattern of results was noted in a review of findings up to the age of 11 years. [398]

In 2010 MR and the ERA team published a Monograph of the Society for Research in Child Development [20] [53] [147] [152] [154] [458] [457] [501] This provide an update to age 15 years of the findings from the ERA study. It took an innovative approach by centring on the question of how distinctive are DSPs from other forms of psychopathology. The DSPs tested were quasi-autistic patterns (Q-A), disinhibited attachment (DA), inattention/overactivity (I/O) and cognitive impairment $(\mathrm{Cl})$. They conclude that DSPs are indeed caused by institutional deprivation and are distinctively different from emotional disturbance and disruptive behaviours arising from other causes. In addition, DSPs are persistent at least up to middle adolescence. It is highlighted that the mediating mechanisms that result in DSPs are little understood. There is also a need for a more research to identify possible moderators of the effect of institutional deprivation that account for the substantial heterogeneity in outcome. ${ }^{\left[{ }^{[11]}\right.}$ A review of the ERA study findings extended into early adulthood by Edmund Sonuga-Barke et al. [concluded:
"Notwithstanding the resilience shown by some adoptees and the adult remission of cognitive impairment, extended early deprivation was associated with long-term deleterious effects on wellbeing that seem insusceptible to years of nurturance and support in adoptive families." [500]

The ERA study is now able to examine the pathways between early experience and adult function. ${ }^{[143]}$

\section{Institutional care - Studies in Greece}

Vorria et al. conducted a study on 9 and 11-yearold Greek children who had experienced at least 2.5 years of residential care and matched control group experiencing care in their own two parent families. ${ }^{[532]}$ The care group were observed to be more inattentive, passive and involved in non-productive activities. These children showed more emotional difficulties on rating scales and the boys had more conduct problems and hyperactivity. Examining possible mediating mechanisms, it was found that family cohesion and stability before admission to residential care was the single most powerful predictor of the children's functioning at the time of the study. ${ }^{[533]}$

A subsequent study was conducted on 52 Greek children who had been adopted from the Metera Babies Centre and who were followed up when the children were 13 years of age. The study found that compared to 36 non-adopted adolescents the ex-care children showed more overactive and inattentive 
behaviour, ${ }^{[528]}$ good attachment relationships with their adoptive parents, ${ }^{\left[{ }^{531]}\right.}$ lower cognitive and school performance. ${ }^{[529]}$ These findings were reviewed, and policy implications were drawn. ${ }^{[30]}$

\section{Institutional care - Overview of studies on institutional care}

Woodhouse et al. produced an overview of the findings of studies on the effects of institutional care from Romania, Greece and Hong-Kong, China. [353] This suggested that early institutional rearing is not inevitably damaging. It is a risk factor, but the most damaging effects are only found when accompanied by gross deprivation, as was the case in Romania.

\section{LANGUAGE DEVELOPMENT IN TWINS}

Twins are likely to develop language at a slower rate than singletons. MR \& Jane Redshaw reviewed this phenomenon and concluded that the pre and peri-natal biological hazards experienced by twins do not account for their delays in language development. ${ }^{[444]}$ Rather its origins lie in the patterns of family interaction associated with the twin situation. Based on a study twins from the Avon Longitudinal Study of Parents and Children (ALSPAC), MR was able to provide evidence in support of these conclusions. ${ }^{[462]}$ [518]

A 'secrete language' is found more commonly in twin than in singleton siblings. By studying twins from the ALSPAC cohort, Thorpe et al. found that this was largely restricted to the second year of life but those twins, mainly male, where it persisted, the outcome was poor when normal language development was not acquired alongside the use of a private language. ${ }^{[517]}$

\section{MATERNAL DEPRIVATION}

A very significant strand of MR's early research and writings concerned the question of child/parent separation and its short- and long-term importance for child development and mental health. MR published an influential summary of the literature on this question and findings are reported from a detailed and intensive longitudinal study of patients' families. ${ }^{[251]}$ This paper concluded:

"... that a child's separation from his family constitutes a potential cause of shortterm distress but separation is of little direct importance as a cause of longterm disorder. Separation experiences have some association with the later development of antisocial behaviour, but this is due not to the fact of separation itself, but rather to the family discord which precedes and accompanies the separation. Both active discord and lack of affection are associated with antisocial disorder but a good relationship with one parent can go some way toward mitigating the harmful effect of a quarrelsome unhappy home. The association between family disharmony and anti-social disorder is probably largely mediated by environmental influences. Children differ in their response to family discord; these differences are associated with both sex and temperamental factors." [251]

This work included a re-examination of the concepts of maternal deprivation, [Book7] [252] [265] attachment ${ }^{[262]}$ ${ }^{[320]}{ }^{[388]}$ and the significance of day care for preschool children. ${ }^{[275]}\left[{ }^{[88]}\left[{ }^{[00]}\left[{ }^{[68]}[24]\right.\right.\right.$ MR revisited the question of the effects of separation ${ }^{[266]}$ and adverse early experiences. ${ }^{[267]}$

David Quinton and MR studied the experience of separation associated with hospital admission. ${ }^{[225]}$ Specifically, this paper was able to confirm a previous finding by Douglas (1975) that single admissions for up to a week carried no increased risk of later emotional disturbance.

\section{PARENTAL MENTAL ILLNESS AND THE CHILD}

MR's first research monograph on the psychological well-being of children of sick parents considers the question of whether the adverse effects shown on the children of parents was due to their experience of parental illness or arise from genetic factors. [Book] He considered the role of temperamental factors as influences on the reaction of the child to the experience of parental illness. The impact of the experience of separation from the parent and of a "broken home" on the child is addressed. He concludes that the effect of parent chronic illness on children is most striking for a parental mental illness.

In this 1966 monograph knowledge of parental mental illness as a risk factor for the child is considered as a possible avenue for the prevention of some mental disorders in children. He returned to the question of prevention in a stringent appraisal of the evidence relating to the prevention of psychosocial disorders in children. ${ }^{[278]}$ He concluded that:

"There is a potential for effective primary prevention but, so far, it remains largely unrealized." ${ }^{[278]}$

The effect of parental psychiatric disorder on children was studied in a 4-year prospective study of 137 patients with children under the age of 15 years. ${ }^{[43]}$ This found that:

"The children of psychiatric patients

had an increased rate of persistent 
emotional/behavioural disturbance, which tended to involve disorders of conduct. The psychiatric risk to the children was greatest in the case of personality disorders associated with high levels of exposure to hostile behaviour. Boys showing temperamental risk features were most vulnerable to the ill-effects associated with parental mental disorder." [443]

$M R$ reviewed the significance of parental depression for the child with a specific emphasis on the research that needs to be undertaken to investigate the processes involved in the transmission of risk. ${ }^{[308]} \mathrm{Kim}$-Cohen et al. examined the joint effects of maternal depression and maternal antisocial behaviour on their children's metal health. ${ }^{[46]}$ Compared to mothers with depression alone, the children of those with both conditions were at an elevated risk of experiencing multiple caregiving abuses, including physical maltreatment, high levels of maternal hostility, and exposure to domestic violence. These children had significantly higher rates of DSM-IV conduct disorder.

\section{PHYSICAL HEALTH CONDITIONS}

In an early paper the characteristics of patients attending a general hospital for psychiatric assessment were described. ${ }^{[145]}$ A second early paper attempted to determine whether social and psychological characteristics predicted short term course of peptic ulcer in a consecutive series of 80 patients. ${ }^{[235]}$ These factors did not predict the frequency of ulcer symptoms 6 months later.

Graham et al. investigated the psychological characteristics of children with asthma using data from the loW Study. ${ }^{[109]}$ This paper emphasised the importance of using an epidemiological approach based on a general population sample to avoid sampling biases. A prevalence rate of around $2 \%$ was found for asthma in 9-11-year olds. The rate of psychiatric disorder in those children with asthma was higher (10.5\%) than that in the general population $(6.3 \%)$ but similar to that for children with other physical disorders. Emotional stress frequently acted as a trigger for individual asthma attacks.

\section{READING}

Based on data from the loW and IL studies, the regression relationship between reading attainment and IQ was used to identify a group of children with specific reading retardation (SRR) that was not associated with low IQ. ${ }^{[539]}$ The utility of the distinction between SRR and reading backwardness, where poor reading was below average regardless of IQ, was established as follows:

"Reading retardation is shown to differ significantly from reading backwardness in terms of sex ratio, neurological disorder, pattern of neurodevelopmental deficits and educational prognosis." [467]

MR \& Barbara Maughan reviewed the contribution of this work by Bill Yule and MR over the subsequent 40-year period. ${ }^{[429]}$ A long-term follow-up did not find a difference between these groups in terms of educational outcome and progress in reading. ${ }^{[178]}$ However these difficulties with reading were stable into the middle years of adulthood. ${ }^{[179]}$

The main behaviour disorder shown during adolescence by poor readers was inattentiveness. The increased rate of delinquency in those with SRR was associated with their poor school attendance rather than reading problems themselves. ${ }^{[181]}$ The question of whether sex differences, i.e. the excess of males amongst those with reading disabilities, were found internationally was examined in the joint analysis of 4 major epidemiological studies in New Zealand and the UK. ${ }^{[402]}$ This analysis confirmed that it was indeed a robust finding that was replicated in each of the independent studies.

Children with SRR are more likely than others to show antisocial behaviour. When these two factors were examined independently ${ }^{[177]}$ each contributed adverse long-term outcomes:
"While all the retarded readers experienced some continuing difficulties, there were clear differences between those with and without associated behavioural problems at a number of points. For retarded readers without marked behaviour problems the findings suggest a cumulative pattern of restricted opportunities, persisting reading problems for the majority resulting in poor examination attainments, and these in turn playing at least some part in limiting job opportunities. For those with additional behaviour difficulties, additional later factors intervened. Behavioural disturbance appeared to have little effect on direct progress in reading, but high rates of early school leaving, indications of unstable work records and the most seriously depressed job skill levels were all characteristic of the group with behaviour difficulties." [177]

MR also considered the association between educational underachievement and emotional disorders ${ }^{[259]}$ and in that review specifically addressed 
the question of the direction of effects between these characteristics. He concluded that emotional factors do not play a causal role in specific reading retardation. However, he raises the possibility that they do play a role in educational difficulties "which arise later in childhood after initial success".

The poor reading performance in children from families of West Indian origins was reported and it was found that this was especially marked in those children not born in the UK. ${ }^{[537]}$ The particular lack of progress in reading in black children in inner London was addressed in a study which followed children from the IL study from ages 10 to 14 years. ${ }^{[176]}$ Compared with white girls, black girls maintained comparable progress but that of black boys was slower than that of white boys. When these children were assessed at the end of their school careers a similarly positive result was found for the black pupils ${ }^{[182]}$ :

"Our data have enabled exploration of two broad issues: first, how far black and white pupils in the final years of secondary schooling maintained similar rates of progress in examination performance, given their earlier assessed attainments; and, second, how the groups compared in levels of achievement by the time they left school. On the first point, analyses of both fifth- and sixth-year results showed black candidates performing very similarly, to whites of a comparable level of earlier attainment. There was no evidence of any relative decline or improvement in the expected performance of black examination candidates in their final years at secondary school. On the second point, however, the greater involvement and persistence of black pupils in the examination system meant that, as a group, their final school-leaving qualifications were in some respects better than might have been predicted for a comparable white group." [182]

Reynolds et al. investigated the role of genetic and environmental influences on reading attainment in twins in early adolescence in the VTSABD. ${ }^{[231]}$ They found that $69 \%$ of the phenotypic variance in reading was explained by genetic differences between children with similar estimates for males and females.

\section{RESEARCH METHODS AND RESEARCH DESIGNS}

In many studies it is possible that data missing on subjects may bias the findings. Cox et al. took advantage of repeated measures available in the loW and IL longitudinal studies to investigate if such biases could be identified. ${ }^{[75]}$ It was found that those participants for whom data was missing tended to include a higher proportion with problems such as, behavioural deviance, reading backwardness, child or adult psychiatric disorder, and marital discord. These biases could lead to false conclusions under some circumstances.

The value of natural experiments to tease apart causal processes when true experimental methods cannot be applied is a recurrent theme in MR's writing. ${ }^{[362]}$ The principle value of natural experiments is that they can potentially separate factors that lead to exposure to risk from other variables that may influence psychopathology. ${ }^{\left[{ }^{16]}\right]}$ This principle is illustrated by results from genetically informative designs that find that exposure to negative life-events and bullying are relate to later depression. In the case of prenatal exposure to smoking, genetically informative research designs do not support the notion that this is causally related to ADHD or antisocial behaviour. The potential for neurodevelopmental problems in children exposed to alcohol in utero has yet to be firmly established. The value of natural experimental approaches to be used to test whether mothers drinking alcohol during pregnancy ${ }^{[10]}$ and other prenatal risks ${ }^{[515]}$ have been outlined. A study of 24,259 Norwegian participants was able to examine the impact of family disharmony and maternal anxiety/depression measured both pre- and post-natally on children's emotional and behavioural problems at 36 months of age. ${ }^{[23]}$ The stability of both these social factors was strong and the impact on children's behaviour was not a function of either pre-natal or post-natal exposure separately but rather from an enduring risk. MR outlined the strengths and weaknesses of a natural experiment approach to testing causal relationship. ${ }^{[436]}$ This paper provided an examination of threats to validity in research in child psychiatry and psychology and the possibilities arising from genetics, neuroimaging, and biomarkers to provide supporting validation for studies in these fields.

MR provided a commentary on a "natural experiment" study by Costello et al. (2003) which took advantage of radical increase in income for American Indian families that arose from payments of profits from a casino that was developed on their land. ${ }^{[349]}$ Children in these families experienced a change in income from below to above the federal poverty line. Over the subsequent 4-year period there was a significant reduction in behavioural symptoms of oppositional/defiant and conduct disorders. MR concludes that this natural experiment allows "a reasonably strong inference that the effect represented social causation.'

MR \& Robert Plomin made a distinction between translational research that "goes from the basic science laboratory to the bedside of individual patients" and 
that which provides health benefits to the population. ${ }^{[44]}$ MR \& Tytti Solantaus considered six examples of the way the translation between basic science and patient care can mislead if science and common sense are treated as equivalent. ${ }^{[456]}$ In doing this they draw upon the thinking of Peter Medawar (1982) that emphasises the role of hypothesis generation and the testing of hypotheses by experiments as the essence of a scientific approach to the understating of mechanisms. The:

"Common sense (like early science) tends to rely on an inductive approach in which natural observations are followed by a logical reasoning of what these might mean. By contrast, science requires some form of experiment (either a natural experiment or a contrived intervention experiment) and the testing of two or more alternative explanations or mechanisms. This may, or may not, involve induction, but common sense differs in having to rely only on induction rather than experiments." ${ }^{[456]}$

\section{RESILIENCE}

There is a strand of MR writing that has centred on the variation in outcome when different people are exposed to an adverse event or circumstance. The protective factors that result in the relative absence of an adverse outcome produce resilience. ${ }^{[364]}$ The key features of these protective factors are secure, stable affectionate relationships and the experience of success and achievement. ${ }^{[290][295]}$ Characteristics of the person themselves such as sex and temperament can also contribute to resilience. The personal meaning of events may also be pertinent especially where, for example, role conflict is involved. ${ }^{[295]}$ Indeed, to understand resilience MR emphasises the need to move beyond treating it as a property of an individual to consider the protective role of the family and broader social groups. ${ }^{[34]}{ }^{[366]}{ }^{[337]}$ MR elaborated the ways in which vulnerability and protective factors are defined. ${ }^{[297]} \mathrm{He}$ sees them as opposite poles of the same concept; protective factors reduce the adverse effect of risk exposure; vulnerability factors do the opposite. In both case they have no effects on outcome in the absence of risk. In analysis terms, the influence of vulnerability and protective factors on an outcome must show an interaction with a risk variable and not a main effect of their own. He then goes on to describe research that has identified the mechanisms underlying protective process. These relate to reduction of risk impact; reduction of negative chain reactions; establishment and maintenance of selfesteem and self-efficacy; and opening of opportunities. These mechanisms are illustrated in a follow-up study of those in the loW study who retrospectively reported childhood sexual and physical abuse. ${ }^{[65]}$

The following is the abstract from a paper which provided a succinct and clear account of MR's views on the possibilities and limitation on intervention related to resilience. ${ }^{[322]}$ For this reason the abstract is quoted in full:

"There is a huge individual variation in how people (both children and adults) respond to all manner of life stressors and adversities. Some succumb with disorders, whereas others show resilience, and a few even come through negative experiences strengthened. What is known about the nature and origins of resilience is briefly reviewed. It is concluded that protective mechanisms probably fall into five main groups:

1. those that involve reduction in the personal impact of risk experiences;

2. those that reduce negative chain reactions;

3. those that promote self-esteem and self-efficacy;

4. those that open up positive opportunities; and

5. the positive cognitive processing of negative experiences.

Both clinicians and social scientists tend to speak and write as if a great deal was known about how to prevent psychiatric disorders in young people. There is a vast literature on variables associated with an increased risk of disorder-ranging from broad social variables such as poverty, homelessness and unemployment to family features such as family break-up, institutional rearing, parental neglect and family discord to more individually focussed psychosocial risks such as scapegoating and the experience of physical or sexual abuse. The task would simply seem to be that of setting about reducing the extent to which these psychosocial risk factors occur in society and impinge on young people. Of course, that is not by any means a straightforward matter. ${ }^{[278]}$ Knowing which are the risk factors and knowing how to change them are two very different issues. Thus, what should society do to reduce the rate of family discord or parental neglect? There are some useful leads to follow but the truth of the matter is that we do not really know." [322] 
MR has highlighted the importance of GxE as an influence on resilience. ${ }^{[360]}{ }^{[383]}$ The following five implications are drawn from the former review:

"(1) resistance to hazards may derive from controlled exposure to risk (rather than its avoidance); (2) resistance may derive from traits or circumstances that are without major effects in the absence of the relevant environmental hazards; (3) resistance may derive from physiological or psychological coping processes rather than external risk or protective factors; (4) delayed recovery may derive from "turning point" experiences in adult life; and (5) resilience may be constrained by biological programming or damaging effects of stress/adversity on neural structures." [360]

Environmental mediation of risk is a necessary condition for inferring resilience and MR has examined the use of natural experiments to test for this. ${ }^{\left[{ }^{385]} \mathrm{He}\right.}$ concluded that nearly all risk factors are mediated by a complex mixture of genetic and environmental processes. These effects can be tested for using quantitative genetic analysis of data from genetic informative designs such as twin studies. However, MR argues that molecular genetic studies are more powerful ${ }^{[355]}$ as they can examine the interaction of the effects of known susceptibility genes and measured environments. ${ }^{[52]}$

\section{RISK AND ADVERSE EXPERIENCES}

MR has examined the processes whereby adverse experience creates a vulnerability to develop psychiatric disorders mediated by biology [393], the continuity of adverse experiences ${ }^{[339]}$, the individual's conceptualisation of stress ${ }^{[276]}$ and the ecological effect of living in cities ${ }^{[277]}$. He reaffirmed the importance of psychosocial adversity as an influence on child disorders ${ }^{[339]}$ which needs to be appraised alongside the role of genetic factors. ${ }^{[356]}$

The various ways social context contributes to psychopathology were formulated. [340] These effects were classified as five types:

$$
\begin{aligned}
& \text { "the impact of social connotation or } \\
& \text { meaning of risk/protective factors; social } \\
& \text { comparison effects; compositional effects } \\
& \text { deriving from the make-up of a social } \\
& \text { group; a social contextual effect reflecting } \\
& \text { the ethos of a broader social environment; } \\
& \text { and a social group characteristics effect } \\
& \text { stemming from the behaviour/values of a } \\
& \text { peer group." [340] }
\end{aligned}
$$

MR laid out the outstanding issues in the conceptualisation and testing of the processes involved in the "biological embedding of social adversity". [379]
He reviewed the developments in conceptualising and testing risk mechanisms in psychopathology. ${ }^{[370]}$ The conceptualisation of protective factors being those that modify the effects of a risk or stress factor has been central to MR's formulations of the interplay between influences on adverse outcomes ${ }^{[275]}$ and that such effects are shown by interactions between risk and protective factors. ${ }^{[310]}$

A number of commentaries and reviews of risk research emphasised the value of longitudinal research designs, natural experiments and genetically informative studies to identify some of the possible causal processes involved. ${ }^{[203]}$ [427] [98] [343] MR addressed the specific issue of intergenerational continuities and discontinuities in psychosocial risk. ${ }^{[334]}$

MR \& Seija Sanderg reviewed the evidence that adverse life events are associated with psychiatric disorders in children. ${ }^{[446]}$ They concluded that an understanding of the significance of life-events was still as yet incomplete. The paper concentrated upon identifying "conceptual dilemmas and on the methodological and scientific issues that remain to be resolved." The specific question of the accuracy of long-term recall of adversity in childhood was reviewed. ${ }^{[184]}$ This review concluded that although retrospective recall was adequately reliable it would prudent to "include corroborative evidence wherever feasible."

The need to develop systematic appraisal of psychosocial experiences in children led to the development of the standardised interview Psychosocial Assessment of Childhood Experiences (PACE). The PACE was found to have acceptable reliability and discriminant validity. ${ }^{[471]}$ The challenges faced in developing such measures were reviewed ${ }^{\left[18_{3}\right]}$ and especially issues concerning retrospective recall. ${ }^{[13]}$ Using the PACE psychiatrically disturbed children were found to experience both more behaviour-dependent life events and more long-term adversities than other children. ${ }^{[470]}$ However, in this study, life events were not seen to play a major role in the onset of psychiatric disorder in childhood. ${ }^{[473]}$

\section{SCHOOL EFFECTIVENESS}

The book Fifteen thousand hours: secondary schools and their effects on children ${ }^{[B o o k 15]}$ reported on a landmark study of which features of school organisation matter in terms of influencing pupils' behaviour, attendance and attainment. MR provided a summary of the main conclusions from the study. ${ }^{[268]}$ By adopting an innovative approach to addressing this question, the book received close scrutiny. ${ }^{[180]}[431]$

The Journal of Child Psychology and Psychiatry published a Critical Notice of Fifteen Thousand Hours. Critiques were provided by Barbara Tizard and Harvey Goldstein. 
The former concluded that "the authors did succeed in measuring aspects of school life often thought to be unmeasurable" and "the study does address itself to the crucial question of how a school's functioning affects children". Goldstein reviews the statistical procedures adopted in the study. He is largely negative about the methods used and concludes that the results should be treated with "caution if not scepticism." MR provided a response to the two commentaries. [432] He concentrated on a rebuttal of the difficulties raised by Goldstein and stated that they stand by their conclusion that "the result's carry the strong implication that schools can do much to foster good behaviour and attainment."

There is an additional response by MR and colleagues in the discussion of a paper read before the Royal Statistical Society. ${ }^{[1]}$ The results from Fifteen thousand hours are placed in the context of previous research on the topic of school effectiveness. ${ }^{[286]} \mathrm{MR}$ reflected on the subsequent work on school effectiveness and on the unanswered questions that are important for policy and practice. ${ }^{[428]}$

MR gave a more general consideration of schools as environmental variables causally related to differences in antisocial behaviour ${ }^{[291]}$ and as having effects on cognitive development. [292]

Using data from the study of London schools [466] [Book15] Barbara Maughan \& MR analysed the relationship between the balance in ability at intake to schools, and outcome for pupils. ${ }^{\left[{ }^{183]}\right.}$ They were cautious about the interpretation of the findings since a number of other characteristics of schools were difficult to control. Nevertheless they suggested that more able children do better in schools with a larger proportion of able pupils. However such an imbalance was "no necessary bar to attainments on a par with those in grammar schools." The latter being at the extreme end of a spectrum an imbalance in pupil ability at intake.

\section{TEMPERAMENT}

At an early stage in his career MR spent time on the New York Longitudinal Study (NYLS) with Stella Chess and Alexander Thomas (see Carrey, 2010) and became engaged in research that considered the early emerging behaviour characteristics that constitute temperament. [236] [60] Using data on eight pairs of twins and 26 pairs of sibs aged 2 years or older from the NYLS, MR (with Sam Korn and Herb Birch) undertook analyses of twin sib resemblances to attempt to identify both genetic and environmental influences on "primary reaction patterns" which were so labelled because of their early onset as aspects of temperament. ${ }^{[418]}$ The results identified evidence for both genetic and nongenetic influences on the primary reaction patterns. In summarising their findings the authors say:
"In the broadest sense it is essential that one avoid the sterile genetic versus environmental categorization in developmental research. Clearly, effective environment, representing those features of the surround which may influence developmental course, is the result of the selective sensitivity and capacities for response of the organism. Thus, appropriate concern in development must be directed at delineation of the elements of a process of mutual and continuous interaction between organism and environment. Our attempt to explore genetic influence has occurred within this conceptual frame." [418]

From this earliest stage MR's focus was on the interaction between such biologically based behavioural variation and the environment in influencing behavioural disorders. ${ }^{[399]}$ MR attempted to replicate the findings in the New York Longitudinal Study in a study of a UK sample at high risk of developing psychiatric problems i.e. children of mentally ill parents. ${ }^{[08]}$ The replication showed that temperamental characteristics can be reliably identified and that some of these are predictive of the later development of psychiatric disorder.

In 1982 MR organised a CIBA Foundation Symposium which brought together a number of experts to examine the way "the claims and findings from the New York study stimulated a mass of research by other investigators." ${ }^{[281]}{ }^{[282]}$ Later he reflected on the relationship between the concepts of temperamental variation, personality and psychiatric disorders. ${ }^{[298]}$ [299]

\section{TREATMENT OF CHILD PSYCHIATRIC DISORDERS}

In an overview of the treatment of child psychiatric disorder MR concluded that despite progress since a previous review by Lee Robins (1973) there was still a need to better address three methodological issues she identified:

"namely, evaluation at an appropriate
time after completion of treatment,
proper attention to dropout from
treatment, and comparison of different
treatments and not just testing against
no-treatment." [279]

Many of MR's papers have rightly become highly cited but this paper which provides a thorough and important framework for considering the development and evaluation of psychological therapies, has been referenced only infrequently. 


\section{NOT ELSEWHERE CLASSIFIED}

The following are papers that are not easily included in the grouping used above in this digest.

The first paper authored by MR in a peer reviewed journal was published in 1958. ${ }^{[142]}$ It presented a case study of a pair of siblings with juvenile familial amaurotic idiocy. They were extensively investigated with radiological, biochemical, and electroencephalographic methods. The study suggested that this:

"lipid disorder may be widespread rather than restricted to cerebro-retinal neurones. Both also showed signs of Cushing's syndrome, and raised serum gamma globulin, neither reported before." ${ }^{[42]}$

In a review in 1964 of the literature of studies on IQ and psychiatric disorders in children published before the mid-1960s, MR observed that these studies were often published many years earlier and in general lacked rigour. ${ }^{[237]}$ In this paper data on children first attending the Maudsley in 1955 are presented. It was concluded that abnormality in intelligence is not a major factor in the aetiology of behavioural or neurotic disorders. However, IQ is "worthy of psychiatric attention for other reasons." The association between learning disabilities and psychiatric disorder in children was reviewed again in 1972. ${ }^{[255]}$ MR concluded that there is a "strong and important" association between the two. Nevertheless, many children with mental retardation show no emotional or behavioural difficulties. However, many do and the rate of psychiatric disorder in this group is well above that in the general population.

A third early paper investigated cerebral involvement degenerative disorder condition - Duchenne-type muscular dystrophy. ${ }^{[240]}$

Data on patients attending the Maudsley Hospital emergency clinic was analysed to assess what proportion of patients might benefit from attending a psychiatric day hospital from which they can return home at night-time. ${ }^{[99]}$ They conclude that many patients could not be cared for a day alone. An expansion of day hospitals is recommended. However, the paper called for clarity in the aims of day hospitals and for careful evaluation.

In providing guidance for prospective adoptive parents on the likely later development of infants, MR concluded that any prediction of later individual differences in psychological development in the normal range from characteristics discernible at 6 months of age is very poor. ${ }^{[248]}$

At intervals MR has published overview of the work of the Units he has directed. He surveyed the work of the Department of Child and Adolescent Psychiatry at the
Institute of Psychiatry between 1967 and 1976. ${ }^{[260]}$ The work of the MRC Unit in Child Psychiatry, Institute of Psychiatry since in inauguration in 1984 was similarly surveyed with Eric Taylor. ${ }^{[51]}$ The Social, Genetic and Developmental Psychiatry Centre at the Institute of Psychiatry was founded in 1994 under the Directorship of MR. MR and Peter McGuffin (his successor as

Director) reviewed the first 10 year of the work of the Centre. ${ }^{433]}$ This paper also describes the evolution of MRC funded psychiatry research units at the Institute of Psychiatry since the inaugural unit was established in 1948.

MR reviewed the complex issues related to psychosexual development. ${ }^{[250]}$ The paper was summarised as follows:

"The course and process of normal sexual
development is reviewed with respect
to physical maturation, sexual activity
and interests, sex "drive", psychosexual
competence and maturity, gender role,
object choice, children's concepts of
sexual differences, sex role preference, sex
role standards, and psychosexual stages.
Biologic, psychoanalytic and psychosocial
theories of sexual development are briefly
considered in the light of these findings."
$[250]$

A commentary on an immunoreactive theory of the origins of gender differences in childhood Eric Taylor \& MR concluded that:
"We are left rather doubtful about the wider explanatory power of the hypothesis; and even more sceptical of its potential to replace psychosocial factors as a main part of the environmental influence on impairments of cognition and behaviour." [510]

MR et al. suggested that the well replicated evidence that males and females differ in their rates of different forms of psychopathology provides a possible route to identifying aetiological processes. ${ }^{[403]}$ These differences are shown in a male excess which mainly applies to early onset disorders that involve some kind of neurodevelopmental impairment and a female excess which mainly occurs in adolescent-onset emotional disorders.

MR published two studies with Susan Golombok on children being raised under atypical circumstances. The first, investigated children being raised in lesbian households. ${ }^{[103]}$ They concluded that this experience did not per se lead to atypical psychosexual development or constitute a psychiatric risk factor. The second, similarly found no adverse consequences for the child of being conceived by donor insemination when followed up to age 12 years. ${ }^{[102]}$ 
MR gave a conceptual critique of Jerome Kagan's framework for understanding emotion with an emphasis on the need for more on the way genes operate and on the variety of gene-environment interplay. ${ }^{[373]}$

At various times MR has assessed progress in the field of child psychiatry. He provided a commentary on a report on the future of child psychiatry produced for the American Academy of Child Psychiatry. ${ }^{[287]}$ MR commended the recommendations in the report but made observations on issues it does not address. MR is particularly critical in commenting on the lack of importance placed on the role of other professions dealing with child mental health including clinical psychologists and behavioural paediatricians. The commentary included the following appraisal by MR of the status of psychoanalytic theory:
"Reference to the recent new edition, of the authoritative Mussen's (1983) Handbook of Child Psychology shows that psychoanalytic theories have lost their place as the dominant influence on developmental research. Of course, psychoanalysis has rightly had a lasting influence on thinking in psychiatry and in child development; many of its tenets are now accepted by all the major schools of thought. But equally it has proved wrong or irrelevant with respect to many of the key issues and problems and other conceptual systems have come to the fore." [287]

MR reviewed the field of child psychiatry again in 1986 but on this occasion with a focus on future developments up to 30 year ahead whilst recognising the near impossibility of doing so with any accuracy. [294] In a telling comment MR expressed concern over increasing uniformity in the approach to research:
"Child psychiatry has benefited greatly in the past from individuals who have followed idiosyncratic routes and who have brought special skills that they might not have had if they had received a more orthodox training.... The history of medicine, as well as of other professions, should warn us against the shackles of an imposed conformity." [294]

These same views were reflected in a paper considering the relationship between clinical practice and research in child psychiatry. ${ }^{[307]}$

"In research we have the tyrannies of theory, of methods, and of measures, and all must be resisted. Of course, each has an essential place; investigations need to be hypothesis guided and good investigations are based on well-conceived and well tested methods and measures. But the questions to be tackled need to determine the strategies and tactics, not the other way around. Both research and clinical practice need to challenge the given truths of the moment." [307]

In 1997 MR provided a synopsis of a collection of papers on child psychiatry published in the Archives of General Psychiatry. ${ }^{\left[{ }^{2} 2\right]}$ The focus was on the issues of measurement, causal mechanisms, and therapeutic interventions. On the occasion of the 5oth Anniversary of the Journal of the American Academy of Child and Adolescent Psychiatry MR provided a commentary of three papers from the journal that have contributed to the development of clinical practice. ${ }^{[375]} \mathrm{He}$ concluded that after 50 years there is now "much better integration of scientific ideas, concepts, and findings into medical practice."

In 1998 MR produced a review of progress to date and a future view of child psychiatry research. ${ }^{[333]}$ Here he placed emphasis on how research into causal processes has led to changes in clinical practice using examples from autism, hyperactivity/attention deficit syndromes, conduct disorders, depressive conditions, genetic research, organic brain dysfunction, and psychosocial risk processes. A subsequent review of the field was published in 2010. ${ }^{[37]}$

With Alan Sroufe, MR established the case for developmental psychopathology as a distinct research field, as the following quote states:
"Developmental psychopathology is a special discipline within developmental psychology and is distinguished from this larger field in its emphases. It also is distinct from abnormal psychology and psychiatry in that its scope is broader than the description, differentiation, and treatment of disordered behavior, although it is related to these disciplines. And it is fundamentally distinct from clinical child psychology and child psychiatry, though interaction among these disciplines is important." [502]

The distinctive focus is as follows:

"The developmental psychopathologist
is concerned with the origins and time
course of a given disorder, its varying
manifestation with development, its
precursors and sequelae, and its relation
to nondisordered patterns of behavior." [502]

MR developed further the principles of developmental psychopathology with illustrations from childhood depression, autism and schizophrenia, and the effects 
of adverse life experiences. ${ }^{[296]}$ These papers were highly influential in creating a coherent framework for an approach to the developmental study of behaviour which culminated in the inauguration of the journal Development and Psychopathology in 1989. In 2000 MR and Sroufe provided an updated overview of the origins and progress in developmental psychopathology. ${ }^{[459]}$ In 2013 MR returned to provide an appraisal of the success of the developmental psychopathology approach stipulating that it:

"...is not a theory and it is not a discipline. It is not a theory because it does not propose an overall explanatory account. It is not a discipline because it does not refer to a definable body of knowledge, and it does not involve a single profession. Rather, it constitutes a conceptualization that leads to crucial questions on continuities and discontinuities and which is dedicated to the discovery of mediating mechanisms." [387]

MR has argued that the status of development as a concept in psychopathology is problematic. This was first addressed in 1989 in a paper which was entailed "Age as an ambiguous variable in developmental research...". [303] MR returned to these issues in 2005. ${ }^{[358]} \mathrm{He}$ concluded that

"...developmental research is a rich field of high potential, but it needs to be processoriented rather than norm-oriented, it needs to focus on interconnections between brain and mind, and it needs to have a major interest in individual differences." [358]

The issue of the role of cognition in child development and psychiatric disorders was reviewed by MR ${ }^{[300]}$ and he concluded that:

"The ways in which we appraise our life circumstances and the ways in which we react to experiences of all kinds are greatly influenced by how we think about ourselves and our environment. Research has begun to suggest some of the mechanisms that may be involved in these cognitive processes. It is clear that biases and distortions in such processing may be associated with social and emotional malfunction. These biases may derive from earlier experiences, from intrinsic temperamental styles, or from deficits in the ability to process incoming information." [300]

MR contributed to an obituary for Lee Robins ${ }^{[69]}$ who he described as a "crucially important mentor" and as having "conducted the world's best long-term longitudinal study." In 2004 MR wrote an obituary in the BMJ for his father, Llewellyn Charles Rutter, who he had followed into medicine both having been trained at the University of Birmingham. ${ }^{\text {[350] }}$

The occasion of MR's retirement from the MRC Child Psychiatry Unit led to events organised by the Association for Child Psychology and Psychiatry and the Child and Adolescent Psychiatry Faculty of the Royal College of Psychiatrists. The presentations to these commemorative events were published as a Festschrift (Green \& Yule, 2001a) along with a second volume of MR's own classic publications (Green \& Yule, 2001b). The final chapter of Volume 1 is an "Appreciation of Professor Sir Michael Rutter" by Ann Le Couteur. This provides a brief biography, an appraisal of some of the key books MR has authored or edited and a more personal reflection on MR as a clinician and researcher.

Green \& Yule (2001b) is a collection of MR's writings 1965-1999. It also includes a listing of MR's "Principal scientific publications" 1958-2001. This listing includes book chapters which have not been covered in this digest. The volume is introduced by "An Appreciation of the scientific contribution of Michael Rutter" written by Eric Taylor. Taylor characterises MR's view that "research should tackle big and pressing questions, focus on the mechanisms of development of disorder and ask questions about how it arises; and that research and clinical practice should illuminate one another." 


\section{Books authored or co-authored by Michael Rutter 1966 to 2019}

\section{Book1.}

Rutter, M. (1966). Children of sick parents: An environmental and psychiatric study. London: Oxford University Press.

ISBN-13: 9780000000750 ISBN-10: 0000000752

In 1962 MR submitted an M.D. thesis to the University of Birmingham entitled "Illness in parents and children: psychiatric and physical illness in the parents of children attending a psychiatric clinic". This Maudsley Monograph (Number 16) gives an account of the research in that thesis. The children studied in this monograph were attending the Maudsley Hospital Children's department. From an initial sample of 922 children 739 were designated disturbed with either neurotic or behavioural disorders and 147 were non- disturbed. Two comparison groups were selected - a dental and paediatric group attending the respective clinical departments at King's College Hospital and an out-patient clinic at the Belgrave Hospital for Children. The aim of the study was to test the hypothesis that there would be a significantly higher rate of parental illness (both physical and psychiatric illness) among children with psychiatric disorder. This association was found for both physical and psychiatric illness in the parent. However, not all children exposed to this risk factor showed deviant development and differential susceptibility in the child was identified as an important area for future research. A section of the monograph addresses the question of whether the association between parental and child illness is mediated by genetic or environmental influences i.e. the deleterious effects of experiencing parent illness. This question is left unresolved.

\section{Book2.}

Rutter, M. (1970). Language retardation and psychological development. London: Invalid Children's Aid Association.

No ISBN

This is recorded as a book in the British Library catalogue. It is a typed copy of an address given by MR to the 82nd AGM of the Invalid Children's Association on 17th November 1970. It provides a summary of the psychological difficulties of children with language retardation. It concludes that these "... are in part intrinsic but in larger secondary to the way in which they are dealt with by society and so potentially preventable."

\section{Book3.}

Rutter, M., Graham, P., \& Yule, W. (1970). A neuropsychiatric study in childhood. London: Spastics International Medical Publications in association with William Heinemann Medical Books.

ISBN-13: 9780521411981 ISBN-10: 052141198X

A detailed account of the findings from the Isle of Wight study is given in this book that relate to the psychological manifestations of mild neurological disorder. It aims to address three questions: how can mild neurological disorder be diagnosed in the clinic, how frequent are the common manifestations of neurological abnormality and what influences has organic brain dysfunction on psychological development. It compliments the other major source of material of the Isle of Wight Study i.e. Rutter, Tizard and Whitmore (1970) - see below

\section{Book4.}

Rutter, M., Tizard, J., \& Whitmore, K. (eds.) (1970). Education, health and behaviour. London: Longmans.

ISBN-13: 9780582320987 ISBN-10: 0582320984.

Many of MR's later research interests had their origins in the Isle of Wight study. This was a pioneering large scale epidemiological of the physical and psychological well-being and educational attainment of 9-10 year old children living on the Isle of Wight. This book provides the main account of the design of the study and a presentation of the findings. The Isle of Wight Study was followed later in the 1970s by the Inner London study where many of the same questions concerning prevalence of problems were repeated in an urban setting (for example see ${ }^{[409][466][465]}$ ).

\section{Book5.}

Rutter, M. (Ed.) (1971). Infantile autism: Concepts, characteristics and treatment. Edinburgh: Churchill Livingstone.

ISBN-13: 9780700015337 ISBN-10: 0700015337.

This is a collection of papers presented at a Study Group on Infantile Autism held at the CIBA Foundation. A summary of the conclusions is given in the Preface: "In contrast to what would have been the situation 10 years ago, there was a substantial measure of agreement among the study group participants on many of the key issues - that autism is a disorder beginning the first two and half years of life; characterised by a defect in the development of social relationships, a global language impairment and rigid or ritualistic patterns of behaviour; not primarily caused by psychogenic influences; and probably due to some variety of cognitive, perceptual or language deficit." A marker of how things would change over the next 10 years, not least as result of MR's own studies, that in a chapter written by MR himself (with Lawrence Bartak and Steven Newman) it was stated there "So far there is remarkably little evidence on possible genetic factors."

\section{Book6.}

Rutter, M., \& Martin, J. A. M. (Eds.). (1972). The child with delayed speech. London: William Heinemann Medical Books.

ISBN-13: 9780433203346 ISBN-10: 043320334X.

The Spastics Society funded a study group held in 1970 to discuss the problems of children with speech and language disorders. This book was prepared on the basis of papers presented at that meeting and augmented by additional papers commissioned for the book. The book was prepared to provide clinicians with a useful introduction to field and to guide further reading. 


\section{Book7.}

Rutter, M. (1972). Maternal deprivation reassessed. Harmondsworth: Penguin Books.

ISBN-13: 9780140805611 ISBN-10: 0140805613.

Here MR examines the evidence related to John Bowlby's assertion that "...individuals suffering from any type of psychiatric disorder always show an impairment of the capacity for affectional bonding that frequently is disturbance of bonding in childhood which has caused later psychiatric disorder." The book concludes that "The concept of 'maternal deprivation' has undoubtedly been useful in focusing attention on the sometimes grave consequences of disturbed or defiant care in early life. However, it is now evident that the experiences included under the term 'maternal deprivation' are too heterogeneous and the effects too varied for it to have any usefulness. It has served its purpose and should now be abandoned." This was the first book by MR for a wider general readership.

\section{Book8.}

Rutter, M., Shaffer, D. \& Shepherd, M. (1975). Multiaxial classification of child psychiatric disorders: An evaluation of a proposal. Geneva: World Health Organization.

ISBN-13: 9789241540506 ISBN-10: 9241540508.

A number of investigations were conducted to evaluate the multi-axial classification of childhood disorders in ICD-9 and are summarised here. A group of 22 child psychiatrists were involved in a study group to appraise the reliability, validity and feasibly of the classification framework. A number of suggestions are put forward for the incorporation of child psychiatric disorders into the ICD.

\section{Bookg.}

Rutter, M. (1975). Helping troubled children. Harmondsworth: Penguin Education.

ISBN-13: 9780140803631 ISBN-10: 0140803637.

A book for the general reader providing "...an account of the thinking and principles underlying the understanding and treatment of these common problems." This refers to "emotional and behavioural problems in childhood." The chapters are organised by the various influences in families and the wider community and by type of problem.

\section{Book1o.}

Rutter, M.L., Shaffer, D. \& Sturge, C. (1975). A guide to a multi-axial classification scheme for psychiatric disorders in childhood and adolescence. London: Dept of Child and Adolescent Psychiatry, Institute of Psychiatry. No ISBN.

This is a guide to the application of the 5 axis classification of child psychiatric disorders presented in the International Classification of Diseases Ninth Revision (ICD-9). The guide was reprinted and corrected in 1983.

\section{Book11.}

Rutter, M. \& Hersov, L. (Eds.). (1976). Child psychiatry: modern approaches. (First Ed.) Oxford: Blackwell.

ISBN-13: 9780632001514 ISBN-10: 0632001518.

The first edition of a what has become the definitive textbook in child psychiatry. This edition contained 41 chapters written by leading experts mainly form the UK but with contributions from authors in the USA too. The Editors were MR and his colleague from the Maudsley Hospital, Lionel Hersov. It is now in its 7 th edition is much expanded and has 6 editors.

\section{Book12.}

Rutter, M., \& Madge, N. (1976). Cycles of disadvantage: A review of research. London: Heinemann.

ISBN-13: 9780435828523 ISBN-10: 0435828525.

This is a review of the worldwide literature on the transmission of deprivation but with a focus on its implications for Britain in the early 1970s. There is a detailed consideration of the different facets of disadvantage, how it can be measured, how disadvantage shows stability within an individual's lifetime but most particularly on intergeneration continuities. No brief summary can be made on this topic. As the authors state "Unfortunately, the subject is too complex to be dealt with by a few succinct conclusions and we request the reader's indulgence and patience in asking that the book be read as a whole"!

\section{Book13.}

Rutter, M., \& Schopler, E. (Eds.). (1978). Autism : A reappraisal of concepts and treatment. London: Plenum Press.

ISBN-13: 9780306310966 ISBN-10: 0306310961.

This edited collection of chapters had its origin in an International Symposium on Autism held in St Gallen, Switzerland in 1976. It aimed to provide a definitive review of knowledge about autism in the mid-1970s.

\section{Book14.}

Rutter, M. (1979). Changing youth in a changing society: Patterns of adolescent development and disorder. London: Nuffield Provincial Hospitals Trust.

ISBN-13: 9780900574313 ISBN-10: 0900574313.

A monograph that was the product of the Rock Carling Fellowship held by MR in 1979. It provides a review of the psychosocial problems of adolescents, whether these are distinctive of the adolescent period, whether they are changing in character and in prevalence over time and how health and services can be geared to cope with them. The material in the first chapter includes previously unpublished findings from the Isle of Wight study. 


\section{Book15.}

Rutter, M., Maughan, B., Mortimer, P., \& Ouston, J. (1979). Fifteen thousand hours: Secondary schools and their effects on children. London: Open Books.

ISBN-13: 9780729101134 ISBN-10: 0729101134.

Between the age of five and school leaving children spend some 15,000 hours at school. The study reported in this book addresses the questions of whether experiences in school have any effect, whether it matters which school is attended and which features of school matter. The research involved detailed assessments twelve secondary schools in London of school attendance, behaviour and attainments. Both physical and administrative features of schools were measured. Importantly school processes were also measured including academic emphasis, teacher actions in lessons, rewards and punishments, pupils conditions, children's opportunities for taking responsibilities and participation in the running of the school, the stability of teaching and friendship groups, staff organisation and skills of teachers. The study showed that secondary schools differ markedly in pupils' behaviour, attendance and attainment. These outcomes were "strongly associated with characteristics of school as social institutions." These included the degree of academic emphasis, teacher actions in the classroom, the availability of rewards and incentives, good conditions for pupils and the extent to which children were given responsibilities. Pupils were not only influenced by the way they were treated as individuals but also by the "ethos" of the school.

\section{Book16.}

Rutter, M. (Ed.) (1980a). Scientific foundations of developmental psychiatry. London: Heinemann.

ISBN-13: 9780433289890 ISBN-10: 0433289899.

This edited book was completed whilst MR was a Fellow at the Centre for Advanced Study in the Behavioural Sciences, Stanford, California (see also ${ }^{\left[{ }^{[B o k 22}\right]}$ ). It provided a general textbook on normal development as a basis for understanding atypical development. One notable feature is that the book is dedicated to two authors contributing chapters who were influential on MRs development as scientist - Jerry Shields and Jack Tizard - both of whom died during the books production. The book was later published as: Rutter, M. (Ed.) (1987). Developmental psychiatry. Washington: American Psychiatric Press. ISBN-13: 9780880482714 ISBN-10: 0880482710.

\section{Book17.}

Rutter, M. (1980b). Raised lead levels and impaired cognitive-behavioural functioning: a review of the evidence. Developmental Medicine and Child Neurology, 22, Supplement no.43., 1-26. doi: 10.1111/j.14698749.1980.tbo4397.x

A special supplement providing a review and critique of studies on the cognitive and behavioural sequelae of moderately raised lead levels in children. There is an emphasis on the methodological limitations on different types of study and the need for further research. He concluded "the evidence suggests that persistently raised blood lead levels in the range above 40mg/10oml may cause slight cognitive impairment (a reduction of one to five points on average and less certainly may increase the risk of behavioural difficulties." See ${ }^{\left[B_{0} o k 20\right]}$ for the outcome of MRs deliberations on the adverse effect of lead on children.

\section{Book18.}

Rutter, M. (1983). Measure of our values: Goals and dilemmas in the upbringing of children. London: Quaker Home Service.

ISBN-13: 9780852451700 ISBN-10: 0852451709.

$M R$, his father and grandfather combined service as medical doctors with membership of the Society of Friends (Quakers). This book outlines the issues for Quakers in the upbringing of children and in the conduct of family life. The book is introduced by a chapter addressing the relation between science and Quakerism. This chapter ends with MR endorsing a quote from Peter Medawar: "...The purpose of scientific inquiry is not to compile an inventory of factual information, nor to build up a totalitarian picture of natural laws. We should think of it rather as a logically articulated structure of justifiable beliefs about nature. It begins with a story about a Possible World - a story which we invent and criticise and modify as we go along, so that it ends by being, as nearly as we can make it, a story about real life." MR then comments "To my mind, that epitomises the essential qualities of both science and Quakerism."

\section{Book19.}

Rutter, M., \& Giller, H. (1983). Juvenile delinquency: Trends and perspectives. Harmondsworth: Penguin.

ISBN-13: 9780140804621 ISBN-10: 0140804625.

The aims of this book were to "assess what was known on the topic of juvenile delinquency with respect to its origins, causation, course, remediation and outcome; and in doing so to derive implications on research strategies that are likely to be fruitful in the future, and on policies and practices that might be effective." It is based on a report to the Home Office and the Department of Health and Social Security which funded the work on the review.

\section{Book20.}

Rutter, M., \& Russell Jones, R. (Eds.). (1983). Lead versus health: Sources and effects of low-level lead exposure. Chichester: Wiley.

ISBN-13: 9780471900283 ISBN-10: 0471900281.

This is an edited version of papers present at an international symposium on "Low level lead exposure and its effects on human beings" organised by the CLEAR Charitable Trust. In his concluding chapter in the book MR highlights the complex issues in identifying possible adverse effects of low-level exposure to health. He also emphases that the putative ill-effects are likely to be slight for most children but could be important effects for some children. He concludes "Accordingly, actions to cut down the amount of lead pollution of the environment should be worthwhile; there is quite sufficient justification for action now." In the European Union lead was removed from petrol 17 years later on 1 January 2000. 


\section{Book21.}

Garmezy, N., \& Rutter, M. (1983). Stress, coping, and development in children. New York: McGraw-Hill.

ISBN-13: 9780070228863 ISBN-10: 0070228868.

In 1979-1980 MR was a Fellow at the Centre for Advanced Study in the Behavioral Sciences at Stanford. A group of Fellows in residence joined together to discuss issues around stress and coping. This edited 12-chapter book was one product of the seminar series that was organised. MR's contribution to the book was a slightly modified version of a previously published paper. ${ }^{[276]}$

\section{Book22.}

Rutter, M. (Ed.) (1984). Developmental neuropsychiatry. Edinburgh: Churchill Livingstone.

ISBN-13: 9780443031502 ISBN-10: 0443031509.

Work on this book was initiated during the tenure of the Fellowship mentioned under [Book21]. The objective of the edited book was "to provide a bridge between research and clinical practice" related to the neuropsychiatry of childhood. The first two sections consider the general psychological sequelae of brain trauma and disorders, the measurement of brain function and dysfunction. The third and fourth sections review aspects of hyperkinetic/attention deficit syndrome. The final section/chapter by MR reviews the material covered in the various sections. It includes a stringent appraisal of the concept of a "minimal brain dysfunction" syndrome in childhood. Despite his scepticism MR concludes that "Clearly, it would be unwarranted to dismiss the possibility of some form of 'MBD' syndrome that is biologically distinct in terms of its aetiology, its mechanisms, or its response top treatment. Further research to investigate that possibility is needed, but it is too early to predict what will be found."

\section{Book23.}

Rutter, M., Izard, C. E., \& Read, P. B. (Eds.). (1985). Depression in young people: Developmental and clinical perspectives. New York: Guilford Press.

ISBN-13: 9780898626605 ISBN-10: 0898626609.

This edited volume presents 18 chapters arising from contributions to a symposium organised under auspices of the UK Social Science Research Council (the predecessor of the present Economic and Social Research Council). The aim was to foster a dialogue between those approaching the study of depression in children from a developmental research perspective and those concerned with the clinical treatment of affective and depressive conditions.

\section{Book24.}

Prior, M.R. \& Griffin, M.W. (1985). Hyperactivity: diagnosis and management. London: Heinemann Medical Books. Foreword by Michael Rutter.

ISBN-13: 9780433263500 ISBN-10: 0433263504

In his Foreword to this book, MR commended the authors on providing a "book that considers hyperactivity in scientifically rigorous fashion, but more especially in practical terms with realistic guidelines on how to help children with such problems". He also notes that there is a proper emphasis on "the importance of children taking responsibility in their behavioural programmes.

\section{Book25.}

Howlin, P., \& Rutter, M. (Eds.). (1987). Treatment of autistic children. Chichester: Wiley.

ISBN-13: 9780471102625 ISBN-10: 0471102628.

This publication describes the work undertaken in a research based treatment programme for autistic children funded by a grant to Michael Berger, Lionel Hersov, MR and William Yule. Patricia Howlin and Rosemary Hemsley undertook the therapeutic work which centred on the use behavioural approached allied with changes to the child's environment with a particular focus on fostering the language development of the children and with the interventions being carried out by parents at home. The following sobering conclusion is reached: "There has been great progress in the development of effective methods of treating the behavioural problems shown by autistic children. It is important that these methods be made generally available to autistic children and their families. Much that is worthwhile can be accomplished and there can be no excuse for failing to provide the help that is so much needed by parents facing the problems of rearing a handicapped child whose autistic deficits serve to make social interactions so unrewarding as well as creating a host of management difficulties. Yet, it is all too apparent that the great majority of autistic individuals will remain handicapped throughout their lives. Treatment does not result in a 'cure' or anything approaching it."

\section{Book26.}

Yule, W., \& Rutter, M. (Eds.). (1987). Language development and disorders. London: Mac Keith Press.

ISBN-13: 9780632015221 ISBN-10: 0632015225.

In many ways this book represents a follow-up to ${ }^{[B o k 6]}$ in that it too was sponsored by the Spastics Society and it too summaries in "reasonably accessible form" the state of knowledge concern the child with language disorders. The topics covered include current knowledge of language development, classifications for language pathology, the epidemiology of language difficulties, assessment and therapy, alternative communication systems and the impact of new technology on communication aids.

\section{Book27.}

Quinton, D., \& Rutter, M. (1988). Parenting breakdown: The making and breaking of inter-generational links. Aldershot: Avebury.

ISBN-13: 9780566055829 ISBN-10: 0566055821.

This monograph provides an integrative overview of the findings from two complementary studies on children who had been in care. The first is a retrospective study of 48 families with European-born parents who had children admitted to residential care and a comparison group of 47 families with similar aged children who had not been 


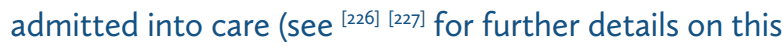
study). The second was a prospective study into their early adult years of 93 young women who in 1964 were in one of two children homes that were run on "group cottage lines" (see King, Raynes \& Tizard, 1971). A comparison group was provided by 51 females from the general population who had not experienced being in care (see ${ }^{[228]}[442]$ for further details on this study). It was concluded that "serious parenting problems as evidence by parenting breakdown very seldom occur in the absence of the experience of poor parenting or marked family disruption in childhood."

\section{Book28.}

Rutter, M. (Ed.) (1988). Studies of psychosocial risk: The power of longitudinal data. Cambridge: Cambridge University Press.

ISBN-13: 9780521353304 ISBN-10: 0521353300.

This edited book arose from a European Science Foundation workshop held in 1998. The purpose of the workshop was:

"discussing the ways in which longitudinal data may be used to study the mechanisms involved in the operation of risk and protective factors for disorders of psychological development."

In particular, the workshop aimed to address how longitudinal studies could be better exploited to examine causal processes. In his introductory chapter to the book MR suggests that:
"It is unduly pessimistic to conclude that causal hypotheses can only be studied through highly controlled laboratory experiments. There are many longitudinal research strategies that can go a long way towards the testing of causal hypotheses. While it would be rarely, if ever, permissible to draw strong conclusions about causation from a single study, combinations of findings from investigations using contrasting but complementary research strategies can do much to increase our understanding of mechanisms. However, almost never will this amount to the identification of one basic underlying cause of some maladaptive outcome. Multiple aetiologies are the rule and most causal processes operate through a series of indirectly connected sequences involving different, relatively short term effects or operations. It is the analysis of these chain effects over time that longitudinal data really come into their own."

\section{Book29.}

Rutter, M., Tuma, A. H., \& Lann, I. S. (Eds.). (1988). Assessment and diagnosis in child psychopathology. New York: Guilford Press.

ISBN-13: 9780898626995 ISBN-10: 0898626994.

This edited volume of 15 chapters had its origins in a National Institute of Mental health sponsored workshop.
It includes 4 chapters authored or co-authored by MR on Depressive disorders, Autism and pervasive developmental disorders, Diagnosis and classification: some outstanding issues and DSM-III-R: A postcrript.

\section{Book30.}

Robins, L. N., \& Rutter, M. (Eds.). (1990). Straight and devious pathways from childhood to adulthood. Cambridge: Cambridge University Press.

ISBN-13: 9780521364089 ISBN-10: 0521364086.

This collection of papers is based on invited papers at A Life History Research Society meeting in October 1987. There is an emphasis on very long-term studies that started in childhood and ended in adulthood. The editors say:
"The goal of these papers is not merely to note the frequency with which childhood factors predict adult outcome, but to observe under what conditions the predicted links occur, and what prevents them from occurring. In addition, these papers ask how consistent the pathway between childhood and adult lie is: Is it straight and narrow, or full of detours and unexpected reversals?"

\section{Book31.}

Rutter, M., \& Casaer, P. (Eds.). (1991). Biological risk factors for psychosocial disorders. Cambridge: Cambridge University Press.

ISBN-13: 9780521401036 ISBN-10: 0521401038.

This book comprises a series of chapters arising from a European Science Foundation Network on Longitudinal Studies on Individual Development held in 1989. The authors:

"were asked to write for a multidisciplinary audience, to adopt a lifespan approach, to focus on the principles involved, to outline the outstanding research and clinical issues and to consider the role of longitudinal studies infurthering knowledge on the psychosocial risks stemming from biological processes."

\section{Book32.}

Rutter, M., \& Rutter, M. (1993). Developing minds: challenge and continuity across the life span. New York: BasicBooks.

ISBN-13: 9780465010370 ISBN-10: 0465010377.

This is a textbook written as a joint enterprise between MR and his wife Marjorie which they describe as having been:
"fun, as well as illuminating, in forcing us to clarify out thinking about what was involved in the process of development and why it was relevant across the lifespan, and not just in childhood."

It aimed to provide a textbook that covered material relevant to clinicians and which extended the study of development into adulthood and old age. 


\section{Book33.}

Rutter, M., \& Hay, D. F. (1994). Development through life: A handbook for clinicians. Oxford: Blackwell

Scientific.

ISBN-13: 9780632036936 ISBN-10: 0632036931.

A 22-chapter edited textbook dealing with aspects of development of relevance to clinicians in trainings in psychiatry, clinical psychology, social work, nursing, paediatrics and special education.

\section{Book34.}

Haggerty, R.J., Sherrod, L.R., Garmezy, N. \& Rutter, M. (Eds.) (1994). Stress, risk, and resilience in children and adolescents: processes, mechanisms, and interventions. Cambridge: Cambridge University Press.

ISBN-13: 9780521441469 ISBN: 0521441463.

This book was seen as an update to Book21 and deals with stress and coping under four themes - risk/outcome relationship, the inter- and intraindividual variation in factors linked to resilience, the processes and mechanisms linking multiple stressors to multiple outcomes and the development of prevention and intervention programmes.

\section{Book35.}

Rutter, M. (Ed.) (1995). Psychosocial disturbances in young people: Challenges for prevention. Cambridge: Cambridge University Press.

ISBN-13: 9780521461870 ISBN-10: 0521461871.

The Johann Jacobs Foundation sponsored a conference in 1992 and the chapters in this book are based on a number of the presentations made to that meeting. The focus of the book is:

"...on why psychosocial disorders in young people are increasing in frequency and what can be done to prevent such disorders or reduce their adverse impact."

In the Preface to the book MR suggests:

"...we do know a lot about the difficulties experienced by adolescents, the factors that create risks for disorder and factors that seem protective. We know about interventions that carry some promise of improving young people's circumstances, enabling them to cope better with the challenges they encounter and reducing the risks of disorder. It is clear from the findings reviewed in this book that we all have a responsibility in this regard. Some of the steps recommended involve interaction with individuals, but many require actions at the level of youth organizations, schools and the community as a whole."

\section{Book36.}

Rutter, M., \& Smith, D. J. (Eds.). (1995). Psychosocial disorders in young people: Time trends and their causes. Chichester: J. Wiley.

ISBN-13: 9780471950547 ISBN-10: 0471950548.

In 1990 Academia Europaea instigated a Study Group to:

"consider the evidence on the question of whether psychosocial disorders in young people had become more, or less, frequent over the last 50 years and to determine how possible causal explanations for any changes found might be tested."

This 843-page edited book of 15 chapters is the resulted from the work of the Study Group. It is concluded that there has been:
"substantial increases in psychosocial disorders of youth since the Second World War in nearly all developed countries."

The evidence on the possible causal mechanisms underlying these increases is complex and it suggests that the explanations must be different for different disorders.

\section{Book37.}

Plomin, R., DeFries, J.C., McClearn, G.E. \& Rutter, M. (1997). Behavior genetics. Third Edition. London: McMillan.

ISBN-13: 9780716728245 ISBN: 0716728249.

MR joined the other three co-authors in this the Third Edition of their book which had become the leading textbook in behaviour genetics. This edition had a change of focus so that:
"Its goal is not to train students to become behaviour geneticists but rather to introduce students in the behavioral, biological, and social sciences to the field of behavior genetics.

\section{Book38.}

W.H.O.(1997). Multiaxial classification of child and adolescent psychiatric disorders: The ICD-10 classification of mental and behavioural disorders in children and adolescents. Cambridge: Cambridge University Press.

ISBN-13: 9780521581332 ISBN: 0521581338.

MR provided the Introduction to this WHO publication which presents the classification of child and adolescent psychiatric disorders in the 1oth revision of the International Classification of Diseases (ICD-10). The framework is based on six axes: One - Clinical psychiatric syndromes, Two Specific disorders of psychological development, Three - Intellectual level, Four - Medical conditions from ICD-10 often associated with mental and behavioural disorders, Five - Associated abnormal psychosocial situations and Six - Global assessment of psychosocial disability. MR has commented on the subsequent revisions in ICD-11. [522] [523] [464] 


\section{Book39.}

Rutter, M., Giller, H., \& Hagel, A. (1998). Antisocial behavior by young people. Cambridge: Cambridge University Press.

ISBN-13: 9780521646086 ISBN: 0521646081.

The Dept. of Health funded a project to produce an updated review of antisocial behaviour in young people. This book is the outcome of that review which builds on the material in the previous review. ${ }^{[B o o k 19]}$ In producing the review there was a deliberate attempt to provide a broad coverage of the various levels of explanation about the origins and nature of antisocial behaviour and ranges from the "biological to the sociological."

\section{Book40.}

Murray, L. \& Cooper, P.J. (1999). Postpartum depression and child development. London: Guilford Press.

ISBN-13: 9781572301979 ISBN: $157230197 X$.

The afterword in this edited book by MR is entitled "Maternal depression and infant development: Cause and consequence; Sensitivity and specificity." It identifies a number of important features of the research presented in the book which advance our understanding of the associations between parental mental-illness and child development. The evidence suggests that in addition to whatever genetic effects are present, an:

"...important part of the risk is environmentally mediated. The research has explicitly recognised that maternal depression is a risk indicator and not necessarily a risk mechanism."

The studies consider the two-way processes between parent and child behaviour and recognise the need "to consider the social context of parent-child interaction." The strength of the research also stems from the wide range of outcomes and mediating and moderating mechanisms being considered.

\section{Book41.}

Moffitt, T.E., Caspi, A., Rutter, M. \& Silva, P.A. (2001). Sex differences in antisocial behaviour: conduct disorder, delinquency, and violence in the Dunedin longitudinal study. Cambridge: Cambridge University Press.

ISBN-13: 9780521804455 ISBN: 0521804450.

The Dunedin Study has followed a sample of 1000 participants from the age of 3 years into adulthood. This book presents findings on sex difference in the changes in antisocial behaviour over the first two decades of lie. An overarching conclusion was:

"that females antisocial behaviour obeys the same causal laws as males. Females are unlikely to develop the neuro-developmental form because they are unlikely to have the risk factors for it, whereas they are as likely as males to develop the socially influence form because they share with males the risk factors for it."

\section{Book42}

Royal College of Psychiatrists (2001). Guidelines for researchers and for research ethics committee on psychiatric research involving human participants. Council Report CR82. London: Gaskell.

ISBN-13: 9781901242645 ISBN-10: 1901242641

MR was Chairman of the Royal College Working Party on Guidelines for Researchers and for Research Ethics Committees on Psychiatric Research involving Human Participants. This publication was produced by the Working Party. In addition to being Chairman, MR wrote an Appendix on "Children's level of understanding of medical conditions."

\section{Book43.}

Rutter, M., \& Tienda, M. (Eds.). (2005). Ethnicity and causal mechanisms. Cambridge: Cambridge University Press.

ISBN-13: 9780521849937 ISBN: 0521849934.

The Jacobs Foundation sponsored a conference on the issues related to the difficulties experienced by ethnic minority groups. This edited book is by-product of this conference. A significant feature of the research presented in the book is the emphasis on differences in outcome both between and within ethnic groups. The research strategy:
"... involves determining which risk or protective factors are significantly associated with particular psychosocial outcomes within each ethnic group. We reasoned that if specific factors mediate an observed between-group difference, then the prevalence of the risk/protective factor will differ between the ethnic groups: moreover, when the factor is introduced into multivariate analysis, it will obliterate (or, at least, bring about a major reduction in) the differences between groups."

\section{Book44.}

Rutter, M. (2006). Genes and behavior: nature -- nurture interplay explained. Oxford: Blackwell.

ISBN-13: 9781405110617 ISBN-10: 1405110619.

In this publication MR sets out to present a "non-technical account of what is involved in the possible various ways in which genetic influences on behaviour may be important." "Nurture" in the title is taken to refer to a broad range of environmental influences on behaviour. The book seeks to address the relative neglect by behaviour geneticists of evidence that does not derive from genetically informative research study designs. MR suggests that some of the protagonists of behaviour genetics have made overblown claims of the importance of genetic factors. This book does not seek to deny the role of genetic influences on behaviour but rather to understand the mechanisms by which genetic and environmental influences co-act and interact in influencing individual differences in behaviour and the occurrence of mental disorders. 


\section{Book45.}

Academy of Medical Sciences (2007). Identifying the environmental causes of disease: how should we decide what to believe and when to take action? / an Academy of Medical Sciences working group report chaired by Michael Rutter. London: Academy of Medical Sciences.

ISBN-13: 9781903401163 ISBN: 190340116X.

This publication provides a distillation of the deliberations of a Working Group sponsored by the Academy of Medical Sciences. It includes recommendations for action by Government and funders of research on the identification of environmental causes of disease both physical and psychiatric. It also provides guideline for researchers and those concerned with the publication and dissemination of research findings. The emphasis is on how best to interpret non-experimental studies and to understand the limitations, but also strengths, in indicating the possible role of environmental factors as causes of disease. This book should be mandatory reading for anyone undertaking research not only in child psychiatry but medical sciences more widely.

\section{Book46.}

Rutter, M. (Ed.) (2008). Genetic effects on environmental vulnerability to disease: State of the art and future directions. Chichester: Wiley-Blackwell.

ISBN-13: 9780470777800 ISBN-10: 047077780X.

This is a collection of papers arising forma Novartis Foundation symposium on "Understanding how geneticenvironment interactions work to predict disorder: a lifecourse approach" held in Dunedin in 2007. The chapters present findings on GxE interactions from a number of fields including breast cancer and asthma as well as behavioural disorders. The consensus conclusions were that:

\begin{abstract}
"we should focus less on the observed GxE and more on the biological mechanism that might be involved. There are two key reasons for that view. First, the focus has to be on the biological meaning and not the statistical interaction as such. Second, it is known that both genetic and environmental effects may be affected by contextual influences - both environmental and genetic (outside the specific $G$ and the specific E being investigated."
\end{abstract}

\section{Book47.}

Dunn, J. (2008). Family relationships. Children's perspectives. London: ONE Plus ONE. Foreword by Michael Rutter.

ISBN-13: 9781874207177 ISBN-10: 1874207178

The charity One Plus One aims to "strengthen relationships for couples, families, communities and workplaces using evidence based training and digital resources." As a Trustee and member of the Research Committee MR provided a Foreword to this monograph by Judy Dunn. He says:

"This important monograph provided valuable insights into how children think about family changes and alerts us all to the need to extend our thinking about family relationship beyond the parent-child dyad."

\section{Book48.}

Rutter, M., Beckett, C., Castle, J., Kreppner, J., Stevens, $\mathrm{S} \&$ Sonuga-Barke, E. (2009). Policy and practice implications from the English and Romanian Adoptees (ERA) study: Forty-five key questions. London: British Association for Adoption and Fostering.

ISBN-13: 9781905664757 ISBN-10: 1905664753.

This is a 48-page article which summarises the findings 2009 from the ERA study and then goes on to focus on the policy and practice issues arising from the research. The questions considered are those most often posed by practitioners and agencies concerned with adoption.

\section{Book49.}

Coleman, L. \& Green, F. (2009). When couples part: understanding the consequences for adults and children. London: ONE Plus ONE. Foreword by Michael Rutter.

ISBN-13: 9781874207184 ISBN-10: 1874207186.

This review aimed to appraise the effects of relationship breakdown on family member. In his Foreword MR emphasises the importance of the topic as follows:
"...humans are social beings: committed partnerships are an intrinsic part of human functioning and breakdown of those partnerships constitute a major stress through the whole life span."

\section{Book50.}

Rutter, M., Sonuga-Barke, E.J, Beckett, C., Castle, J., Kreppner, J., Kumsta, R., Schlotz, W., Stevens, S., Bell, C.A \& Gunnar, M.R (2010). Deprivation-specific psychological patterns: effects of institutional deprivation. Oxford: Wiley-Blackwell.

ISBN-13: 9781444338393 ISBN-10: 1444338390.

[Monographs of the Society for Research in Child Development, No. 295, Vol. 75 No.1]

A monograph containing ten chapters each presenting details of the methods or findings of the English and Romanian Adoptees (ERA) Study.

\section{Book51.}

Dodge, K.A. \& Rutter, M. (Eds.) (2011). Geneenvironment interactions in developmental psychopathology. New York: Guilford Press.

ISBN-13: 9781606235188 ISBN-10: 1606235184.

This is a multi-authored book of 13 chapters. The first 5 chapters present the scientific basis of gene-environment interaction. The final 8 consider the implications of this scientific understanding for practice and policy. MR provides chapters in both sections. The final chapter co-authored with Kenneth Dodge presents a cautious forward view on the potential impact of gene-environment interaction research on science policy, health services policy and judicial policy 
Book52.

Goodman, R. \& Scott, S. (2012). Child and adolescent psychiatry. Chichester: Wiley-Blackwell. Foreword by Michael Rutter.

ISBD-13: 9781119979685 ISBN-10: 1119979684.

MR provided the Foreword to the first edition of this textbook and here to its third edition. He provides an endorsement of its qualities in the first edition by saying "My only regret is that I did not write this excellent book!". For the third edition, he comments that "It is bit like watching one of David Attenborough's marvellous TV programmes - you never feel lectured at, your interest is engaged throughout, but in the course of that engagement you actually learn a lot". 


\section{References}

Anthony, E. J. (1958). An experimental approach to the psychopathology of childhood autism. British Journal Medical Psychology, 33, 211. doi: 10.1111/j.20448341.1958.tbo1968.x

Baron-Cohen, S., Leslie, A.M. \& Frith, U. (1985). Does the autistic child have a "theory of mind"? Cognition, 21, 37-46. doi: 10.1016/0010-0277(85)90022-8

Bettelheim, B. (1967). The empty fortress: Infantile autism and the birth of the self. New York: The Free Press. ISBN: 0029031400

Bregman, J. D., Dykens, E., Watson, M., Ort, S. I., \& Leckman, J. F. (1987). Fragile X syndrome: Variability of phenotypic expression. Journal of the American Academy of Child and Adolescent Psychiatry, 26, 463-471. doi: 10.1097/00004583-198707000-00001

Burt, S.A., Klahr, A.M., Rueter, M.A., McGue, M., \& lacono, W.G. (2011). Confirming the etiology of adolescent acting out behaviors: An examination of observer-ratings in a sample of adoptive and biological siblings. Journal of Child Psychology and Psychiatry, 52. doi: 10.1111/j.1469-7610.2010.02334.x

Cameron, K. (1958). A group of twenty-five psychotic children. Acta Paedopsychiatrica, 25, 117. No doi

Carrey, N. (2010). Interview with Sir Michael Rutter. Journal of the Canadian Academy of Child and Adolescent Psychiatry, 19, 212-217. No doi

Cowan, P. A., Hodinott, B. A., \& Wright, B. A. (1965). Compliance and resistance in the conditioning of autistic children: An exploratory study. Child Development, 36, 913-923. doi: 10.2307/1126933

Costello, E.J., Compton, S.N, Keeler, G. \& Angold, A. (2003). Relationships between poverty and psychopathology: a natural experiment. JAMA, 290, 2023-2029. doi: 10.1001/jama.290.15.2023

Donovan, A.P.A. \& Basson, M.A. (2017). The neuroanatomy of autism - a developmental perspective. Journal of Anatomy, 230, 4-15. doi: 10.1111/ joa.12542

Douglas, J.W.B. (1975). Early hospital admissions and later disturbances of behavior and learning. Developmental Medicine and Child Neurology, 17, 45648o. doi:10.1111/j.1469-8749.1975.tbo3497.x

Goodman, R. (1994). A modified version of the Rutter parent questionnaire including items on children's strengths: A research note. Journal of Child Psychology and Psychiatry, 35, 1483-1494. doi: 10.1111/j.14697610.1994.tbo1289.x
Goodman, R. (1997). The Strengths and Difficulties Questionnaire: a research note. Journal of Child Psychology and Psychiatry, 38, 581-586. doi: 10.1111/ j.1469- 7610.1997.tbo1545.x

Green, J. \& Yule, W. (Eds.) (2001a). Research and innovation on the road to modern child psychiatry. Volume 1: Festschrift for Professor Sir Michael Rutter. London: Royal College of Psychiatrists. ISBN-13: 9781901242621 ISBN-10: 1901242625

Green, J. \& Yule, W. (Eds.) (2001b). Research and innovation on the road to modern child psychiatry: Volume 2: Classic papers by Professor Sir Michael Rutter. London: Royal College of Psychiatrists. ISBN-13: 9781901242638 ISBN-10: 1901242633

Happé, F. \& Frith, U. (2020). Annual Research Review: Looking back to look forward - changes in the concept of autism and implications for future research. Journal of Child Psychology and Psychiatry. In press.

Holton, G. (1997). Other minds. In Wolpert, L. \& Richards, A. (1997). Passionate minds: The inner world of scientists. Oxford: Oxford University Press.

ISBN-13: 9780198549048ISBN-10: 0198549040

Kashani, J. H. \& Sherman, D. D. (1988). Childhood depression: Epidemiology, etiological models, and treatment implications. Integrative Psychiatry, 6, 1-21. No doi

King, R. D., Raynes, N. V. \& Tizard, J. (1971). Patterns of residential care: Sociological studies in institutions for handicapped children. Routledge \& Kegan Paul: Henley-on-Thames. ISBN-13: 9780710070388 ISBN-10: 0710070381

Lotter, V. (1966). Epidemiology of autistic conditions in young children: 1. Prevalence. Social Psychiatry, 1, 124-37. doi: 10.1007/BFo0584048

Medawar, P. B . (1967) The art of the soluble. London: Methuen.

ISBN-13:9780140211221 ISBN-10: 0140211225

Medawar, P. (1982). Pluto's republic. Oxford: Oxford University Press.

ISBN-13: 9780192830395 ISBN-10: 0192830392

Moffitt, T. E. (1993). Adolescent-limited and lifecourse-persistent antisocial behavior: a developmental taxonomy. Psychological Review, 100, 674-701. doi: 10.1037/0033-295X.100.4.674

Munafo, M.R., Zammit, S., \& Flint, J. (2014). Practitioner Review: A critical perspective on gene-environment interaction models - what impact should they have on clinical perceptions and practice? Journal of Child Psychology and Psychiatry, 55, 1092-1101. doi: 10.1111/ jcpp.12261 
Risch, N., Herrell, R., Lehner, T., Liang, K.Y., Eaves, L., Hoh, J., Griern, A., Kovacs, M., Ott, J. \& Merikangas, K.R. (2009). Interaction between the serotonin transporter gene (5-HTTLPR), stressful life events, and risk of depression: A meta-analysis. JAMA: The Journal of the American Medical Association, 301, 2462-2471. doi: 10.1001/jama.2009.878

Robins, L. N. (1973). Evaluation of psychiatric services for children in the United Services. In J. K. Wing and H. Hafner (eds.), Roots of Evaluation: the Epidemiological Basis for Planning Psychiatric Services (pp. 101-130). Oxford University Press: London. ISBN-13: 9780197213759 ISBN-10: 0197213758

Sackett, D.L. (1979). Bias in analytic research. Journal of Chronic Diseases, 32, 51-63. doi: 10.1016/00219681(79)90012-2

Steffenburg, S., Gillberg, C, Hellgren, L., Andersson, L., Gillberg, I., Jakobsson, G. \& Bohman, M. (1989). A twin study of autism in Denmark, Finland, Iceland, Norway and Sweden. Journal of Child Psychology and Psychiatry, 30, 405-416. doi: 10.1111/j.1469-7610.1989.tboo254.x

Tabery, J. (2015). Debating interaction: the history, and an explanation. International Journal of Epidemiology, 44, 1117-1123. doi: 10.1093/ije/dyv053

Tinbergen, N. (1974). Ethology and stress diseases. Science, 185, 20-27. doi:10.1126/science.185.4145.20

Wakefield, A.J., Murch, S.H., Anthony, A., Linnell, J., Casson, D.M., Berelowitz, M., Dhillon, A.P., Thomson, M.A., Harvey, P., Valentine, A., Davies, S.E., WalkerSmith, J.A. (1998). Ileal-lymphoid-nodular hyperplasia, non-specific colitis, and pervasive developmental disorder in children. Lancet, 351, 637-41. 


\section{Peer-reviewed papers authored or co-authored by Michael Rutter 1958-2019}

[1] Aitkin, M., Longford, N., Plewis, I. F., Wakefield, W. B., Chatfield, C., Goldstein, H., ... Smith, T. M. F. (1986). Statistical modeling issues in school effectiveness studies. Journal of the Royal Statistical Society Series A-Statistics in Society, 149, 1-43. doi:10.2307/2981882

[2] Amaral, D., Rogers, S. J., Baron-Cohen, S., Bourgeron, T., Caffo, E., Fombonne, E., ... van der Gaag, R. J. (2011). Against Le Packing: A Consensus Statement. Journal of the American Academy of Child and Adolescent Psychiatry, 50(2), 191-192. doi:10.1016/j. jaac.2010.11.018

[3] Angold, A., Erkanli, A., Costello, E. J., \& Rutter, M. (1996). Precision, reliability and accuracy in the dating of symptom onsets in child and adolescent psychopathology. Journal of Child Psychology and Psychiatry and Allied Disciplines, 37(6), 657-664. doi:10.1111/j.1469-7610.1996.tbo1457.x

[4] Angold, A., Prendergast, M., Cox, A., Harrington, R., Simonoff, E., \& Rutter, M. (1995). The child and adolescent psychiatric-assessment (CAPA). Psychological Medicine, 25(4), 739-753. doi:10.1017/ soo3329170003498x

[5] Angold, A., \& Rutter, M. (1992). Effects of age and pubertal status on depression in a large clinicalsample. Development and Psychopathology, 4(1), 5-28. doi:10.1017/s0954579400005538

[6] Anney, R., Klei, L., Pinto, D., Almeida, J., Bacchelli, E., Baird, G., ... Devlin, B. (2012). Individual common variants exert weak effects on the risk for autism spectrum disorders. Human Molecular Genetics, 21(21), 4781-4792. doi:10.1093/hmg/dds301

[7] Anney, R., Klei, L., Pinto, D., Regan, R., Conroy, J., Magalhaes, T. R., ... Hallmayer, J. (2010). A genomewide scan for common alleles affecting risk for autism. Human Molecular Genetics, 19(20), 4072-4082. doi:10.1093/hmg/ddq307

[8] Bailey, A., Bolton, P., Butler, L., Le Couteur, A., Murphy, M., Scott, S., ... Rutter, M. (1993). Prevalence of the fragile-x anomaly amongst autistic twins and singletons. Journal of Child Psychology and Psychiatry, 34(5), 673-688. doi:10.1111/j.1469-7610.1993.tbo1064.x

[9] Bailey, A., Le Couteur, A., Gottesman, I., Bolton, P., Simonoff, E., Yuzda, E., \& Rutter, M. (1995). Autism as a strongly genetic disorder - evidence from a British twin study. Psychological Medicine, 25(1), 63-77. doi:10.1017/ s0033291700028099

[10] Bailey, A., Luthert, P., Bolton, P., Le Couteur, A., Rutter, M., \& Harding, B. (1993). Autism and megalencephaly. Lancet, 341(8854), 1225-1226. doi:10.1016/0140-6736(93)91065-t
[11] Bailey, A., Luthert, P., Dean, A., Harding, B., Janota, I., Montgomery, M., ... Lantos, P. (1998). A clinicopathological study of autism. Brain, 121, 889-905. doi:10.1093/brain/121.5.889

[12] Bailey, A., Phillips, W., \& Rutter, M. (1996). Autism: Towards an integration of clinical, genetic, neuropsychological, and neurobiological perspectives. Journal of Child Psychology and Psychiatry, 37(1), 89-126. doi:10.1111/j.1469-7610.1996.tbo1381.x

[13] Bailey, A., \& Rutter, M. (1991). Autism. Science Progress (1933- ),75(3/4 (298)), 389-402. Retrieved from www.jstor.org/stable/43421280

[14] Bartak, L., \& Rutter, M. (1973). Special educational treatment of autistic-children - comparative study .1. Design of study and characteristics of units. Journal of Child Psychology and Psychiatry, 14(3), 161-179. doi:10.1111/j.1469-7610.1973.tbo1185.x

[15] Bartak, L., \& Rutter, M. (1974). Use of personal pronouns by autistic children. Journal of Autism and Childhood Schizophrenia, 4(3), 217-222. doi:10.1007/ bfo2115227

[16] Bartak, L., \& Rutter, M. (1976). Differences between mentally-retarded and normally intelligent autisticchildren. Journal of Autism and Childhood Schizophrenia, 6(2), 109-120. doi:10.1007/bfo1538054

[17] Bartak, L., Rutter, M., \& Cox, A. (1975). A Comparative Study of Infantile Autism and Specific Developmental Receptive Language Disorder: I. The Children. British Journal of Psychiatry, 126(FEB), 127-145. doi:10.1192/bjp.126.2.127

[18] Bartak, L., Rutter, M., \& Cox, A. (1977). Comparative-study of infantile-autism and specific developmental receptive language disorders .3. Discriminant function analysis. Journal of Autism and Childhood Schizophrenia, 7(4), 383-396. doi:10.1007/ bfo1540396

[19] Beckett, C., Bredenkamp, D., Castle, J., Groothues, C., O'Connor, T. G., Rutter, M., \& the E.R.A. Study Team (2002). Behavior patterns associated with institutional deprivation: A study of children adopted from Romania. Journal of Developmental and Behavioral Pediatrics, 23(5), 297-303. doi:10.1097/00004703200210000-00001

[20] Beckett, C., Castle, J., Rutter, M., \& Sonuga-Barke, E. J. S. (2010). VI. Institutional deprivation, specific cognitive functions, and scholastic achievement: English and Romanian adoptee (ERA) study findings. Monographs of the Society for Research in Child Development, 75(1), 125-142. doi:10.1111/j.15405834.2010.00553.x 
[21] Beckett, C., Maughan, B., Rutter, M., Castle, J., Colvert, E., Groothues, C., .. . Sonuga-Barke, E. J. S. (2007). Scholastic attainment following severe early institutional deprivation: A study of children adopted from Romania. Journal of Abnormal Child Psychology, 35(6), 1063-1073. doi:10.1007/s10802-007-9155-y

[22] Beckett, C., Maughan, B., Rutter, M., Castle, J., Colvert, E., Groothues, C., ... Sonuga-Barke, E. J. S. (2006). Do the effects of early severe deprivation on cognition persist into early adolescence? Findings from the English and Romanian adoptees study. Child Development, 77(3), 696-711. doi:10.1111/j.14678624.2006.00898.x

[23] Bekkhus, M., Rutter, M., Barker, E. D., \& Borge, A. I. H. (2011). The role of pre- and postnatal timing of family risk factors on child behavior at 36 months. Journal of Abnormal Child Psychology, 39(4), 611-621. doi:10.1007/s10802-010-9477-z

[24] Bekkhus, M., Rutter, M., Maughan, B., \& Borge, A. I. H. (2011). The effects of group daycare in the context of paid maternal leave and high-quality provision.

European Journal of Developmental Psychology, 8(6), 681696. doi:10.1080/17405629.2011.602232

[25] Berger, M., Yule, W., \& Rutter, M. (1975).

Attainment and adjustment in 2 geographical areas .2. Prevalence of specific reading retardation. British Journal of Psychiatry, 126(JUN), 510-519. doi:10.1192/ bjp.126.6.510

[26] Berument, S. K., Rutter, M., Lord, C., Pickles, A., \& Bailey, A. (1999). Autism screening questionnaire: diagnostic validity. British Journal of Psychiatry, 175, 444451. doi:10.1192/bjp.175.5.444

[27] Berument, S. K., Starr, E., Pickles, A., Tomlins, M., Papanikolauou, K., Lord, C., \& Rutter, M. (2005). Pre-linguistic autism diagnostic observation schedule adapted for older individuals with severe to profound mental retardation: A pilot study. Journal of Autism and Developmental Disorders, 35(6), 821-829. doi:10.1007/ s10803-005-0027-4

[28] Bolton, P., Carcani-Rathwell, I., Hutton, J., Goode, S., Howlin, P., \& Rutter, M. (2011). Epilepsy in autism: features and correlates. British Journal of Psychiatry, 198(4), 289-294. doi:10.1192/bjp.bp.109.076877

[29] Bolton, P., Macdonald, H., Pickles, A., Rios, P., Goode, S., Crowson, M., ... Rutter, M. (1994). A case - control family history study of autism. Journal of Child Psychology and Psychiatry, 35(5), 877-900. doi:10.1111/j.1469-7610.1994.tbo230o.x
[30] Bolton, P., Murphy, M., Macdonald, H., Whitlock, B., Pickles, A., \& Rutter, M. (1997). Obstetric complications in autism: Consequences or causes of the condition? Journal of the American Academy of Child and Adolescent Psychiatry, 36(2), 272-281. doi:10.1097/00004583-199702000-00018

[31] Bolton, P., Pickles, A., Butler, L., Summers, D., Webb, T., Lord, C., ... Rutter, M. (1992). Fragile-x in families multiplex for autism and related phenotypes - prevalence and criteria for cytogenetic diagnosis. Psychiatric Genetics, 2(4), 277-300. doi:10.1097/00041444-199210000-00005

[32] Bolton, P., Pickles, A., Harrington, R., Macdonald, H., \& Rutter, M. (1992). Season of birth - issues, approaches and findings for autism. Journal of Child Psychology and Psychiatry, 33(3), 509-530. doi:10.1111/j.1469-7610.1992.tboo888.x

[33] Bolton, P., Pickles, A., Murphy, M., \& Rutter, M. (1998). Autism, affective and other psychiatric disorders: patterns of familial aggregation.

Psychological Medicine, 28(2), 385-395. doi:10.1017/ so033291797006004

[34] Bolton, P., Powell, J., Rutter, M., Buckle, V., Yates, J. R. W., Ishikawabrush, Y., \& Monaco, A. P. (1995). Autism, mental-retardation, multiple exostoses and short stature in a female with 46,X,T(X-8)(P22.13-Q22.1). Psychiatric Genetics, 5(2), 51-55. doi:10.1097/00041444199522000-00001

[35] Bolton, P. \& Rutter, M. (1990). Genetic influences on autism. International Review of Psychiatry, 2, 67-80. doi:10.3109/09540269009028273.

[36] Bolton, P., Rutter, M., Butler, L., \& Summers, D. (1989). Females with autism and the fragile-x. Journal of Autism and Developmental Disorders, 19(3), 473-476. doi:10.1007/bfo2212946

[37] Bonora, E., Lamb, J. A., Barnby, G., Sykes, N., Moberly, T., Beyer, K. S., . . Imgsac. (2005). Mutation screening and association analysis of six candidate genes for autism on chromosome 7q. European Journal of Human Genetics, 13(2), 198-207. doi:10.1038/ sj.ejhg.5201315

[38] Borge, A. I. H., Rutter, M., Cote, S., \& Tremblay, R. E. (2004). Early childcare and physical aggression: differentiating social selection and social causation. Journal of Child Psychology and Psychiatry, 45(2), 367376. doi:10.1111/j.1469-7610.2004.00227.x

[39] Boullin, D., Freeman, B. J., Geller, E., Ritvo, E., Rutter, M., \& Yuwiler, A. (1982). Towards the resolution of conflicting findings. Journal of Autism and Developmental Disorders, 12(1), 97-98. doi:10.1007/ bfol531680 
[40] Brown, G. \& Rutter, M. (1966). The measurement of family activities and relationships: A methodological study. Human Relations, 19(3), 241-263. doi:10.1177\% 2Fo01872676601900301

[41] Brown, G., Chadwick, O., Shaffer, D., Rutter, M., \& Traub, M. (1981). A prospective-study of children with head-injuries: 3. Psychiatric sequelae. Psychological Medicine, 11(1), 63-78. doi:10.1017/s0033291700053289

[42] Cantwell, D., Baker, L., \& Rutter, M. (1977). Families of autistic and dysphasic children .2. Mothers speech to children. Journal of Autism and Childhood Schizophrenia, 7(4), 313-327. doi:10.1007/bfo1540390

[43] Cantwell, D., Baker, L., \& Rutter, M. (1978). Comparative-study of infantile-autism and specific developmental receptive language disorder .4 . Analysis of syntax and language function. Journal of Child Psychology and Psychiatry, 19(4), 351-362. doi:10.1111/j.1469-7610.1978.tboo481.x

[44] Cantwell, D., Baker, L., \& Rutter, M. (1979). Families of autistic and dysphasic children: 1. Family-life and interaction patterns. Archives of General Psychiatry, 36(6), 682-687. doi:10.1001/ archpsyc.1979.01780060072008

[45] Cantwell, D., Baker, L., Rutter, M., \& Mawhood, L. (1989). Infantile-autism and developmental receptive dysphasia - a comparative follow-up into middle childhood. Journal of Autism and Developmental Disorders, 19(1), 19-31. doi:10.1007/bfo2212715

[46] Cantwell, D., Howlin, P., \& Rutter, M. (1977). Analysis of language level and language function - methodological study. British Journal of Disorders of Communication, 12(2), 119-135. doi:10.3109/13682827709011316

[47] Carbonneau, R., Eaves, L. J., Silberg, J. L., Simonoff, E., \& Rutter, M. (2002). Assessment of the within-family environment in twins: absolute versus differential ratings, and relationship with conduct problems. Journal of Child Psychology and Psychiatry, 43(8), 1064-1074. doi:10.1111/1469-7610.00233

[48] Carbonneau, R., Rutter, M., Silberg, J. L., Simonoff, E., \& Eaves, L. J. (2002). Assessment of genetic and environmental influences on differential ratings of within-family experiences and relationships in twins. Psychological Medicine, 32(4), 729-741. doi:10.1017/ so033291702005639

[49] Caron, C., \& Rutter, M. (1991). Comorbidity in child psychopathology - concepts, issues and research strategies. Journal of Child Psychology and Psychiatry, 32(7), 1063-1080. doi:10.1111/j.1469-7610.1991.tboo350.x
[50] Casey, J. P., Magalhaes, T., Conroy, J. M., Regan, R., Shah, N., Anney, R., ... Ennis, S. (2012). A novel approach of homozygous haplotype sharing identifies candidate genes in autism spectrum disorder. Human Genetics, 131(4), 565-579. doi:10.1007/s00439-011-1094-6

[51] Caspi, A., Langley, K., Milne, B., Moffitt, T. E., O'Donovan, M., Owen, M. J., ... Thapar, A. (2008). A replicated molecular genetic basis for subtyping antisocial behavior in children with attention-deficit/ hyperactivity disorder. Archives of General Psychiatry, 65(2), 203-210. doi:10.1001/archgenpsychiatry.2007.24

[52] Caspi, A., Moffitt, T. E., Morgan, J., Rutter, M., Taylor, A., Arseneault, L., ... Polo-Tomas, M. (2004). Maternal expressed emotion predicts children's antisocial behavior problems: Using monozygotictwin differences to identify environmental effects on behavioral development. Developmental Psychology, 40(2), 149-161. doi:10.1037/0012-1649.40.20.149

[53] Castle, J., Beckett, C., Rutter, M., \& SonugaBarke, E. J. S. (2010). VIII. Postadoption environmental features. Monographs of the Society for Research in Child Development, 75(1), 167-186. doi:10.1111/j.15405834.2010.00555.x

[54] Castle, J., Groothues, C., Beckett, C., Colvert, E., Hawkins, A., Kreppner, J., . . . Rutter, M. (2009). Parents' evaluation of adoption success: a follow-up study of intercountry and domestic adoptions. American Journal of Orthopsychiatry, 79(4), 522-531. doi:10.1037/a0017262

[55] Castle, J., Groothues, C., Bredenkamp, D., Beckett, C., O'Connor, T., Rutter, M., \& the E.R.A. Study Team (1999). Effects of qualities of early institutional care on cognitive attainment. American Journal of Orthopsychiatry, 69(4), 424-437. doi:10.1037/hoo80391

[56] Chadwick, O., Rutter, M., Brown, G., Shaffer, D., \& Traub, M. (1981). A prospective-study of children with head-injuries .2. Cognitive sequelae. Psychological Medicine, $11(1)$, 49-61. doi:10.1017/s0033291700053277

[57] Chadwick, O., Rutter, M., Thompson, J., \& Shaffer, D. (1981). Intellectual-performance and readingskills after localized head-injury in childhood. Journal of Child Psychology and Psychiatry, 22(2), 117-139. doi:10.1111/j.1469-7610.1981.tboo538.x

[58] Chadwick, O., Rutter, M., Shaffer, D. \& Shrout, P.E. (1981). A prospective study of children with head injuries. IV. Specific cognitive deficits. Journal of Clinical Neuropsychology, 3, 101-120. doi: 10.1080/01688638108403117

[59] Champion, L. A., Goodall, G., \& Rutter, M. (1995). Behavior problems in childhood and stressors in early adult life .1. A 20-year follow-up of London school-children. Psychological Medicine, 25(2), 231-246. doi:10.1017/s003329170003614X 
[6o] Chess, S., Thomas, A., Rutter, M., \& Birch, H. G. (1963). Interaction of temperament and environment in the production of behavioral disturbances in children. Amer Jour Psychiat, 120((2)), 142-148. doi:10.1176/ ajp.120.2.142

[61] Clark, P., \& Rutter, M. (1977). Compliance and resistance in autistic-children. Journal of Autism and Childhood Schizophrenia, 7(1), 33-48. doi:10.1007/ bfols31113

[62] Clark, P., \& Rutter, M. (1979). Task-difficulty and task-performance in autistic-children. Journal of Child Psychology and Psychiatry, 20(4), 271-285. doi:10.1111/j.1469-7610.1979.tboo514.x

[63] Clark, P., \& Rutter, M. (1981). Autistic childrens responses to structure and to interpersonal demands. Journal of Autism and Developmental Disorders, 11(2), 201-217. doi:10.1007/bfo1531685

[64] Clegg, J., Hollis, C., Mawhood, L., \& Rutter, M. (2005). Developmental language disorders a follow-up in later adult life. Cognitive, language and psychosocial outcomes. Journal of Child Psychology and Psychiatry, 46(2), 128-149. doi:10.1111/j.1469-7610.2004.00342.x

[65] Collishaw, S., Pickles, A., Messer, J., Rutter, M., Shearer, C., \& Maughan, B. (2007). Resilience to adult psychopathology following childhood maltreatment: Evidence from a community sample. Child Abuse \& Neglect, 31(3), 211-229. doi:10.1016/j.chiabu.2007.02.004

[66] Colvert, E., Rutter, M., Beckett, C., Castle, J., Groothues, C., Hawkins, A., ... Sonuga-Barke, E. J. S. (2008). Emotional difficulties in early adolescence following severe early deprivation: Findings from the English and Romanian adoptees study. Development and Psychopathology, 20(2), 547-567. doi:10.1017/ so9545794080oo278

[67] Colvert, E., Rutter, M., Kreppner, J., Beckett, C., Castle, J., Groothues, C., ... Sonuga-Barke, E. J. S. (2008). Do Theory of Mind and executive function deficits underlie the adverse outcomes associated with profound early deprivation? Findings from the English and Romanian adoptees study. Journal of Abnormal Child Psychology, 36(7), 1057-1068. doi:10.1007/s10802008-9232-x

[68] Cote, S. M., Borge, A. I., Geoffroy, M. C., \& Rutter, M. (2008). Nonmaternal care in infancy and emotional/ behavioral difficulties at 4 years old: Moderation by family risk characteristics. Developmental Psychology, 44(1), 155-168. doi:10.1037/0012-1649.44.1.155

[69] Cottler, L. B., Regier, D. A., Helzer, J. E., Earls, F. J., Wells, J. E., Sartorius, N., ... Zorumski, C. F. (2010). A tribute to Lee Nelken Robins: from colleagues and friends OBITUARY. Social Psychiatry and Psychiatric Epidemiology, 45(7), 681-693. doi:10.1007/s00127-0100243-X
[70] Cox, A., Holbrook, D., \& Rutter, M. (1981). Psychiatric interviewing techniques .6. Experimentalstudy - eliciting feelings. British Journal of Psychiatry, 139(AUG), 144-152. doi:10.1192/bjp.139.2.144

[71] Cox, A., Hopkinson, K., \& Rutter, M. (1981). Psychiatric interviewing techniques .2. Naturalistic study - eliciting factual information. British Journal of Psychiatry, 138(APR), 283-291. doi:10.1192/bjp.138.4.283

[72] Cox, A., Rutter, M., \& Holbrook, D. (1981). Psychiatric interviewing techniques .5. Experimentalstudy - eliciting factual information. British Journal of Psychiatry, 139(JUL), 29-37. doi:10.1192/bjp.139.1.29

[73] Cox, A., Rutter, M., \& Holbrook, D. (1988). Psychiatric interviewing techniques - A 2nd experimental-study - eliciting feelings. British Journal of Psychiatry, 152, 64-72. doi:10.1192/bjp.152.1.64

[74] Cox, A., Rutter, M., Newman, S., \& Bartak, L. (1975). Comparative study of infantile autism and specific developmental receptive language disorder .2. Parental characteristics. British Journal of Psychiatry, 126(, 146159. doi:10.1192/bjp.126.2.146

[75] Cox, A., Rutter, M., Yule, B., \& Quinton, D. (1977). Bias resulting from missing information - some epidemiological findings. British Journal of Preventive \& Social Medicine, 31(2), 131-136. doi:10.1136/jech.31.2.131

[76] Croft, C., Beckett, C., Rutter, M., Castle, J., Colvert, E., Groothues, C., . . Sonuga-Barke, E. J. S. (2007). Early adolescent outcomes of institutionallydeprived and non-deprived adoptees. II: Language as a protective factor and a vulnerable outcome. Journal of Child Psychology and Psychiatry, 48(1), 31-44. doi:10.1111/ j.1469-7610.2006.01689.x

[77] Croft, C., O'Connor, T. G., Keaveney, L., Groothues, C., Rutter, M., English, \& the Romanian Adoption Study Team (2001). Longitudinal change in parenting associated with developmental delay and catch-up. Journal of Child Psychology and Psychiatry, 42(5), 649-659. doi:10.1017/s0021963001007417

[78] de Jonge, M., Parr, J., Rutter, M., Wallace, S., Kemner, C., Bailey, A., ... Pickles, A. (2015). New interview and observation measures of the broader autism phenotype: group differentiation. Journal of Autism and Developmental Disorders, 45(4), 893-901. doi:10.1007/s10803-014-2230-7

[79] Dilavore, P. C., Lord, C., \& Rutter, M. (1995). The pre-linguistic Autism Diagnostic Observation Schedule. Journal of Autism and Developmental Disorders, 25(4), 355-379. doi:10.1007/bfo2179373

[8o] Dowdney, L., Mrazek, D., Quinton, D., \& Rutter, M. (1984). Observation of parent child interaction with 2-year-olds to 3-year-olds. Journal of Child Psychology and Psychiatry and Allied Disciplines, 25(3), 379-407. doi:10.1111/j.1469-7610.1984.tbool59.x 
[81] Dowdney, L., Skuse, D., Rutter, M., Quinton, D., \& Mrazek, D. (1985). The nature and qualities of parenting provided by women raised in institutions. Journal of Child Psychology and Psychiatry, 26(4), 599-625. doi:10.1111/j.1469-7610.1985.tbo1644.x

[82] Eaves, L. J., Rutter, M., Silberg, J. L., Shillady, L., Maes, H., \& Pickles, A. (2000). Genetic and environmental causes of covariation in interview assessments of disruptive behavior in child and adolescent twins. Behavior Genetics, 30(4), 321-334. doi:10.1023/a:1026553518272

[83] Eaves, L. J., Silberg, J. L., Hewitt, J. K., Rutter, M., Meyer, J. M., Neale, M. C., \& Pickles, A. (1993). Analyzing twin resemblance in multisymptom data - genetic applications of a latent class model for symptoms of conduct disorder in juvenile boys. Behavior Genetics, 23(1), 5-19. doi:10.1007/bfo1067550

[84] Eaves, L. J., Silberg, J. L., Meyer, J. M., Maes, H. H., Simonoff, E., Pickles, A., ... Hewitt, J. K. (1997). Genetics and developmental psychopathology .2. The main effects of genes and environment on behavioral problems in the Virginia Twin Study Of Adolescent Behavioral Development. Journal of Child Psychology and Psychiatry, 38(8), 965-980. doi:10.1111/j.1469-7610.1997.tbo1614.x

[85] Elander, J., \& Rutter, M. (1996a). Use and development of the Rutter parents' and teachers' scales. International Journal of Methods in Psychiatric Research, 6(2), 63-78. doi:10.1002/(sici)1234988x(199607)6:2<63::aid-mpr151>3.3.co;2-m

[86] Elander, J. \& Rutter, M. (1996b). An update on the status of the Rutter parents' and teachers' scales. Child Psychology and Psychiatry Review, 1, 31-35 No doi

[87] Elander, J., Rutter, M., Simonoff, E., \& Pickles, A. (2000). Explanations for apparent late onset criminality in a high-risk sample of children followed up in adult life. British Journal of Criminology, 40(3), 497-509. doi:10.1093/bjc/40.3.497

[88] Elander, J., Simonoff, E., Pickles, A., Holmshaw, J. \& Rutter, M. (2000). Longitudinal study of adolescent and adult conviction rates among children referred to psychiatric services for behavioural or emotional problems. Criminal Behaviour and Mental Health, 10, 4059. doi: $10.1002 / \mathrm{cbm} .342$

[89] Foley, D. L., Pickles, A., Rutter, M., Gardner, C. O., Maes, H. H., Silberg, J. L., \& Eaves, L. J. (2004). Risks for conduct disorder symptoms associated with parental alcoholism in stepfather families versus intact families from a community sample. Journal of Child Psychology and Psychiatry, 45(4), 687-696. doi:10.1111/j.14697610.2004.00263.x

[9o] Foley, D. L., Rutter, M., Angold, A., Pickles, A., Maes, H. M., Silberg, J. L., \& Eaves, L. J. (2005). Making sense of informant disagreement for overanxious disorder. Journal of Anxiety Disorders, 19(2), 193-210. doi:10.1016/j.janxdis.2004.01.006

[91] Foley, D. L., Rutter, M., Pickles, A., Angold, A., Maes, H., Silberg, J., \& Eaves, L. (2004). Informant disagreement for separation anxiety disorder. Journal of the American Academy of Child and Adolescent Psychiatry, 43(4), 452-460. doi:10.1097/01. CHI.0000112482.08386.d7

[92] Folstein, S. E., \& Rutter, M. (1977a). Genetic influences and infantile-autism. Nature, 265(5596), 726728. doi:10.1038/265726ao

[93] Folstein, S. E., \& Rutter, M. (1977b). Infantileautism - genetic study of 21 twin pairs. Journal of Child Psychology and Psychiatry, 18(4), 297-321. doi:10.1111/j.1469-7610.1977.tboo443.x

[94] Folstein, S. E., \& Rutter, M. (1988). Autism - familial aggregation and genetic-implications. Journal of Autism and Developmental Disorders, 18(1), 3-30. doi:10.1007/ bfo2211815

[95] Fombonne, E., Bolton, P., Prior, J., Jordan, H., \& Rutter, M. (1997). A family study of autism: Cognitive patterns and levels in parents and siblings. Journal of Child Psychology and Psychiatry, 38(6), 667-683. doi:10.1111/j.1469-7610.1997.tbo1694.x

[96] Fombonne, E., Wostear, G., Cooper, V., Harrington, R., \& Rutter, M. (2001a). The Maudsley long-term follow-up of child and adolescent depression 1. Psychiatric outcomes in adulthood. British Journal of Psychiatry, 179, 210-217. doi:10.1192/bjp.179.3.210

[97] Fombonne, E., Wostear, G., Cooper, V., Harrington, R., \& Rutter, M. (2001b). The Maudsley long-term follow-up of child and adolescent depression 2. Suicidality, criminality and social dysfunction in adulthood. British Journal of Psychiatry, 179, 218-223. doi:10.1192/bjp.179.3.218

[98] Fox, N. A., \& Rutter, M. (2010). Introduction to the Special Section on The Effects of Early Experience on Development. Child Development, 81(1), 23-27. doi:10.1111/j.1467-8624.2009.01379.x

[99] Fox, R., Rutter, M., \& Smith, E. B. O. (1960). Psychiatric day hospitals. The Lancet, 275(7128), 824-825. doi:10.1016/s0140-6736(60)90701-7

[100] Geoffroy, M. C., Cote, S. M., Borge, A. I. H., Larouche, F., Seguin, J. R., \& Rutter, M. (2007).

Association between nonmaternal care in the first year of life and children's receptive language skills prior to school entry: the moderating role of socioeconomic status. Journal of Child Psychology and Psychiatry, 48(5), 490-497. doi:10.1111/j.1469-7610.2006.01704.x

[101] Gilchrist, A., Green, J., Cox, A., Burton, D., Rutter, M., \& Le Couteur, A. (2001). Development and current 
functioning in adolescents with Asperger syndrome: A comparative study. Journal of Child Psychology and Psychiatry, 42(2), 227-240. doi:10.1111/1469-7610.00714

[102] Golombok, S., MacCallum, F., Goodman, E., \& Rutter, M. (2002). Families with children conceived by donor insemination: A follow-up at age twelve. Child Development, 73(3), 952-968. doi:10.1111/14678624.00449

[103] Golombok, S., Spencer, A., \& Rutter, M. (1983). Children in lesbian and single-parent households psychosexual and psychiatric appraisal. Journal of Child Psychology and Psychiatry and Allied Disciplines, 24(4), 551-572. doi:10.1111/j.1469-7610.1983.tboo132.x

[104] Goode, S, Howlin, P. \& Rutter, M. (1987). A follow-up-study of cognitive and social outcome in autism. International Journal of Rehabilitation Research, 10, 455-457. doi:10.1097/00004356-198712000-00025

[105] Graham, P., \& Rutter, M. (1968a). Organic brain dysfunction and child psychiatric disorder. British medical journal, 3(5620), 695-700. doi:10.1136/ bmj.3.5620.695

[106] Graham, P., \& Rutter, M. (1968b). The reliability and validity of the psychiatric assessment of the child: II. Interview with the parent. British Journal of Psychiatry, 114((510)), 581-592. doi:10.1192/bjp.114.510.581

[107] Graham, P., \& Rutter, M. (1973). Psychiatricdisorder in young adolescent - follow-up study. Proceedings of the Royal Society of Medicine-London, 66(12), 1226-1229. doi:10.1177/003591577306601232

[108] Graham, P., Rutter, M., \& George, S. (1973). Temperamental characteristics as predictors of behavior disorders in children. American Journal of Orthopsychiatry, 43(3), 328-339. doi:10.1111/j.1939-0025.1973.tboo8o2.x

[109] Graham, P., Rutter, M., Yule, W., \& Pless, I. B. (1967). Childhood asthma: a psychosomatic disorder? Some epidemiological considerations. British journal of preventive \& social medicine, 21(2), 78-85. doi:10.1136/ jech.21.2.78

[110] Gray, R., Mukherjee, R. A. S., \& Rutter, M. (2009). Alcohol consumption during pregnancy and its effects on neurodevelopment: what is known and what remains uncertain. Addiction, 104(8), 1270-1273. doi:10.1111/j.1360-0443.2008.02441.x

[111] Gurling, H. M. D., Bolton, P. F., Vincent, J., Melmer, G., \& Rutter, M. (1997). Molecular and cytogenetic investigations of the fragile $X$ region including the Frax $A$ and Frax E CGG trinucleotide repeat sequences in families multiplex for autism and related phenotypes. Human Heredity, 47(5), 254-262. doi:10.1159/000154421

[112] Gustavson, K., Ystrom, E., Stoltenberg, C., Susser, E., Suren, P., Magnus, P., Knudsen, G.P, Davey Smith,
G., Langley, K., Rutter, M., Aase, H. \& ReichbornKjennerud, T. (2017). Smoking in pregnancy and child ADHD. Pediatrics, 139(2). doi:10.1542/peds.2016-2509

[113] Hardt, J., \& Rutter, M. (2004). Validity of adult retrospective reports of adverse childhood experiences: review of the evidence. Journal of Child Psychology and Psychiatry, 45(2), 260-273. doi:10.1111/j.14697610.2004.00218.x

[114] Harrington, R., Bredenkamp, D., Groothues, C., Rutter, M., Fudge, H., \& Pickles, A. (1994). Adult outcomes of childhood and adolescent depression .3. Links with suicidal behaviors. Journal of Child Psychology and Psychiatry, 35(7), 1309-1319. doi:10.1111/j.1469-7610.1994.tbo1236.x

[115] Harrington, R., Fudge, H., Rutter, M., Pickles, A., \& Hill, J. (1990). Adult outcomes of childhood and adolescent depression .1. Psychiatric status. Archives of General Psychiatry, 47(5), 465-473. doi:10.1001/ archpsyc.1990.01810170065010

[116] Harrington, R., Fudge, H., Rutter, M., Pickles, A., \& Hill, J. (1991). Adult outcomes of childhood and adolescent depression .2. Links with antisocial disorders. Journal of the American Academy of Child and Adolescent Psychiatry, 30(3), 434-439. doi:10.1097/00004583-199105000-00013

[117] Harrington, R., Fudge, H., Rutter, M. L., Bredenkamp, D., Groothues, C., \& Pridham, J. (1993). Child and adult depression - a test of continuities with data from a family study. British Journal of Psychiatry, 162, 627-633. doi:10.1192/bjp.162.5.627

[118] Harrington, R., Hill, J., Rutter, M., John, K., Fudge, H., Zoccolillo, M., \& Weissman, M. (1988). The assessment of lifetime psychopathology - a comparison of 2 interviewing styles. Psychological Medicine, 18(2), 487-493. doi:10.1017/s0033291700008023

[119] Harrington, R., Rutter, M., \& Fombonne, E. (1996). Developmental pathways in depression: Multiple meanings, antecedents, and endpoints. Development and Psychopathology, 8(4), 601-616. doi:10.1017/ s095457940000732x

[120] Harrington, R., Rutter, M., Weissman, M., Fudge, H., Groothues, C., Bredenkamp, D., ... Wickramaratne, P. (1997). Psychiatric disorders in the relatives of depressed probands.1. Comparison of prepubertal, adolescent and early adult onset cases. Journal of Affective Disorders, 42(1), 9-22. doi:10.1016/s01650327(96)00091-2

[121] Heavey, L., Phillips, W., Baron-Cohen, S., \& Rutter, M. (2000). The Awkward Moments Test: A naturalistic measure of social understanding in autism. Journal of Autism and Developmental Disorders, 30(3), 225-236. doi:10.1023/a:1005544518785 
[122] Herold, S., Frackowiak, R. S. J., Le Couteur, A., Rutter, M., \& Howlin, P. (1988). Cerebral blood-flow and metabolism of oxygen and glucose in young autistic adults. Psychological Medicine, 18(4), 823-831. doi:10.1017/so033291700009752

[123] Hewitt, J. K., Silberg, J. L., Rutter, M., Simonoff, E., Meyer, J. M., Maes, H., Neale, M.C., Erickson, M.T., Kendler, K.S., Truett, K.R. \& Eaves, L. J. (1997). Genetics and developmental psychopathology .1. Phenotypic assessment in the Virginia twin study of adolescent behavioral development. Journal of Child Psychology and Psychiatry, 38(8), 943-963. doi:10.1111/j.1469-7610.1997.tbo1613.x

[124] Hill, J., Fudge, H., Harrington, R., Pickles, A., \& Rutter, M. (1995). The Adult Personality Functioning Assessment (APFA) - factors influencing agreement between subject and informant. Psychological Medicine, 25(2), 263-275. doi:10.1017/s0033291700036163

[125] Hill, J., Fudge, H., Harrington, R., Pickles, A., \& Rutter, M. (2000). Complementary approaches to the assessment of personality disorder - The personality assessment schedule and adult personality functioning assessment compared. British Journal of Psychiatry, 176, 434-439. doi:10.1192/bjp.176.5.434

[126] Hill, J., Harrington, R., Fudge, H., Rutter, M., \& Pickles, A. (1989). Adult Personality Functioning Assessment (APFA) - an investigator-based standardized interview. British Journal of Psychiatry, 155, 24-35. doi:10.1192/bjp.155.1.24

[127] Honda, H., Shimizu, Y., \& Rutter, M. (2005). No effect of MMR withdrawal on the incidence of autism: a total population study. Journal of Child Psychology and Psychiatry, 46(6), 572-579. doi:10.1111/j.1469$7610.2005 .01425 \cdot x$

[128] Hopkinson, K., Cox, A., \& Rutter, M. (1981). Psychiatric interviewing techniques .3. Naturalistic study - eliciting feelings. British Journal of Psychiatry, 138(MAY), 406-415. doi:10.1192/bjp.138.5.406

[129] Howlin, P., Cantwell, D., Marchant, R., Berger, M. \& Rutter, M. (1973). Analyzing mothers' speech to young autistic children: a methodological study. Journal of Abnormal Child Psychology, 1, 317-339. doi:10.1007/ BFoog17631

[130] Howlin, P., Goode, S., Hutton, J., \& Rutter, M. (2004). Adult outcome for children with autism. Journal of Child Psychology and Psychiatry, 45(2), 212-229. doi:10.1111/j.1469-7610.2004.00215.x

[131] Howlin, P., Goode, S., Hutton, J., \& Rutter, M. (2009). Savant skills in autism: psychometric approaches and parental reports. Philosophical Transactions of the Royal Society B-Biological Sciences, 364(1522), 1359-1367. doi:10.1098/rstb.2008.0328
[132] Howlin, P., Marchant, R., Rutter, M., Berger, M., Hersov, L., \& Yule, W. (1973). Home-based approach to treatment of autistic children. Journal of Autism and Childhood Schizophrenia, 3(4), 308-336. doi:10.1007/ bfol538540

[133] Howlin, P., Mawhood, L., \& Rutter, M. (2000). Autism and developmental receptive language disorder - a follow-up comparison in early adult life. II: Social, behavioural, and psychiatric outcomes. Journal of Child Psychology and Psychiatry, 41(5), 561-578. doi:10.1111/1469-7610.00643

[134] Howlin, P., Moss, P., Savage, S., Bolton, P., \& Rutter, M. (2015). Outcomes in adult life among siblings of individuals with autism. Journal of Autism and Developmental Disorders, 45(3), 707-718. doi:10.1007/ s10803-014-2224-5

[135] Howlin, P., Moss, P., Savage, S., \& Rutter, M. (2013). Social outcomes in mid- to later adulthood among individuals diagnosed with autism and average nonverbal IQ as children. Journal of the American Academy of Child and Adolescent Psychiatry, 52(6), 572581. doi:10.1016/j.jaac.2013.02.017

[136] Howlin, P., \& Rutter, M. (1989). Mothers speech to autistic-children - a preliminary causal-analysis. Journal of Child Psychology and Psychiatry, 30(6), 819-843. doi:10.1111/j.1469-7610.1989.tboo285.x

[137] Howlin, P., Savage, S., Moss, P., Tempier, A., \& Rutter, M. (2014). Cognitive and language skills in adults with autism: a 40-year follow-up. Journal of Child Psychology and Psychiatry, 55(1), 49-58. doi:10.1111/ jcpp.12115

[138] Hutton, J., Goode, S., Murphy, M., Le Couteur, A., \& Rutter, M. (2008). New-onset psychiatric disorders in individuals with autism. Autism, 12(4), 373-390. doi:10.1177/1362361308091650

[139] International Molecular Genetic Study of Autism Consortium. (1998). A full genome screen for autism with evidence for linkage to a region on chromosome 79. Human Molecular Genetics, 7, 571-578. doi: 10.1093/ $\mathrm{hmg} / 7 \cdot 3 \cdot 571$

[140] Jacobson, R., Le Couteur, A., Howlin, P., \& Rutter, M. (1988). Selective subcortical abnormalities in autism. Psychological Medicine, 18(1), 39-48. doi:10.1017/ so03329170000186o

[141] Jaffee, S. R., Caspi, A., Moffitt, T. E., Dodge, K. A., Rutter, M., Taylor, A., \& Tully, L. A. (2005). Nature $X$ nurture: Genetic vulnerabilities interact with physical maltreatment to promote conduct problems. Development and Psychopathology, 17(1), 67-84. doi:10.1017/s0954579405050042

[142] Jefferson, M., \& Rutter, M. L. (1958). A report of two cases of the juvenile form of amaurotic familial idiocy (cerebromacular degeneration). Journal of 
neurology, neurosurgery, and psychiatry, 21(1), 31-37. doi:10.1136/jnnp.21.1.31

[143] Kennedy, M., Kreppner, J., Knights, N., Kumsta, R., Maughan, B., Golm, D., .. . Sonuga-Barke, E. (2017). Adult disinhibited social engagement in adoptees exposed to extreme institutional deprivation: examination of its clinical status and functional impact. British Journal of Psychiatry, 211(5), 289-295. doi:10.1192/ bjp.bp.117.200618

[144] Kennedy, M., Kreppner, J., Knights, N., Kumsta, R., Maughan, B., Golm, D., ... Sonuga-Barke, E. J. S. (2016). Early severe institutional deprivation is associated with a persistent variant of adult attentiondeficit/hyperactivity disorder: clinical presentation, developmental continuities and life circumstances in the English and Romanian Adoptees study. Journal of Child Psychology and Psychiatry, 57(10), 1113-1125. doi:10.1111/jcpp.12576

[145] Kenyon, F. E., \& Rutter, M. L. (1963). The psychiatrist and the general hospital. Comprehensive Psychiatry, 4, 80-89. doi:10.1016/soo10440x(63)80089-9

[146] Kim-Cohen, J., Caspi, A., Rutter, M., Tomas, M. P., \& Moffitt, T. E. (2006). The caregiving environments provided to children by depressed mothers with or without an antisocial history. American Journal of Psychiatry, 163(6), 1009-1018. doi:10.1176/appi. ajp.163.6.1009

[147] Kreppner, J., Kumsta, R., Rutter, M., Beckett, C., Castle, J., Stevens, S., \& Sonuga-Barke, E. J. S. (2010). IV. Developmental course of deprivationspecific psychological patterns: early manifestations, persistence to age 15, and clinical features. Monographs of the Society for Research in Child Development, 75(1), 79-101. doi:10.1111/j.1540-5834.2010.00551.x

[148] Kreppner, J., O’Connor, T. G., Rutter, M., \& English Romanian Adoptees Study Team (2001). Can inattention/overactivity be an institutional deprivation syndrome? Journal of Abnormal Child Psychology, 29(6), 513-528. doi:10.1023/a:1012229209190

[149] Kreppner, J., Rutter, M., Beckett, C., Castle, J., Colvert, E., Groothues, C. ... \& Sonuga-Barke, E. J. S. (2007). Normality and impairment following profound early institutional deprivation: A longitudinal follow-up into early adolescence. Developmental Psychology, 43(4), 931-946. doi:10.1037/0012-1649-43.4.931

[150] Kreppner, J., Rutter, M., Marvin, R., O'Connor, T., \& Sonuga-Barke, E. J. S. (2011). Assessing the Concept of the 'Insecure-Other' Category in the Cassidy-Marvin Scheme: Changes Between 4 and 6 Years in the English and Romanian Adoptee Study. Social Development, 20(1), 1-16. doi:10.1111/j.1467-9507.2009.00569.x
[151] Kumsta, R., Kreppner, J., Kennedy, M., Knights, N., Rutter, M., \& Sonuga-Barke, E. (2015). Psychological Consequences of Early Global Deprivation An Overview of Findings From the English \& Romanian Adoptees Study. European Psychologist, 20(2), 138-151. doi:10.1027/1016-9040/a000227

[152] Kumsta, R., Kreppner, J., Rutter, M., Beckett, C., Castle, J., Stevens, S., \& Sonuga-Barke, E. J. S. (2010). III. Deprivation-specific psychological patterns. Monographs of the Society for Research in Child Development, 75(1), 48-78. doi:10.1111/j.15405834.2010.00550.x

[153] Kumsta, R., Marzi, S. J., Viana, J., Dempster, E. L., Crawford, B., Rutter, M. ... \& Sonuga-Barke, E. J. S. (2016). Severe psychosocial deprivation in early childhood is associated with increased DNA methylation across a region spanning the transcription start site of CYP2E1. Translational Psychiatry, 6,e830 doi:10.1038/tp.2016.95

[154] Kumsta, R., Rutter, M., Stevens, S., \& SonugaBarke, E. J. S. (2010). IX. Risk, causation, mediation, and moderation. Monographs of the Society for Research in Child Development, 75(1), 187-211. doi:10.1111/j.15405834.2010.00556.x

[155] Kumsta, R., Schlotz, W., Golm, D., Moser, D., Kennedy, M., Knights, N. ... \& Sonuga-Barke, E. (2017). HPA axis dysregulation in adult adoptees twenty years after severe institutional deprivation in childhood. Psychoneuroendocrinology, 86, 196-202. doi:10.1016/j. psyneuen.2017.09.021

[156] Kumsta, R., Sonuga-Barke, E. J. S., \& Rutter, M. (2012). Adolescent callous-unemotional traits and conduct disorder in adoptees exposed to severe early deprivation. British Journal of Psychiatry, 200(3), 197-201. doi:10.1192/bjp.bp.110.089441

[157] Kumsta, R., Stevens, S., Brookes, K., Schlotz, W., Castle, J., Beckett, C. ... \& Sonuga-Barke, E. J. S. (2010). 5 HTT genotype moderates the influence of early institutional deprivation on emotional problems in adolescence: evidence from the English and Romanian Adoptee (ERA) study. Journal of Child Psychology and Psychiatry, 51(7), 755-762. doi:10.1111/j.14697610.2010.02249.x

[158] Laurens, K. R., Hodgins, S., Maughan, B., Murray, R. M., Rutter, M. L., \& Taylor, E. A. (2007). Community screening for psychotic-like experiences and other putative antecedents of schizophrenia in children aged 9-12 years. Schizophrenia Research, 90(1-3), 130-146. doi:10.1016/j.schres.2006.11.006

[159] Le Couteur, A., Bailey, A., Goode, S., Pickles, A., Robertson, S., Gottesman, I., \& Rutter, M. (1996). A broader phenotype of autism: The clinical spectrum in twins. Journal of Child Psychology and Psychiatry, 37(7), 785-801. doi:10.1111/j.1469-7610.1996.tbo1475.x 
[160] Le Couteur, A., Rutter, M., Lord, C., Rios, P., Robertson, S., Holdgrafer, M., \& McLennan, J. (1989). Autism Diagnostic Interview - a standardized investigator-based instrument. Journal of Autism and Developmental Disorders, 19(3), 363-387. doi:10.1007/ bfo2212936

[161] Le Couteur, A., Rutter, M., Summers, D., \& Butler, L. (1988). Fragile-x in female autistic twins. Journal of Autism and Developmental Disorders, 18(3), 458-46o. doi:10.1007/bfo2212201

[162] Le Couteur, A., Trygstad, O., Evered, C., Gillberg, C., \& Rutter, M. (1988). Infantile-autism and urinaryexcretion of peptides and protein-associated peptide complexes. Journal of Autism and Developmental Disorders, 18(2), 181-190. doi:10.1007/bfo2211945

[163] Lennox, C., Callias, M., \& Rutter, M. (1977). Cognitive characteristics of parents of autistic-children. Journal of Autism and Childhood Schizophrenia, 7(3), 243261. doi:10.1007/bfo1539001

[164] Lockyer, L., \& Rutter, M. (1969). A 5 to 15 year follow-up study of infantile psychosis Part 3 psychological aspects. British Journal of Psychiatry, 115(525), 865-882. doi:10.1192/bjp.115.525.865

[165] Lockyer, L., \& Rutter, M. (1970). A 5- to 15-year follow-up study of infantile psychosis .4. Patterns of cognitive ability. British Journal of Social and Clinical Psychology, 9(2), 152-\&. doi:10.1111/j.2044-8260.1970. tboo654.x

[166] Lord, C., Pickles, A., McLennan, J., Rutter, M., Bregman, J., Folstein, S., ... Minshew, N. (1997). Diagnosing autism: Analyses of data from the Autism Diagnostic Interview. Journal of Autism and Developmental Disorders, 27(5), 501-517. doi:10.1023/a:1025873925661

[167] Lord, C., Risi, S., Lambrecht, L., Cook, E. H., Leventhal, B. L., DiLavore, P. C. ... \& Rutter, M. (2000). The Autism Diagnostic Observation Schedule-Generic: A standard measure of social and communication deficits associated with the spectrum of autism. Journal of Autism and Developmental Disorders, 30(3), 205-223. doi:10.1023/a:1005592401947

[168] Lord, C., Rutter, M., Goode, S., Heemsbergen, J., Jordan, H., Mawhood, L., \& Schopler, E. (1989). Autism Diagnostic Observation Schedule - a standardized observation of communicative and social-behavior. Journal of Autism and Developmental Disorders, 19(2), 185-212. doi:10.1007/bfo2211841

[169] Lord, C., Rutter, M., \& Le Couteur, A. (1994). Autism Diagnostic Interview-Revised - A revised version of a diagnostic interview for caregivers of individuals with possible pervasive developmental disorders. Journal of Autism and Developmental Disorders, 24(5), 659-685. doi:10.1007/bfo2172145
[170] Lord, C., Storoschuk, S., Rutter, M., \& Pickles, A. (1993). Using the ADI-R to diagnose autism in preschool-children. Infant Mental Health Journal, 14(3), 234-252. doi:10.1002/1097-0355(199323)14:3<234::aidimhj2280140308>3.0.co;2-f

[171] Macdonald, H., Rutter, M., Howlin, P., Rios, P., Leconteur, A., Evered, C., \& Folstein, S. (1989). Recognition and expression of emotional cues by autistic and normal adults. Journal of Child Psychology and Psychiatry, 30(6), 865-877. doi:10.1111/j.1469-7610.1989.tboo288.x

[172] Maes, H. H., Neale, M. C., Kendler, K. S., Hewitt, J. K., Silberg, J. L., Foley, D. L. ... \& Eaves, L. J. (1998). Assortative mating for major psychiatric diagnoses in two population-based samples. Psychological Medicine, 28(6), 1389-1401. doi:10.1017/s0033291798007326

[173] Maes, H. H., Woodard, C. E., Murrelle, L., Meyer, J. M., Silberg, J. L., Hewitt, J. K. ... \& Eaves, L. J. (1999). Tobacco, alcohol and drug use in eight- to sixteenyear-old twins: The Virginia Twin Study of Adolescent Behavioral Development. Journal of Studies on Alcohol, 60(3), 293-305. doi:10.15288/jsa.1999.60.293

[174] Marchant, R., Howlin, P., Yule, W., \& Rutter, M. (1974). Graded change in treatment of behavior of autistic-children. Journal of Child Psychology and Psychiatry and Allied Disciplines, 15(3), 221-227. doi:10.1111/j.1469-7610.1974.tbo1247.x

[175] Martin, J., Hamshere, M. L., O’Donovan, M. C., Rutter, M., \& Thapar, A. (2014). Factor structure of autistic traits in children with ADHD. Journal of Autism and Developmental Disorders, 44(1), 204-215. doi:10.1007/s10803-013-1865-0

[176] Maughan, B., Dunn, G., \& Rutter, M. (1985). Black-pupils progress in secondary-school .1. Reading attainment between 10 and 14. British Journal of Developmental Psychology, 3(JUN), 113-121. doi:10.1111/ j.2044-835X.1985.tboog63.x

[177] Maughan, B., Gray, G., \& Rutter, M. (1985). Reading retardation and antisocial-behavior - a follow-up into employment. Journal of Child Psychology and Psychiatry, 26(5), 741-758. doi:10.1111/j.1469-7610.1985.tboo588.x

[178] Maughan, B., Hagell, A., Rutter, M., \& Yule, W. (1994). Poor readers in secondary-school. Reading and Writing, 6(2), 125-150. doi:10.1007/bfo1026909

[179] Maughan, B., Messer, J., Collishaw, S., Pickles, A., Snowling, M., Yule, W., \& Rutter, M. (2009). Persistence of literacy problems: spelling in adolescence and at mid-life. Journal of Child Psychology and Psychiatry, 50(8), 893-901. doi:10.1111/j.1469-7610.2009.02079.x

[180] Maughan, B., Mortimore, P., Ouston, J., \& Rutter, M. (1980). 15,000 hours - a reply. Oxford Review of Education, 6(3), 289-303. doi:10.1080/0305498800060309 
[181] Maughan, B., Pickles, A., Hagell, A., Rutter, M., \& Yule, W. (1996). Reading problems and antisocial behaviour: Developmental trends in comorbidity. Journal of Child Psychology and Psychiatry, 37(4), 405418. doi:10.1111/j.1469-7610.1996.tbo1421.x

[182] Maughan, B., \& Rutter, M. (1986). Black-pupils progress in secondary-schools .2. Examination attainments. British Journal of Developmental Psychology, 4, 19-29. doi:10.1111/j.2044-835X.1986. tboog94.x

[183] Maughan, B. \& Rutter, M. (1987). Pupil progress in selective and non-selective schools. Schools Organisation, 7, 50-68. doi: 10.1080/0260136870070110

[184] Maughan, B., \& Rutter, M. (1997). Retrospective reporting of childhood adversity: Issues in assessing long-term recall. Journal of Personality Disorders, $11(1)$, 19-33. doi:10.1521/pedi.1997.11.1.19

[185] Mawhood, L., Howlin, P., \& Rutter, M. (2000). Autism and developmental receptive language disorder - a comparative follow-up in early adult life. I: Cognitive and language outcomes. Journal of Child Psychology and Psychiatry, 41(5), 547-559. doi:10.1017/ s002196309900579x

[186] Mehta, M. A., Golembo, N. I., Nosarti, C., Colvert, E., Mota, A., Williams, S. C. R. ... \& Sonuga-Barke, E. J. S. (2009). Amygdala, hippocampal and corpus callosum size following severe early institutional deprivation: The English and Romanian Adoptees Study Pilot. Journal of Child Psychology and Psychiatry, 50(8), 943951. doi:10.1111/j.1469-7610.2009.02084.x

[187] Meyer, J. M., Rutter, M., Silberg, J. L., Maes, H. H., Simonoff, E., Shillady, L. L. ... \& Eaves, L. J. (2000). Familial aggregation for conduct disorder symptomatology: the role of genes, marital discord and family adaptability. Psychological Medicine, 30(4), 759774. doi:10.1017/s0033291799002408

[188] Milne, B. J., Caspi, A., Crump, R., Poulton, R., Rutter, M., Sears, M. R., \& Moffitt, T. E. (2009). The validity of the family history screen for assessing family history of mental disorders. American Journal of Medical Genetics Part B-Neuropsychiatric Genetics, 150B(1), 41-49. doi:10.1002/ajmg.b.30764

[189] Milne, B. J., Caspi, A., Harrington, H., Poulton, R., Rutter, M., \& Moffitt, T. E. (2009). Predictive value of family history on severity of illness the case for depression, anxiety, alcohol dependence, and drug dependence. Archives of General Psychiatry, 66(7), 738747. doi:10.1001/archgenpsychiatry.2009.55

[190] Milne, B. J., Moffitt, T. E., Crump, R., Poulton, R., Rutter, M., Sears, M. R. ... \& Caspi, A. (2008). How should we construct psychiatric family history scores? A comparison of alternative approaches from the Dunedin Family Health History Study.
Psychological Medicine, 38(12), 1793-1802. doi:10.1017/ so033291708003115

[191] Moffitt, T. E., Caspi, A., \& Rutter, M. (2005). Strategy for investigating interactions between measured genes and measured environments. Archives of General Psychiatry, 62(5), 473-481. doi:10.1001/ archpsyc.62.5.473

[192] Moffitt, T. E., Caspi, A., \& Rutter, M. (2006). Measured gene-environment interactions in psychopathology concepts, research strategies, and implications for research, intervention, and public understanding of genetics. Perspectives on Psychological Science, 1(1), 5-27. doi:10.1111/j.17456916.2006.00002.x

[193] Moss, P., Howlin, P., Savage, S., Bolton, P., \& Rutter, M. (2015). Self and informant reports of mental health difficulties among adults with autism findings from a long-term follow-up study. Autism, 19(7), 832841. doi:10.1177/1362361315585916

[194] Mrazek, D. A., Dowdney, L., Rutter, M. L., \& Quinton, D. L. (1982). Mother and preschool-child interaction - a sequential approach. Journal of the American Academy of Child and Adolescent Psychiatry, 21(5), 453-464. doi:10.1016/s0002-7138(09)60794-9

[195] Murphy, M., Bolton, P. F., Pickles, A., Fombonne, E., Piven, J., \& Rutter, M. (2000). Personality traits of the relatives of autistic probands. Psychological Medicine, 30(6), 1411-1424. doi:10.1017/ so033291799002949

[196] Nadder, T. S., Rutter, M., Silberg, J. L., Maes, H. H., \& Eaves, L. J. (2002a). Genetic effects on the variation and covariation of attention deficithyperactivity disorder (ADHD) and oppositionaldefiant disorder/conduct disorder (ODD/CD) symptomatologies across informant and occasion of measurement. Psychological Medicine, 32(1), 39-53.

[197] Nadder, T. S., Rutter, M., Silberg, J. L., Maes, H. H., \& Eaves, L. J. (2002b). Genetic effects on the variation and covariation of attention deficit-hyperactivity disorder (ADHD) and oppositional-defiant disorder/ conduct disorder (ODD/CD) symptomatologies across informant and occasion of measurement. (vol 32, pg 39, 2002). Psychological Medicine, 32(2), 378-378. doi:10.1017/s0033291702229530

[198] Nadder, T. S., Silberg, J. L., Rutter, M., Maes, H. H., \& Eaves, L. J. (2001). Comparison of multiple measures of ADHD symptomatology: A multivariate genetic analysis. Journal of Child Psychology and Psychiatry and Allied Disciplines, 42(4), 475-486. doi:10.1111/1469-7610.00741

[199] Nemeroff, C. B., Weinberger, D., Rutter, M., MacMillan, H. L., Bryant, R. A., Wessely, S. ... \& Lysaker, P. (2013). DSM-5: a collection of psychiatrist views on 
the changes, controversies, and future directions. $B M C$ Medicine, 11. doi:10.1186/1741-7015-11-202

[200] O'Connor, T. G., Bredenkamp, D., \& Rutter, M. (1999). Attachment disturbances and disorders in children exposed to early severe deprivation. Infant Mental Health Journal, 20(1), 10-29. doi:10.1002/ (sici)1097-0355(199921)20:1<10::aid-imhj2>3.0.co;2-s

[201] O'Connor, T. G., Deater-Deckard, K., Fulker, D., Rutter, M., \& Plomin, R. (1998). Genotype-environment correlations in late childhood and early adolescence: Antisocial behavioral problems and coercive parenting. Developmental Psychology, 34(5), 970-981. doi:10.1037/0012-1649.34.5.970

[202] O'Connor, T. G., Marvin, R. S., Rutter, M., Olrick, J. T., Britner, P. A. \& the English and Romanian Adoptees Study Team (2003). Child-parent attachment following early institutional deprivation. Development and Psychopathology, 15(1), 19-38. doi:10.1017/ so954579403000026

[203] O'Connor, T. G., \& Rutter, M. (1996). Risk mechanisms in development: Some conceptual and methodological considerations. Developmental Psychology, 32(4), 787-795. doi:10.1037/00121649.32.4.787

[204] O'Connor, T. G., Rutter, M., Beckett, C., Keaveney, L., Kreppner, J. M., \& English Romanian Adoptees Study Team (2000). The effects of global severe privation on cognitive competence: Extension and longitudinal follow-up. Child Development, 71(2), 376-390. doi:10.1111/1467-8624.00151

[205] O'Connor, T. G., Rutter, M., \& the English and Romanian Adoptees Study Team (2000). Attachment disorder behavior following early severe deprivation: Extension and longitudinal follow-up. Journal of the American Academy of Child and Adolescent Psychiatry, 39(6), 703-712. doi:10.1097/00004583-20000600000008

[206] Obel, C., Zhu, J. L., Olsen, J., Breining, S., Li, J., Gronborg, T. K., Gissler, M. \& Rutter, M. (2016). The risk of attention deficit hyperactivity disorder in children exposed to maternal smoking during pregnancy - a re-examination using a sibling design. Journal of Child Psychology and Psychiatry, 57(4), 532-537. doi:10.1111/ jcpp.12478

[207] Palferman, S., Matthews, N., Turner, H., Moore, J., Hervas, A., Aubin, A., . . International Molecular Genetic Study of Autism Consortium (2001b). Further characterization of the autism susceptibility locus AUTS1 on chromosome 7q. Human Molecular Genetics, 10(9), 973-982. doi:10.1093/hmg/10.9.973

[208] Palferman, S., Matthews, N., Turner, M., Moore, J., Hervas, A., Aubin, A., ... International Molecular Genetic Study of Autism Consortium (2001a). A genomewide screen for autism: Strong evidence for linkage to chromosomes 2q, 7q, and 16p. American Journal of Human Genetics, 69(3), 570-581. doi:10.1086/323264

[209] Parr, J. R., De Jonge, M. V., Wallace, S., Pickles, A., Rutter, M. L., Le Couteur, A. S., ... Bailey, A. J. (2015). New interview and observation measures of the broader autism phenotype: description of strategy and reliability findings for the interview measures. Autism Research, 8(5), 522-533. doi:10.1002/aur.1466

[210] Parr, J. R., Le Couteur, A., Baird, G., Rutter, M., Pickles, A., Fombonne, E., ... IMGSAC. (2011). Early developmental regression in autism spectrum disorder: evidence from an international multiplex sample. Journal of Autism and Developmental Disorders, 41(3), 332-340. doi:10.1007/s10803-010-1055-2

[211] Phillips, W., Baron-Cohen, S., \& Rutter, M. (1998). Understanding intention in normal development and in autism. British Journal of Developmental Psychology, 16, 337-348. doi:10.1111/j.2044-835X.1998.tboo756.x

[212] Phillips, W., Baron-Cohen, S., \& Rutter, M. (1992). The role of eye contact in goal detection - evidence from normal infants and children with autism or mental handicap. Development and Psychopathology, 4(3), 375-383. doi:10.1017/s0954579400000845

[213] Phillips, W., Baron-Cohen, S., \& Rutter, M. (1995). To what extent can children with autism understand desire. Development and Psychopathology, 7(1), 151-169. doi:10.1017/s0954579400006398

[214] Pickles, A., Aglan, A., Collishaw, S., Messer, J., Rutter, M., \& Maughan, B. (2010). Predictors of suicidality across the life span: The Isle of Wight study. Psychological Medicine, 40(9), 1453-1466. doi:10.1017/ so033291709991905

[215] Pickles, A., Bolton, P., Macdonald, H., Bailey, A., Le Couteur, A., Sim, C. H., \& Rutter, M. (1995). Latent-class analysis of recurrence risks for complex phenotypes with selection and measurement error a twin and family history study of autism. American Journal of Human Genetics, 57(3), 717-726. No doi

[216] Pickles, A., Crouchley, R., Simonoff, E., Eaves, L., Meyer, J., Rutter, M., .. . Silberg, J. (1994). Survival models for developmental genetic data - age-of-onset of puberty and antisocial-behavior in twins. Genetic Epidemiology, 11(2), 155-170. doi:10.1002/gepi.1370110206

[217] Pickles, A., Neale, M., Simonoff, E., Rutter, M., Hewitt, J., Meyer, J. ... \& Eaves, L. (1994). A simple method for censored age-of-onset data subject to recall bias - mothers reports of age of puberty in male twins. Behavior Genetics, 24(5), 457-468. doi:10.1007/ bfolo 66181

[218] Pickles, A., Parr, J. R., Rutter, M. L., De Jonge, M. V., Wallace, S., Le Couteur, A. S., ... Bailey, A. J. 
(2013). New interview and observation measures of the broader autism phenotype: impressions of interviewee measure. Journal of Autism and Developmental Disorders, 43(9), 2082-2089. doi:10.1007/s10803-013-1810-2

[219] Pickles, A., Rowe, R., Simonoff, E., Foley, D., Rutter, M., \& Silberg, J. (2001). Child psychiatric symptoms and psychosocial impairment: relationship and prognostic significance. British Journal of Psychiatry, 179, 230-235. doi:10.1192/bjp.179.3.230

[220] Pickles, A., Starr, E., Kazak, S., Bolton, P., Papanikolaou, K., Bailey, A., ... Rutter, M. (2000). Variable expression of the autism broader phenotype: Findings from extended pedigrees. Journal of Child Psychology and Psychiatry and Allied Disciplines, 41(4), 491-502. doi:10.1017/s0021963099005557

[221] Pinto, D., Pagnamenta, A. T., Klei, L., Anney, R., Merico, D., Regan, R., ... Betancur, C. (2010). Functional impact of global rare copy number variation in autism spectrum disorders. Nature, 466(7304), 368372. doi:10.1038/natureog146

[222] Plomin, R., \& Rutter, M. (1998). Child development, molecular genetics, and what to do with genes once they are found. Child Development, 69(4), 1223-1242. doi:10.2307/1132371

[223] Quinton, D., Gulliver, L., \& Rutter, M. (1995). A 15-20 year follow-up of adult psychiatric-patients - psychiatricdisorder and social functioning. British Journal of Psychiatry, 167, 315-323. doi:10.1192/bjp.167.3.315

[224] Quinton, D., Pickles, A., Maughan, B., \& Rutter, M. (1993). Partners, peers, and pathways - assortative pairing and continuities in conduct disorder. Development and Psychopathology, 5(4), 763-783. doi:10.1017/s0954579400006271

[225] Quinton, D., \& Rutter, M. (1976a). Early hospital admissions and later disturbances of behavior - attempted replication of Douglas findings. Developmental Medicine and Child Neurology, 18(4), 447459. doi:10.1111/j.1469-8749.1976.tbo3684.x

[226] Quinton, D., \& Rutter, M. (1984a). Parents with children in care .1. Current circumstances and parenting. Journal of Child Psychology and Psychiatry, 25(2), 211-229. doi:10.1111/j.1469-7610.1984.tbool45.x

[227] Quinton, D., \& Rutter, M. (1984b). Parents with children in care .2. Intergenerational continuities. Journal of Child Psychology and Psychiatry, 25(2), 231-250. doi:10.1111/j.1469-7610.1984.tbool46.x

[228] Quinton, D., Rutter, M., \& Liddle, C. (1984). Institutional rearing, parenting difficulties and marital support. Psychological Medicine, 14(1), 107-124. doi:10.1017/s0033291700003111

[229] Quinton, D., Rutter, M., \& Rowlands, O. (1976). Evaluation of an interview assessment of marriage.
Psychological Medicine, 6(4), 577-586. doi:10.1017/ so033291700018201

[230] Rende, R., Weissman, M., Rutter, M., Wickramaratne, P., Harrington, R., \& Pickles, A. (1997). Psychiatric disorders in the relatives of depressed probands .2. Familial loading for comorbid nondepressive disorders based upon proband age of onset. Journal of Affective Disorders, 42(1), 23-28. doi:10.1016/ so165-0327(97)84643-5

[231] Reynolds, C. A., Hewitt, J. K., Erickson, M. T., Silberg, J. L., Rutter, M., Simonoff, E., Meyer, J. \& Eaves, L. J. (1996). The genetics of children's oral reading performance. Journal of Child Psychology and Psychiatry, 37(4), 425-434. doi:10.1111/j.1469-7610.1996.tbo1423.x

[232] Roy, P., \& Rutter, M. (2006). Institutional care: associations between inattention and early reading performance. Journal of Child Psychology and Psychiatry, 47(5), 480-487. doi:10.1111/j.1469-7610.2005.01526.x

[233] Roy, P., Rutter, M., \& Pickles, A. (2000). Institutional care: Risk from family background or pattern of rearing? Journal of Child Psychology and Psychiatry, 41(2), 139-149. doi:10.1111/1469-7610.00555

[234] Roy, P., Rutter, M., \& Pickles, A. (2004). Institutional care: associations between overactivity and lack of selectivity in social relationships. Journal of Child Psychology and Psychiatry, 45(4), 866-873. doi:10.1111/j.1469-7610.2004.00278.x

[235] Rutter, M. (1963a). Psychosocial factors in the short-term prognosis of physical disease. I. Peptic ulcer. Journal of Psychosomatic Research, 7, 45-60. doi:10.1016/0022-3999(63)90051-5

[236] Rutter, M. (1963b). Some current research issues in American child psychiatry. The Milbank Memorial Fund Quarterly, 41, 339-370. doi:10.2307/3348797

[237] Rutter, M. (1964). Intelligence and childhood psychiatric disorder. British Journal of Social and Clinical Psychology, 3, 120-129. doi:10.1111/j.2044-8260.1964. tboo414.x

[238] Rutter, M. (1965a). Classification and categorization in child psychiatry. Journal of Child Psychology and Psychiatry, 6(2), 71-83. doi:10.1111/j.1469-7610.1965.tbo2229.x

[239] Rutter, M. (1965b). The influence of organic and emotional factors on the origins, nature and outcome of childhood psychosis. Developmental Medicine and Child Neurology, 7(5), 518-528. doi:10.1111/j.1469-8749.1965.tb1096o.x

[240] Rutter, M. (1966). Cerebral involvement in Duchenne-type muscular dystrophy? Developmental Medicine and Child Neurology, 8(1), 85-87. doi:10.1111/j.1469-8749.1966.tbo8280.x 
[241] Rutter, M. (1967a). A children's behaviour questionnaire for completion by teachers: Preliminary findings. Journal of Child Psychology and Psychiatry, 8((1)), 1-11. doi:10.1111/j.1469-7610.1967.tbo2175.x

[242] Rutter, M. (1967b). Schooling and the 'autistic' child. Special education, 56(2), 19-24. No doi

[243] Rutter, M. (1967). The autistic child. The Royal Institute of Public Health and Hygiene journal, 30(4), 130132. No doi

[244] Rutter, M. (1968a). Concepts of autism: a review of research. Journal of Child Psychology and Psychiatry, 9(1), 1-25. doi:10.1111/j.1469-7610.1968.tbo2204.x

[245] Rutter, M. (1968b). Infantile psychosis. British Journal of Psychiatry, 114(510), 648-649. doi:10.1192/ bjp.114.510.648-a

[246] Rutter, M. (1968c). Lesion cérébrale organique hyperkinesie et retard mental. La Psychiatrie de L'Enfant, 11, 475-492.

[247] Rutter, M. (1970a). Autistic children - infancy to adulthood. Seminars in Psychiatry, 2(4), 435-450. No doi

[248] Rutter, M. (1970b). Psychological development - predictions from infancy. Journal of Child Psychology and Psychiatry, 11(1), 49-\&. doi:10.1111/j.1469-7610.1970. tbolo12.x

[249] Rutter, M. (1970c). Psychosocial disorders in childhood and their outcome in adult life. Journal of the Royal College of Physicians, London, 4, 211-218. No doi

[250] Rutter, M. (1971a). Normal psychosexual development. Journal of Child Psychology and Psychiatry, 11(4), 259-283. doi:10.1111/j.1469-7610.1970.tbo1044.x

[251] Rutter, M. (1971b). Parent-child separation - psychological effects on children. Journal of Child Psychology and Psychiatry, 12(4), 233-260. doi:10.1111/j.1469-7610.1971.tbo1086.x

[252] Rutter, M. (1972a). Maternal deprivation reconsidered. Journal of Psychosomatic Research, 16(4), 241-\&. doi:10.1016/0022-3999(72)90005-0

[253] Rutter, M. (1972b). Childhood schizophrenia reconsidered. Journal of Autism and Childhood Schizophrenia, 2(4), 315-337. doi:10.1007/bfo1537622

[254] Rutter, M. (1972C). Relationships between child and adult psychiatric disorders - some research considerations. Acta Psychiatrica Scandinavica, 48(1), 3-21. doi:10.1111/j.1600-0447.1972.tbo4346.x

[255] Rutter, M. (1972d). Psychiatric disorders and intellectual impairment in childhood. British Journal of Hospital Medicine, 8, 137-140. No doi

[256] Rutter, M. (1973a). Why are London children so disturbed? Proceedings of the Royal Society of Medicine-London, 66(12), 1221-1225. doi:10.1177/003591577306601231
[257] Rutter, M. (1973b). The assessment and treatment of pre-school autistic children. Early Child Development and Care, 3, 13-29. doi: 10.1080/0300443730030102

[258] Rutter, M. (1974a). Development of infantile autism. Psychological Medicine, 4(2), 147-163. doi:10.1017/s0033291700041982

[259] Rutter, M. (1974b). Emotional disorder and educational underachievement. Archives of Disease in Childhood, 49(4), 249-256. doi:10.1136/adc.49.4.249

[260] Rutter, M. (1976). Institute-Of-Psychiatry Department Of Child And Adolescent-Psychiatry. Psychological Medicine, 6(3), 505-516. doi:10.1017/ so033291700015956

[261] Rutter, M. (1977). Brain-damage syndromes in childhood - concepts and findings. Journal of Child Psychology and Psychiatry, 18(1), 1-21. doi:10.1111/j.1469-7610.1977.tboo413.x

[262] Rutter, M. (1978a). Attachment - its meaning and consequences. Behavioral and Brain Sciences, 1(3), 455456. doi:10.1017/s0140525×00076032

[263] Rutter, M. (1978b). Diagnosis and definition of childhood autism. Journal of Autism and Childhood Schizophrenia, 8(2), 139-161. doi:10.1007/bfo1537863

[264] Rutter, M. (1978c). Diagnostic validity in child psychiatry. Advances in Biological Psychiatry, 2, 2-22. doi: 10.1159/000402269

[265] Rutter, M. (1979a). Maternal-deprivation, 19721978 - new findings, new concepts, new approaches. Child Development, 50(2), 283-305. doi:10.2307/1129404

[266] Rutter, M. (1979b). Separation experiences - new look at an old topic. Journal of Pediatrics, 95(1), 147-154. doi:10.1016/s0022-3476(79)80113-4

[267] Rutter, M. (1980a). The long-term effects of early experience. Developmental Medicine and Child Neurology, 22(6), 800-815. doi:10.1111/j.1469-8749.1980. tbo3751.x. doi:10.1542/peds.65.2.208

[268] Rutter, M. (1980b). School influences on children's behaviour and development: The 1979 Kenneth Blackfan Lecture, Children's Hospital Medical Centre, Boston. Pediatrics, 65, 208-220.

[269] Rutter, M. (1980c). Youth in society: 1. Growing up in a changing world. New Society, 52(915), 98-99. No doi

[270] Rutter, M. (1980d). Youth in society: 2. History and adolescence. New Society, 52(916), 164-165. No doi

[271] Rutter, M. (1980e). Youth in society: 3. Psychosocial adolescence. New Society, 52(917), 225-226. No doi

[272] Rutter, M. (1980f). Youth in society: 4. Disorders in adolescence. New Society, 52(918), 296-297. No doi

[273] Rutter, M. (1981a). Epidemiological-longitudinal strategies and causal research in child-psychiatry. 
Journal of the American Academy of Child and Adolescent Psychiatry, 20(3), 513-544. doi:10.1016/s00027138(og)61643-5

[274] Rutter, M. (1981b). Psychological sequelae of brain-damage in children. American Journal of Psychiatry, 138(12), 1533-1544. doi:10.1176/ajp.138.12.1533

[275] Rutter, M. (1981c). Social-emotional consequences of day-care for preschool-children. American Journal of Orthopsychiatry, 51(1), 4-28. doi:10.1111/j.1939-0025.1981. tbol344.x

[276[ Rutter, M. (1981d). Stress, coping and development - some issues and some questions. Journal of Child Psychology and Psychiatry, 22(4), 323-356. doi:10.1111/j.1469-7610.1981.tboo56o.x

[277] Rutter, M. (1981e). The city and the child. American Journal of Orthopsychiatry, 51(4), 610-625. doi:10.1111/j.1939-0025.1981.tbo1407.x

[278] Rutter, M. (1982a). Prevention of children's psycho-social disorders - myth and substance. Pediatrics, 70(6), 883-894. No doi

[279] Rutter, M. (1982b). Psychological therapies in child-psychiatry - issues and prospects. Psychological Medicine, 12(4), 723-740. doi:10.1017/s0033291700049035

[280] Rutter, M. (1982c). Syndromes attributed to minimal brain-dysfunction in childhood. American Journal of Psychiatry, 139(1), 21-33. doi:10.1176/ajp.139.1.21

[281] Rutter, M. (1982d). Temperament - concepts, issues and problems. Ciba Foundation Symposia, 89, 1-19. doi:10.1002/9780470720714.ch1

[282] Rutter, M. (1982e). Temperamental differences in infants and young-children - Chairman's closing remarks. Ciba Foundation Symposia, 89, 294-297. doi:10.1002/9780470720714.ch18

[283] Rutter, M. (1982f). Developmental neuropsychiatry: Concepts, issues, and prospects. Journal of Clinical Neuropsychology, 4 (2), 91-115. doi:10.1080/01688638208401121

[284] Rutter, M. (1982g). Surveys to answer questions: some methodological considerations. Acta Psychiatrica Scandinavica, 65 (Suppl. 296), 64-76. doi: 10.1111/j.16000447.1982.tboo895.x

[285] Rutter, M. (1983a). Cognitive deficits in the pathogenesis of autism. Journal of Child Psychology and Psychiatry, 24(4), 513-531. doi:10.1111/j.1469-7610.1983. tbool29.x

[286] Rutter, M. (1983b). School effects on pupil progress - research findings and policy implications. Child Development, 54(1), 1-29. doi:10.1111/j.1467-8624.1983.tboo329.x

[287] Rutter, M. (1984a). Project future - the way forward for child-psychiatry. Journal of the American
Academy of Child and Adolescent Psychiatry, 23(5), 577581. doi:10.1016/sooo2-7138(09)60350-2

[288] Rutter, M. (1984b). Psychopathology and development: 1. Childhood antecedents of adult psychiatric-disorder. Australian and New Zealand Journal of Psychiatry, 18(3), 225-234. doi:10.3109/00048678409161295

[289] Rutter, M. (1984c). Psychopathology and development: 2. Childhood experiences and personality-development. Australian and New Zealand Journal of Psychiatry, 18(4), 314-327. doi:10.3109/00048678409158793

[290] Rutter, M. (1985a). Resilience in the face of adversity - protective factors and resistance to psychiatric-disorder. British Journal of Psychiatry, 147, 598-611. doi:10.1192/bjp.147.6.598

[291] Rutter, M. (1985b). Family and school influences on behavioral-development. Journal of Child Psychology and Psychiatry, 26(3), 349-368. doi:10.1111/j.1469-7610.1985.tbo1938.x

[292] Rutter, M. (1985c). Family and school influences on cognitive-development. Journal of Child Psychology and Psychiatry, 26(5), 683-704. doi:10.1111/j.1469-7610.1985.tboo584.x

[293] Rutter, M. (1985d). The treatment of autisticchildren. Journal of Child Psychology and Psychiatry, 26(2), 193-214. doi:10.1111/j.1469-7610.1985.tbo2260.x

[294] Rutter, M. (1986a). Child-psychiatry - looking 30 years ahead. Journal of Child Psychology and Psychiatry, 27(6), 803-840. doi:10.1111/j.1469-7610.1986.tboo202.x

[295] Rutter, M. (1986b). Meyerian psychobiology, personality-development, and the role of life experiences. American Journal of Psychiatry, 143(9), 10771087. doi:10.1176/ajp.143.9.1077

[296] Rutter, M. (1986c). Child-psychiatry - the interface between clinical and developmental research. Psychological Medicine, 16(1), 151-169. doi:10.1017/ so033291700002592

[297] Rutter, M. (1987a). Psychosocial resilience and protective mechanisms. American Journal of Orthopsychiatry, 57(3), 316-331. doi:10.1111/j.1939-0025.1987.tbo3541.x

[298] Rutter, M. (1987b). Temperament, personality and personality-disorder. British Journal of Psychiatry, 150, 443-458. doi:10.1192/bjp.150.4.443

[299] Rutter, M. (1987C). Temperament, personality and personality-disorder. British Journal of Psychiatry, 150, 873-874. doi:10.1192/s0007125000214943

[300] Rutter, M. (1987d). The role of cognition in childdevelopment and disorder. British Journal of Medical Psychology, 60, 1-16. doi:10.1111/j.2044-8341.1987. tbo2712.x 
[301] Rutter, M. (1988a). Epidemiological approaches to developmental psychopathology. Archives of General Psychiatry, 45(5), 486-495. doi:10.1001/ archpsyc.1988.01800290106013

[302] Rutter, M. (1988b). Childhood depression: epidemiology, etiological models and treatment implications. Integrative Psychiatry, 6, 1-21. No doi

[303] Rutter, M. (1989a). Age as an ambiguous variable in developmental research - some epidemiological considerations from developmental psychopathology. International Journal of Behavioral Development, 12(1), 1-34. doi:10.1177/016502548901200101

[304] Rutter, M. (1989b). Child psychiatric-disorders in ICD-10 - Annotation. Journal of Child Psychology and Psychiatry, 30(4), 499-513. doi:10.1111/j.1469-7610.1989. tboo264.x

[305] Rutter, M. (1989c). Isle of Wight revisited - 25 years of child psychiatric epidemiology. Journal of the American Academy of Child and Adolescent Psychiatry, 28(5), 633-653. doi:10.1097/00004583-198909000-00001

[306] Rutter, M. (1989d). Pathways from childhood to adult life. Journal of Child Psychology and Psychiatry, 30(1), 23-51. doi:10.1111/j.1469-7610.1989.tboo768.x

[307] Rutter, M. (1990a). Interface between research and clinical-practice in child-psychiatry - some personal reflections - discussion paper. Journal of the Royal Society of Medicine, 83(7), 444-447. doi: https://doi. org/10.1177/014107689008300711

[308] Rutter, M. (1990b). Some focus and process considerations regarding effects of parental depression on children - commentary. Developmental Psychology, 26(1), 60-67. doi:10.1037/hoog2669

[309] Rutter, M. (1991a). Origins of nurture - its not just effects on measures and its not just effects of nature. Behavioral and Brain Sciences, 14(3), 402-402. doi:10.1017/s0140525×00070461

[310] Rutter, M. (1991b). Protective factors independent or interactive. Journal of the American Academy of Child and Adolescent Psychiatry, 30(1), 151152. doi:10.1097/00004583-199101000-00024

[311] Rutter, M. (1991C). Nature, nurture, and psychopathology. Development and Psychopathology, 3, 125-136. doi:10.1017/So954579400000031

[312] Rutter, M. (1991d). Autism: pathways from syndrome definition to pathogenesis. Comprehensive Mental Health Care, 1, 5-26. No doi

[313] Rutter, M. (1992). Adolescence as a transition period - continuities and discontinuities in conduct disorder. Journal of Adolescent Health, 13(6), 451-460. doi:10.1016/1054-139x(92)90006-w

[314] Rutter, M. (1993a). Resilience - some conceptual considerations. Journal of Adolescent Health, 14(8), 626-
631. doi:10.1016/1054-139x(93)90196-v

[315] Rutter, M. (1993b). Cause and course of psychopathology: some lessons from longitudinal data. Paediatric and Perinatal Epidemiology, 7, 115-120. doi: 10.1111/j.1365-3016.1993.tboo387.x

[316] Rutter, M. (1994a). Beyond longitudinal data causes, consequences, changes, and continuity. Journal of Consulting and Clinical Psychology, 62(5), 928-940. doi:10.1037/0022-006x.62.5.928

[317] Rutter, M. (1994b). Psychiatric genetics - research challenges and pathways forward. American Journal of Medical Genetics, 54(3), 185-198. doi:10.1002/ ajmg.1320540305

[318] Rutter, M. (1994c). There are connections between brain and mind and it is important that Rett-syndrome be classified somewhere. Journal of Child Psychology and Psychiatry, 35(2), 379-381. doi:10.1111/j.1469-7610.1994.tbo1170.x

[319] Rutter M. (1994d). Family discord and conduct disorder: cause, consequence or correlate. Journal of Family Psychology, 8, 170-186. doi: 10.1037/08933200.8.2.170

[320] Rutter, M. (1995a). Clinical implications of attachment concepts - retrospect and prospect. Journal of Child Psychology and Psychiatry, 36(4), 549-571. doi:10.1111/j.1469-7610.1995.tbo2314.x

[321] Rutter, M. (1995b). Relationships between mentaldisorders in childhood and adulthood. Acta Psychiatrica Scandinavica, 91(2), 73-85. doi:10.1111/j.1600-0447.1995. tbog745.x

[322] Rutter, M. (1995c). Psychosocial adversity: risk, resilience and recovery. South African Journal of Child and Adolescent Psychiatry, 7, 75-88. No doi

[323] Rutter, M. (1996a). Alcohol misuse and juvenile offending in adolescence - Testing causal hypotheses about mechanisms in comorbidity - Comment. Addiction, 91(4), 495-498. doi:10.1111/j.136o-0443.1996.tbo2303.x

[324] Rutter, M. (1996b). Autism research: Prospects and priorities. Journal of Autism and Developmental Disorders, 26(2), 257-275. doi:10.1007/bfo2172023

[325] Rutter, M. (1996c). Autism research: Prospects and priorities (vol 26, pg 257, 1996). Journal of Autism and Developmental Disorders, 26(4), 477-477. doi:10.1007/ bfo2172834

[326] Rutter, M. (1996d). Connections between child and adult psychopathology. European Child \& Adolescent Psychiatry, 5, 4-7. doi:10.1007/bfoo538535

[327] Rutter, M. (1996e). Epidemiological testing of causal hypotheses: The case of mild head injury Commentary. Journal of Developmental and Behavioral Pediatrics, 17(3), 183-185. doi: 10.1097/00004703199606000-00007 
[328] Rutter, M. (1996f). Transitions and turning points in developmental psychopathology: As applied to the age span between childhood and mid-adulthood. International Journal of Behavioral Development, 19(3), 603-626. doi:10.1177/016502549601900309

[329] Rutter, M. (1997a). Child psychiatric disorder - Measures, causal mechanisms, and interventions. Archives of General Psychiatry, 54(9), 785-789. doi:10.1001/archpsyc.1997.01830210021002

[330] Rutter, M. (1997b). Implications of genetic research for child psychiatry. Canadian Journal of Psychiatry-Revue Canadienne De Psychiatrie, 42(6), 569576. doi:10.1177/070674379704200602

[331] Rutter, M. (1997c). Nature-nurture integration - The example of antisocial behavior. American Psychologist, 52(4), 390-398. doi:10.1037//0003066x.52.4.390

[332] Rutter, M. (1997d). Comorbidity: Concepts, claims and choices. Criminal Behaviour and Mental Health, 7, 265-286. doi: https://doi.org/10.1002/cbm.190

[333] Rutter, M. (1998a). Practitioner review: Routes from research to clinical practice in child psychiatry: Retrospect and prospect. Journal of Child Psychology and Psychiatry, 39(6), 805-816. doi:10.1111/14697610.00382

[334] Rutter, M. (1998b). Some research considerations on intergenerational continuities and discontinuities:

Comment on the special section. Developmental Psychology, 34(6), 1269-1273. doi:10.1037/00121649.34.6.1269

[335] Rutter, M. (1998c). What we learn from highly developed special skills? Behavioral and Brain Sciences, 21(3), 422-+. doi:10.1017/s0140525×98401237

[336] Rutter, M. (1999a). Resilience concepts and findings: implications for family therapy. Journal of Family Therapy, 21(2), 119-144. doi:10.1111/14676427.00108

[337] Rutter, M. (1999b). Resilience as the millennium Rorschach: Response to Smith and Gorrell Barnes. Journal of Family Therapy, 21(2), 159-160. doi:10.1111/1467-6427.00111

[338] Rutter, M. (1999c). The Emanuel Miller Memorial Lecture 1998 - Autism: Two-way interplay between research and clinical work. Journal of Child Psychology and Psychiatry, 40(2), 169-188. doi:10.1111/14697610.00431

[339] Rutter, M. (1999d). Psychosocial adversity and child psychopathology. British Journal of Psychiatry, 174X, 480-493. doi:10.1192/bjp.174.6.480

[340] Rutter, M. (1999e). Social context: meanings, measures and mechanisms. European Review, 7, 139-149. doi:10.1017/s106279870000380x
[341] Rutter, M. (2000a). Children in substitute care: Some conceptual considerations and research implications. Children and Youth Services Review, 22(910), 685-703. doi:10.1016/so190-7409(0o)00116-x

[342] Rutter, M. (200ob). Genetic studies of autism: From the 1970s into the millennium. Journal of Abnormal Child Psychology, 28(1), 3-14. doi:10.1023/a:1005113900068

[343] Rutter, M. (2000c). Psychosocial influences: Critiques, findings, and research needs. Development and Psychopathology, 12(3), 375-405. doi:10.1017/ s0954579400003072

[344] Rutter, M. (2002a). Nature, nurture, and development: From evangelism through science toward policy and practice. Child Development, 73(1). doi:10.1111/1467-8624.00388

[345] Rutter, M. (2002b). The interplay of nature, nurture, and developmental influences - The challenge ahead for mental health. Archives of General Psychiatry, 59(11), 996-1000. doi:10.1001/archpsyc.59.11.996

[346] Rutter, M. (2003a). Categories, dimensions, and the mental health of children and adolescents Keynote address. Annals of the New York Academy of Sciences, 1008, 11-21. doi:10.1196/annals.1301.002

[347] Rutter, M. (2003b). Commentary: Causal processes leading to antisocial behavior. Developmental Psychology, 39(2), 372-378. doi:10.1037/0012-1649.39.2.372

[348] Rutter, M. (2003C). Commentary: Naturenurture interplay in emotional disorders. Journal of Child Psychology and Psychiatry, 44(7), 934-944. doi:10.1111/1469-7610.00178

[349] Rutter, M. (2003d). Poverty and child mental health - Natural experiments and social causation. JAMA-Journal of the American Medical Association, 290(15), 2063-2064. doi:10.1001/jama.290.15.2063

[350] Rutter, M. (2004a). Llewellyn Charles Rutter Obituary. British Medical Journal, 328(7438), 527-527. doi:10.1136/bmj.328.7438.527-e

[351] Rutter, M. (2004b). Pathways of genetic influences on psychopathology. European Review, 12,19-33. doi:10.1017/s1062798704000031

[352] Rutter, M. (2005a). Aetiology of autism: findings and questions. Journal of Intellectual Disability Research, 49, 231-238. doi:10.1111/j.1365-2788.2005.00676.x

[353] Rutter, M. (2005b). Commentary: What is the meaning and utility of the psychopathy concept? Journal of Abnormal Child Psychology, 33(4), 499-503. doi:10.1007/s10802-005-5730-2

[354] Rutter, M. (2005c). Autism research: Lessons from the past and prospects for the future. Journal of Autism and Developmental Disorders, 35(2), 241-257. doi:10.1007/s10803-005-2003-4 
[355] Rutter, M. (2005d). Environmentally mediated risks for psychopathology: Research strategies and findings. Journal of the American Academy of Child and Adolescent Psychiatry, 44(1), 3-18. doi:10.1097/01. chi.0000145374.45992.c9

[356] Rutter, M. (2005e). How the environment affects mental health. British Journal of Psychiatry, 186, 4-6. doi:10.1192/bjp.186.1.4

[357] Rutter, M. (2005f). Incidence of autism spectrum disorders: Changes over time and their meaning. Acta Paediatrica, 94(1), 2-15. doi:10.1080/08035250410023124

[358] Rutter, M. (2005g). Multiple meanings of a developmental perspective on psychopathology. European Journal of Developmental Psychology, 2(3), 221252. doi:10.1080/17405620500237706

[359] Rutter, M. (2006a). Autism: Its recognition, early diagnosis, and service implications. Journal of Developmental and Behavioral Pediatrics, 27(2), S54-S58. doi:10.1097/00004703-200604002-00002

[36o] Rutter, M. (2006b). Implications of resilience concepts for scientific understanding. Annals of the New York Academy of Sciences, 1094, 1-12. doi:10.1196/ annals.1376.002

[361] Rutter, M. (2007a). Gene-environment interdependence. Developmental Science, 10(1), 12-18. doi:10.1111/j.1467-7687.2007.00557.x

[362] Rutter, M. (2007b). Proceeding from observed correlation to causal inference the use of natural experiments. Perspectives on Psychological Science, 2(4), 377-395. doi:10.1111/j.1745-6916.2007.00050.x

[363] Rutter, M. (2007c). Psychopathological development across adolescence. Journal of Youth and Adolescence, 36(1), 101-110. doi:10.1007/s10964-006-9125-7

[364] Rutter, M. (2007d). Resilience, competence, and coping. Child Abuse \& Neglect, 31(3), 205-209. doi:10.1016/j.chiabu.2007.02.001

[365] Rutter, M. (2008a). Biological implications of gene-environment interaction. Journal of Abnormal Child Psychology, 36(7), 969-975. doi:10.1007/s10802oo8-9256-2

[366] Rutter, M. (2008b). Discussion meeting issue 'the neurobiology of violence: implications for prevention and treatment' organized by Sheilagh Hodgins, Essi Viding and Anna Plodowski - Introduction. Philosophical Transactions of the Royal Society B-Biological Sciences, 363(1503), 2485-2489. doi:10.1098/ rstb.2008.0038

[367] Rutter, M. (2008c). Institutional effects on children: design issues and substantive findings. Monographs of the Society for Research in Child Development, 73(3), 271-278. doi:10.1111/j.15405834.2008.00497.x
[368] Rutter, M. (2009a). Commentary: Fact and artefact in the secular increase in the rate of autism. International Journal of Epidemiology, 38(5), 1238-1239. doi:10.1093/ije/dyp257

[369] Rutter, M. (2009b). Epidemiological methods to tackle causal questions. International Journal of Epidemiology, 38(1), 3-6. doi:10.1093/ije/dyn253

[370] Rutter, M. (2009c). Understanding and testing risk mechanisms for mental disorders. Journal of Child Psychology and Psychiatry, 50(1-2), 44-52. doi:10.1111/ j.1469-7610.2008.01976.x

[371] Rutter, M. (2010a). Child and adolescent psychiatry: past scientific achievements and challenges for the future. European Child \& Adolescent Psychiatry, 19(9), 689-703. doi:10.1007/s00787-010-0111-y

[372] Rutter, M. (2010b). Gene-environment interplay. Depression and Anxiety, 27(1), 1-4. doi:10.1002/da.20641

[373] Rutter, M. (2010c). Mediating mechanisms and emotions. Emotion Review, 2(2), 111-112. doi:10.1177/1754073909356598.

[374] Rutter, M. (2011a). Commentary: Revisiting the dismissal of shared environmental influences as argued by Burt et al. (2011). Journal of Child Psychology and Psychiatry, 52(5), 527-528. doi:10.1111/j.14697610.2011.02402.x

[375] Rutter, M. (2011b). Integrating science and clinical practice. Journal of the American Academy of Child and Adolescent Psychiatry, 50(1), 3-5. doi:10.1016/i. jaac.2010.06.005

[376] Rutter, M. (2011c). Research Review: Child psychiatric diagnosis and classification: concepts, findings, challenges and potential. Journal of Child Psychology and Psychiatry, 52(6), 647-66o. doi:10.1111/ j.1469-7610.2011.02367.x

[377] Rutter, M. (2011d). Progress in understanding autism: 2007-2010. Journal of Autism and Developmental Disorders, 41(4), 395-404. doi:10.1007/s10803-011-1184-2

[378] Rutter, M. (2011e). Response: Growing consensus on classification needs. Journal of Child Psychology and Psychiatry, 52(6), 673-675. doi:10.1111/j.1469$7610.2011 .02385 . x$

[379] Rutter, M. (2012a). Achievements and challenges in the biology of environmental effects. Proceedings of the National Academy of Sciences of the United States of America, 109, 17149-17153. doi:10.1073/pnas.1121258109

[380] Rutter, M. (2012b). ADHD and conduct disorder. European Neuropsychopharmacology, 22, Sil4-Sil4. doi:10.1016/so924-977x(12)70119-0

[381] Rutter, M. (2012c). Gene-environment interdependence. European Journal of Developmental Psychology, 9(4), 391-412. doi:10.1080/17405629.2012.66 1174 
[382] Rutter, M. (2012d). Psychopathy in childhood: is it a meaningful diagnosis? British Journal of Psychiatry, 200(3), 175-176. doi:10.1192/bjp.bp.111.092072

[383] Rutter, M. (2012e). Resilience as a dynamic concept. Development and Psychopathology, 24(2), 335344. doi:10.1017/s0954579412000028

[384] Rutter, M. (2012f). Response to commentaries on discussion paper Gene-environment interdependence. European Journal of Developmental Psychology, 9(4), 426-431. doi:10.1080/17405629.2012.698942

[385] Rutter, M. (2013a). Annual Research Review: Resilience - clinical implications. Journal of Child Psychology and Psychiatry, 54(4), 474-487. doi:10.1111/ j.1469-7610.2012.02615.x

[386] Rutter, M. (2013b). Changing concepts and findings on autism. Journal of Autism and Developmental Disorders, 43(8), 1749-1757. doi:10.1007/s10803-012-1713-7

[387] Rutter, M. (2013c). Developmental psychopathology: A paradigm shift or just a relabelling? Development and Psychopathology, 25(4), 1201-1213. doi:10.1017/s0954579413000564

[388] Rutter, M. (2014a). Commentary: Attachment is a biological concept - a reflection on Fearon et al. (2014). Journal of Child Psychology and Psychiatry, 55(9), 10421043. doi:10.1111/jcpp.12301

[389] Rutter, M. (2014b). Commentary: G x E in child psychiatry and psychology: a broadening of the scope of enquiry as prompted by Munafo et al. (2014). Journal of Child Psychology and Psychiatry, 55(10), 1102-1104. doi:10.1111/jcpp.12309

[390] Rutter, M. (2014c). Addressing the issue of fractionation in autism spectrum disorder: a commentary on Brundson and Happe, Frazier et al., Hobson and Mandy. Autism, 18(1), 55-57. doi:10.1177/1362361313513522

[391] Rutter, M. (2015a). Psychopathology after foster care or institutional rearing. Lancet Psychiatry, 2(7), 576577. doi:10.1016/s2215-0366(15)00117-0

[392] Rutter, M. (2015b). Some of the complexities involved in gene-environment interplay. International Journal of Epidemiology, 44(4), 1128-1129. doi:10.1093/ije/ dyv054

[393] Rutter, M. (2016a). Why is the topic of the biological embedding of experiences important for translation? Development and Psychopathology, 28(4), 1245-1258. doi:10.1017/s0954579416000821

[394] Rutter, M., Andersen-Wood, L., Beckett, C., Bredenkamp, D., Castle, J., Groothues, C., ... and the English and Romanian Adoptees Study Team (1999). Quasi-autistic patterns following severe early global privation. Journal of Child Psychology and Psychiatry, 40(4), 537-549. doi:10.1017/s0021963099003935
[395] Rutter, M., Bailey, A., Bolton, P., \& Le Couteur, A. (1994). Autism and known medical conditions myth and substance. Journal of Child Psychology and Psychiatry, 35(2), 311-322. doi:10.1111/j.1469-7610.1994. tbol164.x

[396] Rutter, M., \& Bartak, L. (1971). Causes of infantile autism - some considerations from recent research. Journal of Autism and Childhood Schizophrenia, 1(1), 2032. doi:10.1007/bfo1537740

[397] Rutter, M., \& Bartak, L. (1973). Special educational treatment of autistic-children - comparative study. 2.

Follow-up findings and implications for services. Journal of Child Psychology and Psychiatry, 14(4), 241-270. doi:10.1111/j.1469-7610.1973.tbo1193.x

[398] Rutter, M., Beckett, C., Castle, J., Colvert, E., Kreppner, J., Mehta, M., ... Sonuga-Barke, E. J. S. (2007). Effects of profound early institutional deprivation: An overview of findings from a UK longitudinal study of Romanian adoptees. European Journal of Developmental Psychology, 4(3), 332-350. doi:10.1080/17405620701401846

[399] Rutter, M., Birch, H. G., Thomas, A., \& Chess, S. (1964). Temperamental characteristics in infancy and the later development of behavioural disorders. British Journal of Psychiatry, 110((468)), 651-661. doi:10.1192/ bjp.110.468.651

[400] Rutter, M., Bolton, P., Harrington, R., Le Couteur, A., Macdonald, H., \& Simonoff, E. (1990). Geneticfactors in child psychiatric-disorders .1. A review of research strategies. Journal of Child Psychology and Psychiatry, 31(1), 3-37. doi:10.1111/j.1469-7610.1990. tbo2272.x

[401] Rutter, M., \& Brown, G. (1966). The reliability and validity of measures of family life and relationships in families containing a psychiatric patient. Social Psychiatry, 1(1), 38-53. doi:10.1007/bfoo583828

[402] Rutter, M., Caspi, A., Fergusson, D., Horwood, L. J., Goodman, R., Maughan, B., ... Carroll, J. (2004). Sex differences in developmental reading disability - New findings from 4 epidemiological studies. Jama-Journal of the American Medical Association, 291(16), 2007-2012. doi:10.1001/jama.291.16.2007

[403] Rutter, M., Caspi, A., \& Moffitt, T. E. (2003). Using sex differences in psychopathology to study causal mechanisms: unifying issues and research strategies. Journal of Child Psychology and Psychiatry, 44(8), 10921115. doi:10.1111/1469-7610.00194

[404] Rutter, M., Chadwick, O., Shaffer, D., \& Brown, G. (1980). A prospective-study of children with headinjuries .1. Design and methods. Psychological Medicine, 10(4), 633-645. doi:10.1017/s0033291700054933

[405] Rutter, M., Colvert, E., Kreppner, J., Beckett, C., Castle, J., Groothues, C., ... Sonuga-Barke, E. J. S. 
(2007a). Early adolescent outcomes for institutionallydeprived and non-deprived adoptees. I: Disinhibited attachment. Journal of Child Psychology and Psychiatry, 48(1), 17-30. doi:10.1111/j.1469-7610.2006.01688.x

[406] Rutter, M., Colvert, E., Kreppner, J., Beckett, C., Castle, J., Groothues, C., ... Sonuga-Barke, E. J. S. (2007b). Early adolescent outcomes for institutionally deprived and non-deprived adoptees. I: Disinhibited attachment (vol 48, pg 17, 2007). Journal of Child Psychology and Psychiatry, 48(8), 848-848. doi:10.1111/ j.1469-7610.2007.01797.x

[407] Rutter, M., \& Cox, A. (1981). Psychiatric interviewing techniques .1. Methods and measures. British Journal of Psychiatry, 138(APR), 273-282. doi:10.1192/bjp.138.4.273

[408] Rutter, M., Cox, A., Egert, S., Holbrook, D., \& Everitt, B. (1981). Psychiatric interviewing techniques .4. Experimental-study - 4 contrasting styles. British Journal of Psychiatry, 138(JUN), 456-465. doi:10.1192/bjp.138.6.456

[409] Rutter, M., Cox, A., Tupling, C., Berger, M., \& Yule, W. (1975). Attainment and adjustment in 2 geographical areas .1. Prevalence of psychiatricdisorder. British Journal of Psychiatry, 126(JUN), 493-509. doi:10.1192/bjp.126.6.493

[410] Rutter, M., Dunn, J., Plomin, R., Simonoff, E., Pickles, A., Maughan, B., ... Eaves, L. (1997). Integrating nature and nurture: Implications of person-environment correlations and interactions for developmental psychopathology. Development and Psychopathology, 9(2), 335-364. doi:10.1017/ s0954579497002083

[411] Rutter, M., \& English Romanian Adoptees (ERA) Study Team (1998). Developmental catch-up, and deficit, following adoption after severe global early privation. Journal of Child Psychology and Psychiatry, 39(4), 465-476. doi:10.1017/s0021963098002236

[412] Rutter, M., \& Graham, P. (1966). Psychiatric disorder in 10- and 11-year-old children. Proceedings of the Royal Society of Medicine, 59, 382-387. doi:10.1177/003591576605900422

[413] Rutter, M., \& Graham, P. (1968). The reliability and validity of the psychiatric assessment of the child: I. Interview with the child. British Journal of Psychiatry, 114((510)), 563-579. doi:10.1192/bjp.114.510.563

[414] Rutter, M., Graham, P., \& Birch, H. G. (1966). Interrelations between the choreiform syndrome, reading disability and psychiatric disorder in children of 8-11 years. Developmental Medicine and Child Neurology, 8(2), 149-159. doi:10.1111/j.1469-8749.1966.tbo1720.x

[415] Rutter, M., Graham, P., Chadwick, O. F. D., \& Yule, W. (1976). Adolescent turmoil - fact or fiction. Journal of Child Psychology and Psychiatry, 17(1), 35-56. doi:10.1111/j.1469-7610.1976.tboo372.x
[416] Rutter, M., Greenfield, D., \& Lockyer, L. (1967). A five to fifteen year follow-up study of infantile psychosis. II. Social and behavioural outcome. British Journal of Psychiatry, 113((504)), 1183-1199. doi:10.1192/ bjp.113.504.1183

[417] Rutter, M., Kim-Cohen, J., \& Maughan, B. (2006). Continuities and discontinuities in psychopathology between childhood and adult life. Journal of Child Psychology and Psychiatry, 47(3-4), 276-295. doi:10.1111/ j.1469-7610.2006.01614.x

[418] Rutter, M., Korn, S. \& Birch, H.G. (1963). Genetic and environmental factors in the development of "primary reaction patterns." British Journal of Social and Clinical Psychology, 2, 161. doi:10.1111/j.2044-8260.1963.tboo388.x

[419] Rutter, M., Kreppner, J., Croft, C., Murin, M., Colvert, E., Beckett, C., ... Sonuga-Barke, E. J. S. (2007). Early adolescent outcomes of institutionally deprived and non-deprived adoptees. III. Quasi-autism. Journal of Child Psychology and Psychiatry, 48(12), 12001207. doi:10.1111/j.1469-7610.2007.01792.x

[420] Rutter, M., Kreppner, J., \& Sonuga-Barke, E. J. S. (2009). Emanuel Miller Lecture: Attachment insecurity, disinhibited attachment, and attachment disorders: where do research findings leave the concepts? Journal of Child Psychology and Psychiatry, 50(5), 529-543. doi:10.1111/j.1469-7610.2009.02042.x

[421] Rutter, M., Kreppner, J. M., O'Connor, T. G., \& the English Romanian Adoptees Study Team (2001a). Specificity and heterogeneity in children's responses to profound institutional privation. British Journal of Psychiatry, 179, 97-103. doi:10.1192/bjp.179.2.97

[422] Rutter, M., Kreppner, J. M., O'Connor, T. G., \& English and Romanian Adoptees Study Team, (2001b). Specificity and heterogeneity in children's responses to profound institutional (vol 179, pg 97, 2001). British Journal of Psychiatry, 179, 371-371. doi:10.1192/ s0007125000267548

[423] Rutter, M., Kumsta, R., Schlotz, W., \& SonugaBarke, E. J. S. (2012). Longitudinal Studies Using a "Natural Experiment" Design: The Case of Adoptees From Romanian Institutions. Journal of the American Academy of Child and Adolescent Psychiatry, 51(8), 762770. doi:10.1016/j.jaac.2012.05.011

[424] Rutter, M., Lebovici, S., Eisenberg, L., Sneznevskij, A. V., Sadoun, R., Brooke, E., \& Lin, T. Y. (1969). A tri axial classification of mental disorders in childhood an international study. Journal of Child Psychology and Psychiatry, 10(1), 41-61. doi:10.1111/j.1469-7610.1969. tbo2067.x

[425] Rutter, M., \& Lockyer, L. (1967). A five to fifteen year follow-up study of infantile psychosis. I. Description of sample. British Journal of Psychiatry, 113((504)), 1169-1182. doi:10.1192/bjp.113.504.1169 
[426] Rutter, M., Macdonald, H., Le Couteur, A., Harrington, R., Bolton, P., \& Bailey, A. (1990). Genetic-factors in child psychiatric-disorders .2. Empirical-findings. Journal of Child Psychology and Psychiatry, 31(1), 39-83. doi:10.1111/j.1469-7610.1990. tbo2273.x

[427] Rutter, M., \& Maughan, B. (1997). Psychosocial adversities in childhood and adult psychopathology. Journal of Personality Disorders, 11(1), 4-18. doi:10.1521/ pedi.1997.11.1.4

[428] Rutter, M., \& Maughan, B. (2002). School effectiveness findings 1979-2002. Journal of School Psychology, 40(6), 451-475. doi:10.1016/soo224405(02)00124-3

[429] Rutter, M., \& Maughan, B. (2005). Dyslexia: 19652005. Behavioural and Cognitive Psychotherapy, 33(4), 389-402. doi:10.1017/s1352465805002316

[430] Rutter, M., Maughan, B., Meyer, J., Pickles, A., Silberg, J., Simonoff, E \& Taylor, E. (1997). Heterogeneity of antisocial behavior: Causes, continuities and consequences. Nebraska Symposium on Motivation, 44, 45-118.

[431] Rutter, M., Maughan, B., Mortimore, P., \& Ouston, J. (1980). Educational criteria of success - a reply to Acton. Educational Research, 22(3), 170-174. doi:10.1080/0013188800220302

[432] Rutter, M., Maughan, B., Mortimore, P., Ouston, J. \& Smith, A.J. (1980). School influences on pupil progress: research strategies and tactics. Journal of Child Psychology and Psychiatry, 21, 366-369

[433] Rutter, M., \& McGuffin, P. (2004). The Social, Genetic and Developmental Psychiatry Centre: its origins, conception and initial accomplishments. Psychological Medicine, 34(5), 933-947. doi:10.1017/ so033291704001916

[434] Rutter, M., Moffitt, T. E., \& Caspi, A. (2006). Gene-environment interplay and psychopathology: multiple varieties but real effects. Journal of Child Psychology and Psychiatry, 47(3-4), 226-261. doi:10.1111/ j.1469-7610.2005.01557.x

[435] Rutter, M., O'Connor, T. G., \& English Romanian Adoptees Study, T. (2004). Are there biological programming effects for psychological development? Findings from a study of Romanian adoptees. Developmental Psychology, 40(1), 81-94. doi:10.1037/0012-1649.40.1.81

[436] Rutter, M., \& Pickles, A. (2016). Annual Research Review: Threats to the validity of child psychiatry and psychology. Journal of Child Psychology and Psychiatry, 57(3), 398-416. doi:10.1111/jcpp.12461

[437] Rutter, M., Pickles, A., Murray, R., \& Eaves, L. (2001). Testing hypotheses on specific environmental causal effects on behavior. Psychological Bulletin, 127(3), 291-324. doi:10.1037//0033-2909.127.3.291

[438] Rutter, M., \& Plomin, R. (1997). Opportunities for psychiatry from genetic findings. British Journal of Psychiatry, 171, 209-219. doi:10.1192/bjp.171.3.209

[439] Rutter, M., \& Plomin, R. (1998a). A pocket catalogue of received ideas. Recherche (311), 54-56.

[440] Rutter, M., \& Plomin, R. (1998b). Opportunities for psychiatry from genetic findings - some concerns Authors' reply. British Journal of Psychiatry, 173, 186-186. doi:10.1192/bjp.173.2.186a

[441] Rutter, M., \& Plomin, R. (2009). Pathways from science findings to health benefits. Psychological Medicine, 39(4), 529-542. doi:10.1017/s003329170800398x

[442] Rutter, M., \& Quinton, D. (1984a). Long-term follow-up of women institutionalized in childhood - factors promoting good functioning in adult life. British Journal of Developmental Psychology, 2, 191-204. doi:10.1111/j.2044-835X.1984.tboog25.x

[443] Rutter, M., \& Quinton, D. (1984b). Parental psychiatric-disorder - effects on children. Psychological Medicine, 14(4), 853-880. doi:10.1017/s0033291700019838

[444] Rutter, M., \& Redshaw, J. (1991). Annotation - growing up as a twin - twin-singleton differences in psychological-development. Journal of Child Psychology and Psychiatry, 32(6), 885-895. doi:10.1111/j.1469-7610.1991.tbo1916.x

[445] Rutter, M., \& Sandberg, S. (1985). Epidemiology of child psychiatric-disorder - methodological issues and some substantive findings. Child Psychiatry \& Human Development, 15(4), 209-233. doi:10.1007/bfoo706366

[446] Rutter, M. \& Sandberg, S. (1992). Psychosocial stressor: concepts, causes and effects. European Child and Adolescent Psychiatry, 1, 3-13. doi: 10.1007/ BFo2084429

[447] Rutter, M., \& Schopler, E. (1987). Autism and pervasive developmental disorders - concepts and diagnostic issues. Journal of Autism and Developmental Disorders, 17(2), 159-186. doi:10.1007/bfol495054

[448] Rutter, M., \& Schopler, E. (1992). Classification of pervasive developmental disorders - some concepts and practical considerations. Journal of Autism and Developmental Disorders, 22(4), 459-482. doi:10.1007/ bfolo46322

[449] Rutter, M., \& Schopler, E. (1993). Diagnosis by DSMIII-R versus ICD-10 criteria - response. Journal of Autism and Developmental Disorders, 23(3), 573-575. No doi.

[450] Rutter, M., \& Shaffer, D. (1980). DSM-III - A step forward or back in terms of the classification of child psychiatric-disorders. Journal of the American Academy of Child and Adolescent Psychiatry, 19(3), 371-394. doi:10.1016/sooo2-7138(og)6106o-8 
[451] Rutter, M., Shaffer, D., \& Shepherd, M. (1973).

Evaluation of proposal for a multi-axial classification of child psychiatric-disorders. Psychological Medicine, 3(2), 244-250. doi:10.1017/s0033291700048595

[452] Rutter, M., \& Silberg, J. (2002). Gene-environment interplay in relation to emotional and behavioral disturbance. Annual Review of Psychology, 53, 463-490. doi:10.1146/annurev.psych.53.100901.135223

[453] Rutter, M., Silberg, J., O'Connor, T., \& Simonoff, E. (1999a). Genetics and child psychiatry: I advances in quantitative and molecular genetics. Journal of Child Psychology and Psychiatry and Allied Disciplines, 4O(1), 3-18. doi:10.1017/s002196309800328x

[454] Rutter, M., Silberg, J., O'Connor, T., \& Simonoff, E. (1999b). Genetics and child psychiatry: II - Empirical research findings. Journal of Child Psychology and Psychiatry, 40(1), 19-55. doi:10.1111/1469-7610.00423

[455] Rutter, M., Simonoff, E., \& Plomin, R. (1996). Genetic influences on mild mental retardation: Concepts, findings and research implications. Journal of Biosocial Science, 28(4), 509-526. doi:10.1017/ s0021932000022562

[456] Rutter, M., \& Solantaus, T. (2014). Translation gone awry: differences between commonsense and science. European Child \& Adolescent Psychiatry, 23(5), 247-255. doi:10.1007/s00787-013-0483-x

[457] Rutter, M., \& Sonuga-Barke, E. J. S. (2010). X. Conclusions: overview of findings from the ERA study, inferences, and research implications. Monographs of the Society for Research in Child Development, 75(1), 212229. doi:10.1111/j.1540-5834.2010.00557.x

[458] Rutter, M., Sonuga-Barke, E. J. S., \& Castle, J. (2010). I. investigating the impact of early institutional deprivation on development: background and research strategy of the English and Romanian Adoptees (ERA) Study. Monographs of the Society for Research in Child Development, 75(1), 1-20. doi:10.1111/j.15405834.2010.00548.x

[459] Rutter, M., \& Sroufe, L. A. (2000). Developmental psychopathology: Concepts and challenges.

Development and Psychopathology, 12(3), 265-296. doi:10.1017/s0954579400003023

[460] Rutter, M., \& Sussenwein, F. (1971). Developmental and behavioral approach to treatment of preschool autistic children. Journal of Autism and Childhood Schizophrenia, 1(4), 376-397. doi:10.1007/bfo1540530

[461] Rutter, M., Thapar, A., \& Pickles, A. (2009). Geneenvironment interactions biologically valid pathway or artifact? Archives of General Psychiatry, 66(12), 12871289. doi:10.1001/archgenpsychiatry.2009.167

[462] Rutter, M., Thorpe, K., Greenwood, R., Northstone, K., \& Golding, J. (2003). Twins as a natural experiment to study the causes of mild language delay: I: Design; twin-singleton differences in language, and obstetric risks. Journal of Child Psychology and Psychiatry, 44(3), 326-341. doi:10.1111/1469-7610.00125

[463] Rutter, M., Tizard, J., Yule, W., Graham, P., \& Whitmore, K. (1976). Isle-of-Wight studies, 19641974. Psychological Medicine, 6(2), 313-332. doi:10.1017/ s003329170001388x

[464] Rutter, M., \& Uher, R. (2012). Classification issues and challenges in child and adolescent psychopathology. International Review of Psychiatry, 24(6), 514-529. doi:10.3109/09540261.2012.719862

[465] Rutter, M., Yule, B., Morton, J., \& Bagley, C. (1975). Children of West-Indian immigrants .3. Home circumstances and family patterns. Journal of Child Psychology and Psychiatry, 16(2), 105-123. doi:10.1111/j.1469-7610.1975.tbo1261.x

[466] Rutter, M., Yule, B., Quinton, D., Rowlands, O., Yule, W., \& Berger, M. (1975). Attainment and adjustment in 2 geographical areas .3. Some factors accounting for area differences. British Journal of Psychiatry, 126b(JUN), 520-533. doi:10.1192/bjp.126.6.520

[467] Rutter, M., \& Yule, W. (1975). Concept of specific reading retardation. Journal of Child Psychology and Psychiatry, 16(3), 181-197. doi:10.1111/j.1469-7610.1975. tbo1269.x

[468] Rutter, M., Yule, W., \& Berger, M. (1974). Children of West-Indian migrants. New Society, 27(597), 630-633. No doi.

[469] Rutter, M., Yule, W., Berger, M., Yule, B., Morton, J., \& Bagley, C. (1974). Children of West-Indian immigrants .1. Rates of behavioral deviance and of psychiatric-disorder. Journal of Child Psychology and Psychiatry, 15(4), 241-262. doi:10.1111/j.1469-7610.1974. tbol250.x

[470] Sandberg, S., McGuinness, D., Hillary, C., \& Rutter, M. (1998). Independence of childhood life events and chronic adversities: A comparison of two patient groups and controls. Journal of the American Academy of Child and Adolescent Psychiatry, 37(7), 728735. doi:10.1097/00004583-199807000-00012

[471] Sandberg, S., Rutter, M., Giles, S., Owen, A., Champion, L., Nicholls, J., ... Drinnan, D. (1993). Assessment of psychosocial experiences in childhood - methodological issues and some illustrative findings. Journal of Child Psychology and Psychiatry, 34(6), 879897. doi:10.1111/j.1469-7610.1993.tbo1096.x

[472] Sandberg, S., Rutter, M., \& Jarvi, J. (2003). Brief measure of expressed emotion: internal consistency and stability over time. International Journal of Methods in Psychiatric Research, 12(4), 182-191. doi:10.1002/ mpr.155 
[473] Sandberg, S., Rutter, M., Pickles, A., McGuinness, D., \& Angold, A. (2001). Do high-threat life events really provoke the onset of psychiatric disorder in children? Journal of Child Psychology and Psychiatry, 42(4), 523-532. doi:10.1111/1469-7610.00746

[474] Sandberg, S., Rutter, M., \& Taylor, E. (1978). Hyperkinetic disorder in psychiatric clinic attenders. Developmental Medicine and Child Neurology, 20(3), 279299.

[475] Saudino, K. J., Dale, P. S., Oliver, B., Petrill, S. A., Richardson, V., Rutter, M., ... Plomin, R. (1998). The validity of parent-based assessment of the cognitive abilities of 2-year-olds. British Journal of Developmental Psychology, 16, 349-363. doi:10.1111/j.2044-835X.1998. tboo757.x

[476] Schachar, R., Rutter, M., \& Smith, A. (1981). The characteristics of situationally and pervasively hyperactive-children - implications for syndrome definition. Journal of Child Psychology and Psychiatry, 22(4), 375-392. doi:10.1111/j.1469-7610.1981.tboo562.x

[477] Schachar, R., Sandberg, S., \& Rutter, M. (1986). Agreement between teachers ratings and observations of hyperactivity, inattentiveness, and defiance. Journal of Abnormal Child Psychology, 14(2), 331-345. doi:10.1007/bfoog15450

[478] Schachar, R., Taylor, E., Wieselberg, M., Thorley, G., \& Rutter, M. (1987). Changes in family function and relationships in children who respond to methylphenidate. Journal of the American Academy of Child and Adolescent Psychiatry, 26(5), 728-732. doi:10.1097/00004583-198709000-00019

[479] Schopler, E., Rutter, M., \& Chess, S. (1979). Change of journal scope and title. Journal of Autism and Developmental Disorders, 9(1), 1-10. doi:10.1007/ bfol531287

[480] Seidel, U. P., Chadwick, O. F. D., \& Rutter, M. (1975). Psychological disorders in crippled children comparative study of children with and without braindamage. Developmental Medicine and Child Neurology, 17(5), 563-573. doi:10.1111/j.1469-8749.1975.tbo3522.x

[481] Shaffer, D., Bijur, P., Chadwick, O. F. D., \& Rutter, M. L. (1980). Head-injury and later readingdisability. Journal of the American Academy of Child and Adolescent Psychiatry, 19(4), 592-610. doi:10.1016/s00027138(09)60964-x

[482] Shaffer, D., Gould, M. S., Rutter, M., \& Sturge, C. (1991). Reliability and validity of a psychosocial axis in patients with child psychiatric-disorder. Journal of the American Academy of Child and Adolescent Psychiatry, 30(1), 109-115. doi:10.1097/00004583-199101000-00017

[483] Silberg, J., Erickson, M. T., Meyer, J. M., Eaves, L. J., Rutter, M. L., \& Hewitt, J. K. (1994a). The application of structural equation modeling to maternal ratings of twins behavioral and emotional-problems. Journal of Consulting and Clinical Psychology, 62(3), 510-521. doi:10.1037//0022-006x.62.6.510

[484] Silberg, J., Erickson, M. T., Meyer, J. M., Eaves, L. J., Rutter, M. L., \& Hewitt, J. K. (1994b). The application of structural equation modeling to maternal ratings of twins behavioral and emotional-problems (VOL 62, PG 510, 1994). Journal of Consulting and Clinical Psychology, 62(6), 1234-1234. doi:10.1037/0022-006x.62.6.510

[485] Silberg, J., Moore, A. A., \& Rutter, M. (2015). Age of onset and the subclassification of conduct/dissocial disorder. Journal of Child Psychology and Psychiatry, 56(7), 826-833. doi:10.1111/jcpp.12353

[486] Silberg, J., Parr, T., Neale, M. C., Rutter, M., Angold, A., \& Eaves, L. J. (2003). Maternal smoking during pregnancy and risk to boys' conduct disturbance: An examination of the causal hypothesis. Biological Psychiatry, 53(2), 130-135. doi:10.1016/sooo63223(02)01477-4

[487] Silberg, J., Pickles, A., Rutter, M., Hewitt, J., Simonoff, E., Maes, H., ... Eaves, L. (1999). The influence of genetic factors and life stress on depression among adolescent girls. Archives of General Psychiatry, 56(3), 225-232. doi:10.1001/archpsyc.56.3.225

[488] Silberg, J., Rutter, M., D'Onofrio, B., \& Eaves, L. (2003). Genetic and environmental risk factors in adolescent substance use. Journal of Child Psychology and Psychiatry, 44(5), 664-676. doi:10.1111/14697610.00153

[489] Silberg, J., Rutter, M., \& Eaves, L. (2001a). Genetic and environmental influences on the temporal association between earlier anxiety and later depression in girls. Biological Psychiatry, 49(12), 10401049. doi:10.1016/s0006-3223(01)01161-1

[49o] Silberg, J., Rutter, M., \& Eaves, L. (2001b). Genetic and environmental influences on the temporal association between earlier anxiety and later depression in girls (vol 49, pg 1040, 2001). Biological Psychiatry, 50(5), 393-393. doi: https://doi.org/10.1016/ s0006-3223(01)01233-1

[491] Silberg, J., Rutter, M., Meyer, J., Maes, H., Hewitt, J., Simonoff, E., .. . Eaves, L. (1996). Genetic and environmental influences on the covariation between hyperactivity and conduct disturbance in juvenile twins. Journal of Child Psychology and Psychiatry and Allied Disciplines, 37(7), 803-816. doi:10.1111/j.1469-7610.1996.tbo1476.x

[492] Silberg, J., Rutter, M., Neale, M., \& Eaves, L. (2001). Genetic moderation of environmental risk for depression and anxiety in adolescent girls. British Journal of Psychiatry, 179, 116-121. doi:10.1192/bjp.179.2.116

[493] Silberg, J., Rutter, M., Tracy, K., Maes, H. H., \& Eaves, L. (2007). Etiological heterogeneity in the 
development of antisocial behavior: the Virginia twin study of adolescent Behavioral development and the young adult follow-up. Psychological Medicine, 37(8), 1193-1202. doi:10.1017/s0033291707000293

[494] Simonoff, E., Bolton, P., \& Rutter, M. (1996). Mental retardation: Genetic findings, clinical implications and research agenda. Journal of Child Psychology and Psychiatry, 37(3), 259-280. doi:10.1111/j.1469-7610.1996.tbo1404.x

[495] Simonoff, E., Elander, J., Holmshaw, J., Pickles, A., Murray, R., \& Rutter, M. (2004). Predictors of antisocial personality - Continuities from childhood to adult life. British Journal of Psychiatry, 184, 118-127. doi:10.1192/ bjp.184.2.118

[496] Simonoff, E., Pickles, A., Hervas, A., Silberg, J. L., Rutter, M., \& Eaves, L. (1998). Genetic influences on childhood hyperactivity: contrast effects imply parental rating bias, not sibling interaction. Psychological Medicine, 28(4), 825-837. doi:10.1017/ so033291798006886

[497] Simonoff, E., Pickles, A., Hewitt, J., Silberg, J., Rutter, M., Loeber, R., ... Eaves, L. (1995). Multiple raters of disruptive child-behavior - using a genetic strategy to examine shared views and bias. Behavior Genetics, 25(4), 311-326. doi:10.1007/bfo2197280

[498] Simonoff, E., Pickles, A., Meyer, J. M., Silberg, J. L., Maes, H. H., Loeber, R., ... Eaves, L. J. (1997). The Virginia Twin Study of Adolescent behavioral development - Influences of age, sex, and impairment on rates of disorder. Archives of General Psychiatry, 54(9), 801-808. doi:10.1001/ archpsyc.1997.01830210039004

[499] Sonuga-Barke, E. J. S., Beckett, C., Kreppner, J., Castle, J., Colvert, E., Stevens, S., ... Rutter, M. (2008). Is sub-nutrition necessary for a poor outcome following early institutional deprivation? Developmental Medicine and Child Neurology, 50(9), 664-671. doi:10.1111/j.14698749.2008.03065.x

[500] Sonuga-Barke, E. J. S., Kennedy, M., Kumsta, R., Knights, N., Golm, D., Rutter, M., ... Kreppner, J. (2017). Child-to-adult neurodevelopmental and mental health trajectories after early life deprivation: the young adult follow-up of the longitudinal English and Romanian Adoptees study. Lancet, 389(10078), 15391548. doi:10.1016/s0140-6736(17)30045-4

[501] Sonuga-Barke, E. J. S., Schlotz, W., \& Rutter, M. (2010). VII. Physical growth and maturation following early severe institutional deprivation: do they mediate specific psychopathological effects? Monographs of the Society for Research in Child Development, 75(1), 143-166. doi:10.1111/j.1540-5834.2010.00554.x

[502] Sroufe, L. A., \& Rutter, M. (1984). The domain of developmental psychopathology. Child Development,
55(1), 17-29. doi:10.2307/1129832

[503] Starr, E., Berument, S. K., Pickles, A., Tomlins, M., Bailey, A., Papanikolaou, K., \& Rutter, M. (2001). A family genetic study of autism associated with profound mental retardation. Journal of Autism and Developmental Disorders, 31(1), 89-96. doi:10.1023/a:1005669915105

[504] Starr, E. M., Berument, S. K., Tomlins, M., Papanikolaou, K., \& Rutter, M. (2005). Brief report: Autism in individuals with Down syndrome. Journal of Autism and Developmental Disorders, 35(5), 665-673. doi:10.1007/s10803-005-0010-0

[505] Stevens, S. E., Kumsta, R., Kreppner, J. M., Brookes, K. J., Rutter, M., \& Sonuga-Barke, E. J. S. (2009). Dopamine transporter gene polymorphism moderates the effects of severe deprivation on ADHD symptoms: developmental continuities in geneenvironment Interplay. American Journal of Medical Genetics Part B-Neuropsychiatric Genetics, 150B(6), 753761. doi:10.1002/ajmg.b.31010

[506] Stevens, S. E., Sonuga-Barke, E. J. S., Kreppner, J. M., Beckett, C., Castle, J., Colvert, E., . . Rutter, M. (2008). Inattention/overactivity following early severe institutional deprivation: Presentation and associations in early adolescence. Journal of Abnormal Child Psychology, 36(3), 385-398. doi:10.1007/s10802-007-91855

[507] Szatmari, P., Paterson, A. D., Zwaigenbaum, L., Roberts, W., Brian, J., Liu, X. Q., .. Shih, A. (2007). Mapping autism risk loci using genetic linkage and chromosomal rearrangements. Nature Genetics, 39(3), 319-328. doi:10.1038/ng1985

[508] Tarjan, G., Tizard, J., Strotzka, H., Sartorius, N., Rutter, M., Begab, M., .. . Lin, T. Y. (1972). Classification and mental-retardation - issues arising in Fifth WHO seminar on psychiatric diagnosis, classification, and statistics. American Journal of Psychiatry, 128(11), 34-+. No doi.

[509] Taylor, E., Everitt, B., Thorley, G., Schachar, R., Rutter, M., \& Wieselberg, M. (1986). Conduct disorder and hyperactivity: 2 . A cluster analytic approach to the identification of a behavioral syndrome. British Journal of Psychiatry, 149, 768-777. doi:10.1192/bjp.149.6.768

[510] Taylor, E., \& Rutter, M. (1985). Sex-differences in neurodevelopmental and psychiatric-disorders - one explanation or many. Behavioral and Brain Sciences, 8(3), 460-46o. doi:10.1017/s0140525×00001266

[511] Taylor, E., \& Rutter, M. (1992). The MedicalResearch-Council Unit In Child-Psychiatry. Psychological Medicine, 22(3), 805-813. doi:10.1017/ s0033291700038241

[512] Taylor, E., Schachar, R., Thorley, G., Wieselberg, H. M., Everitt, B., \& Rutter, M. (1987). Which boys 
respond to stimulant medication - a controlled trial of methylphenidate in boys with disruptive behavior. Psychological Medicine, 17(1), 121-143. doi:10.1017/ s0033291700013039

[513] Thapar, A., Cooper, M., \& Rutter, M. (2017). Neurodevelopmental disorders. Lancet Psychiatry, 4(4), 339-246. doi:10.1016/s2215-0366(16)30376-5

[514] Thapar, A., Rice, F., Hay, D., Boivin, J., Langley, K., van den Bree, M., ... Harold, G. (2009). Prenatal smoking might not cause attention-deficit/ hyperactivity disorder: evidence from a novel design. Biological Psychiatry, 66(8), 722-727. doi:10.1016/j. biopsych.2009.05.032

[515] Thapar, A., \& Rutter, M. (2009). Do prenatal risk factors cause psychiatric disorder? Be wary of causal claims. British Journal of Psychiatry, 195(2), 100-101. doi:10.1192/bjp.bp.109.062828

[516] Thapar, A., \& Rutter, M. (2019). Do natural experiments have an important future in the study of mental disorders . Psychological Medicine, 49(7), 10791088. doi:10.1017/s0033291718003896

[517] Thorpe, K., Greenwood, R., Eivers, A., \& Rutter, M. (2001). Prevalence and developmental course of 'secret language'. International Journal of Language \& Communication Disorders, 36(1), 43-62. doi:10.1080/13682820150217563

[518] Thorpe, K., Rutter, M., \& Greenwood, R. (2003). Twins as a natural experiment to study the causes of mild language delay: II: Family interaction risk factors. Journal of Child Psychology and Psychiatry, 44(3), 342-355. doi:10.1111/1469-7610.00126

[519] Tick, B., Bolton, P., Happe, F., Rutter, M., \& Rijsdijk, F. (2016). Heritability of autism spectrum disorders: a meta-analysis of twin studies. Journal of Child Psychology and Psychiatry, 57(5), 585-595. doi:10.1111/jcpp.12499

[520] Topolski, T. D., Hewitt, J. K., Eaves, L., Meyer, J. M., Silberg, J. L., Simonoff, E., \& Rutter, M. (1999). Genetic and environmental influences on ratings of manifest anxiety by parents and children. Journal of Anxiety Disorders, 13(4), 371-397. doi:10.1016/so8876185(99)00011-0

[521] Topolski, T. D., Hewitt, J. K., Eaves, L. J., Silberg, J. L., Meyer, J. M., Rutter, M., ... Simonoff, E. (1997).

Genetic and environmental influences on child reports of manifest anxiety and symptoms of separation anxiety and overanxious disorders: A communitybased twin study. Behavior Genetics, 27(1), 15-28. doi:10.1023/a:1025607107566

[522] Uher, R., \& Rutter, M. (2012a). Basing psychiatric classification on scientific foundation: Problems and prospects. International Review of Psychiatry, 24(6), 591605. doi:10.3109/09540261.2012.721346
[523] Uher, R., \& Rutter, M. (2012b). Classification of feeding and eating disorders: review of evidence and proposals for ICD-11. World Psychiatry, 11(2), 80-92. doi:10.1016/j.wpsyc.2012.05.005

[524] van Goor-Lambo, G., Orley, J., Poustka, F., \& Rutter, M. (1990). Classification of abnormal psychosocial situations - preliminary-report of a revision of a WHO scheme. Journal of Child Psychology and Psychiatry, 31(2), 229-241. Doi: 10.1111/j.14697610.1990.tbo1564.x

[525] van Goor-Lambo, G., Orley, J., Poustka, F., \& Rutter, M. (1994). Abnormal psychosocial situations - preliminary-results of a WHO and a German multicenter study. European Child \& Adolescent Psychiatry, 3(4), 229-241. doi:10.1007/bfo1978112

[526] Volkmar, F. R., Klin, A., Siegel, B., Szatmari, P., Lord, C., Campbell, M., .. . Towbin, K. (1994). Field trial for autistic disorder in DSM-IV. American Journal of Psychiatry, 151(9), 1361-1367. oi:10.1176/ajp.151.9.1361

[527] Volkmar, F. R., \& Rutter, M. (1995). Childhood disintegrative disorder - results of the DSM-IV autism field trial. Journal of the American Academy of Child and Adolescent Psychiatry, 34(8), 1092-1095. doi:10.1097/00004583-199508000-00020

[528] Vorria, P., Ntouma, M., \& Rutter, M. (2014a). The behaviour of adopted adolescents who spent their infancy in residential group care: The Greek Metera study. Adoption \& Fostering, 38, 271-283. doi:10.1177/0308575914543237

[529] Vorria, P., Ntouma, M., \& Rutter, M. (2015b). The cognitive development and school achievement of adopted adolescents: The Greek "Metera" study. European Journal of Developmental Psychology, 12(1), 1-14. doi:10.1080/17405629.2014.933703

[530] Vorria, P., Ntouma, M., \& Rutter, M. (2015c). Vulnerability and resilience after early institutional care: The Greek Metera study. Development and Psychopathology, 27(3), 859-866. doi:10.1017/ so954579415000243

[531] Vorria, P., Ntouma, M., Vairami, M., \& Rutter, M. (2015). Attachment relationships of adolescents who spent their infancy in residential group care: The Greek Metera study. Attachment \& Human Development, 17(3), 257-271. doi:10.1080/14616734.2015.1028947

[532] Vorria, P., Rutter, M., Pickles, A., Wolkind, S., \& Hobsbaum, A. (1998a). A comparative study of Greek children in long-term residential group care and in twoparent families: I. Social, emotional, and behavioural differences. Journal of Child Psychology and Psychiatry, 39(2), 225-236. doi:10.1017/s0021963097001996

[533] Vorria, P., Rutter, M., Pickles, A., Wolkind, S., \& Hobsbaum, A. (1998b). A comparative study of Greek children in long-term residential group care and in 
two-parent families: II Possible mediating mechanisms. Journal of Child Psychology and Psychiatry, 39(2), 237-245. doi:10.1111/1469-7610.00317

[534] Wolkind, S., \& Rutter, M. (1973). Children who have been in care - epidemiological study. Journal of Child Psychology and Psychiatry, 14(2), 97-105. doi:10.1111/j.1469-7610.1973.tbo1178.x

[535] Woodhouse, S., Miah, A., \& Rutter, M. (2018). A new look at the supposed risks of early institutional rearing. Psychological Medicine, 48(1), 1-10. doi:10.1017/ s0033291717001507

[536] Woodhouse, W., Bailey, A., Rutter, M., Bolton, P., Baird, G., \& Le Couteur, A. (1996). Head circumference in autism and other pervasive developmental disorders. Journal of Child Psychology and Psychiatry, 37(6), 665671. doi:10.1111/j.1469-7610.1996.tbo1458.x

[537] Yule, W., Berger, M., Rutter, M., \& Yule, B. (1975). Children of West-Indian immigrants: 2. Intellectual performance and reading attainment. Journal of Child Psychology and Psychiatry, 16(1), 1-17. doi:10.1111/j.1469-7610.1975.tbo1868.x

[538] Yule, W., \& Rutter, M. (1968). Educational aspects of childhood maladjustment: some epidemiological findings. British Journal of Educational Psychology, 38(1), 7-9. doi:10.1111/j.2044-8279.1968.tbo1974.x

[539] Yule, W., Rutter, M., Berger, M., \& Thompson, J. (1974). Over-achievement and under-achievement in reading - distribution in general population. British Journal of Educational Psychology, 44(FEB), 1-12. doi:10.1111/j.2044-8279.1974.tboo76o.x

[540] Zoccolillo, M., Pickles, A., Quinton, D., \& Rutter, M. (1992). The outcome of childhood conduct disorder - implications for defining adult personality-disorder and conduct disorder. Psychological Medicine, 22(4), 971986. doi:10.1017/s003329170003854X 